Supplement of Earth Syst. Sci. Data, 13, 5127-5149, 2021

https://doi.org/10.5194/essd-13-5127-2021-supplement

(C) Author(s) 2021. CC BY 4.0 License.

(c) (i)

Supplement of

\title{
The Boreal-Arctic Wetland and Lake Dataset (BAWLD)
}

David Olefeldt et al.

Correspondence to: David Olefeldt (olefeldt@ualberta.ca)

The copyright of individual parts of the supplement might differ from the article licence. 
45 Table S1. Average percent coverage of each of the 19 BAWLD land cover classes within the 15 identified wetscapes.

\begin{tabular}{|c|c|c|c|c|c|c|c|c|c|c|c|c|c|c|c|c|c|c|c|}
\hline \multirow[t]{2}{*}{ WETSCAPES } & \multirow[b]{2}{*}{ GLA } & \multirow[b]{2}{*}{ ROC } & \multirow[b]{2}{*}{ TUN } & \multirow[b]{2}{*}{ BOR } & \multirow[b]{2}{*}{ BOG } & \multirow[b]{2}{*}{ FEN } & \multirow[b]{2}{*}{ MAR } & \multicolumn{5}{|c|}{ BAWLD LAND COVER CLASSES } & \multirow[b]{2}{*}{ MYL } & \multirow[b]{2}{*}{ SGL } & \multirow[b]{2}{*}{ SPL } & \multirow[b]{2}{*}{ SYL } & \multirow[b]{2}{*}{ LAR } & \multirow[b]{2}{*}{ SPR } & \multirow[b]{2}{*}{ SRR } \\
\hline & & & & & & & & PEB & TUW & LAL & MGL & MPL & & & & & & & \\
\hline Wetland-rich Tundra & 0.0 & 0.7 & 59.8 & 8.3 & 0.1 & 0.3 & 0.3 & 12.2 & 10.4 & 1.2 & 0.7 & 0.8 & 1.4 & 0.4 & 1.0 & 1.7 & 0.4 & 0.1 & 0.1 \\
\hline Wetland and Lake-rich Tundra & 0.0 & 1.4 & 54.7 & 4.0 & 0.4 & 0.5 & 0.6 & 11.3 & 11.5 & 2.5 & 5.2 & 4.4 & 0.1 & 1.3 & 1.6 & 0.0 & 0.4 & 0.1 & 0.1 \\
\hline Wetland and Lake-rich Yedoma Tundra & 0.0 & 0.2 & 44.0 & 8.6 & 0.1 & 0.2 & 0.3 & 11.0 & 15.4 & 4.2 & 2.2 & 3.0 & 6.2 & 0.6 & 1.2 & 1.8 & 0.8 & 0.1 & 0.1 \\
\hline Upland Tundra & 0.6 & 7.7 & 76.3 & 3.9 & 0.3 & 0.3 & 0.1 & 3.9 & 4.0 & 0.5 & 0.9 & 0.3 & 0.1 & 0.5 & 0.4 & 0.1 & 0.1 & 0.2 & 0.0 \\
\hline Lake-rich Shield & 0.0 & 24.3 & 38.2 & 13.3 & 0.3 & 0.7 & 0.2 & 2.0 & 2.5 & 5.9 & 8.5 & 1.0 & 0.0 & 2.4 & 0.3 & 0.0 & 0.1 & 0.1 & 0.0 \\
\hline Alpine and Tundra Barrens & 5.1 & 37.7 & 44.5 & 9.5 & 0.3 & 0.3 & 0.1 & 0.4 & 0.6 & 0.4 & 0.7 & 0.1 & 0.0 & 0.2 & 0.0 & 0.0 & 0.0 & 0.2 & 0.0 \\
\hline ermafrost Peatlands & 0.0 & 0.6 & 17.3 & 30.9 & 4.3 & 6.8 & 1.7 & 27.1 & 3.7 & 2.0 & 1.1 & 1.7 & 0.0 & 0.3 & 1.9 & 0.1 & 0.3 & 0.1 & 0.1 \\
\hline Lake-rich Wetlands & 0.0 & 0.1 & 2.9 & 22.1 & 13.7 & 16.3 & 8.1 & 16.2 & 2.4 & 1.5 & 0.4 & 4.8 & 0.2 & 0.4 & 8.6 & 0.3 & 1.7 & 0.1 & 0.2 \\
\hline Dominant Boreal Wetlands & 0.0 & 0.3 & 0.2 & 28.6 & 26.9 & 28.2 & 3.9 & 4.4 & 0.9 & 1.1 & 0.3 & 1.6 & 0.0 & 0.0 & 2.9 & 0.0 & 0.5 & 0.0 & 0.2 \\
\hline Common Boreal Wetlands & 0.0 & 1.3 & 1.7 & 55.5 & 17.3 & 17.0 & 1.7 & 1.0 & 0.1 & 1.9 & 0.7 & 0.8 & 0.0 & 0.1 & 0.6 & 0.0 & 0.3 & 0.1 & 0.1 \\
\hline Sparse Boreal Wetlands & 0.1 & 5.0 & 2.3 & 69.5 & 7.8 & 6.5 & 1.0 & 0.8 & 0.1 & 3.4 & 2.0 & 0.6 & 0.0 & 0.2 & 0.2 & 0.0 & 0.2 & 0.1 & 0.1 \\
\hline Upland Boreal & 0.0 & 5.5 & 7.7 & 82.0 & 0.8 & 0.8 & 0.1 & 1.4 & 0.4 & 0.3 & 0.2 & 0.0 & 0.0 & 0.0 & 0.0 & 0.0 & 0.3 & 0.2 & 0.0 \\
\hline Large Lakes & 0.0 & 4.0 & 7.0 & 20.9 & 2.1 & 2.3 & 0.5 & 2.2 & 0.7 & 57.4 & 1.3 & 0.5 & 0.0 & 0.7 & 0.2 & 0.0 & 0.0 & 0.0 & 0.0 \\
\hline Large Rivers & 0.3 & 1.5 & 21.9 & 42.8 & 2.2 & 2.6 & 2.0 & 6.8 & 6.2 & 0.6 & 0.9 & 1.0 & 0.5 & 0.5 & 1.3 & 0.5 & 8.2 & 0.1 & 0.1 \\
\hline Glaciers & 91.0 & 4.7 & 3.7 & 0.3 & 0.0 & 0.0 & 0.0 & 0.0 & 0.0 & 0.1 & 0.1 & 0.0 & 0.0 & 0.0 & 0.0 & 0.0 & 0.0 & 0.0 & 0.0 \\
\hline
\end{tabular}

GLA $=$ Glaciers, $\mathrm{ROC}=$ Rocklands, $\mathrm{TUN}=$ Dry Tundra, $\mathrm{BOR}=$ Boreal Forest, $\mathrm{BOG}=$ Bogs, FEN $=$ Fens, MAR $=$ Marshes, $\mathrm{PEB}=$ Permafrost Bogs, TUW = Tundra Wetlands, $\mathrm{LAL}=$ Large Lakes, MGL $=$ Midsize Glacial Lakes, MPL = Midsize Peatland Lakes, MYL = Midsize Yedoma Lakes, SGL = Small Glacial Lakes, SPL = Small Peatland Lakes, SYL =

50 Small Yedoma Lakes, LAR = Large Rivers, SPR = Small Organic-Poor Rivers, SRR $=$ Small Organic-Rich Rivers.

Green, Yellow, and Red circles indicate relatively high, moderate, and low land cover class coverage within wetscapes, relative to each land cover class. 


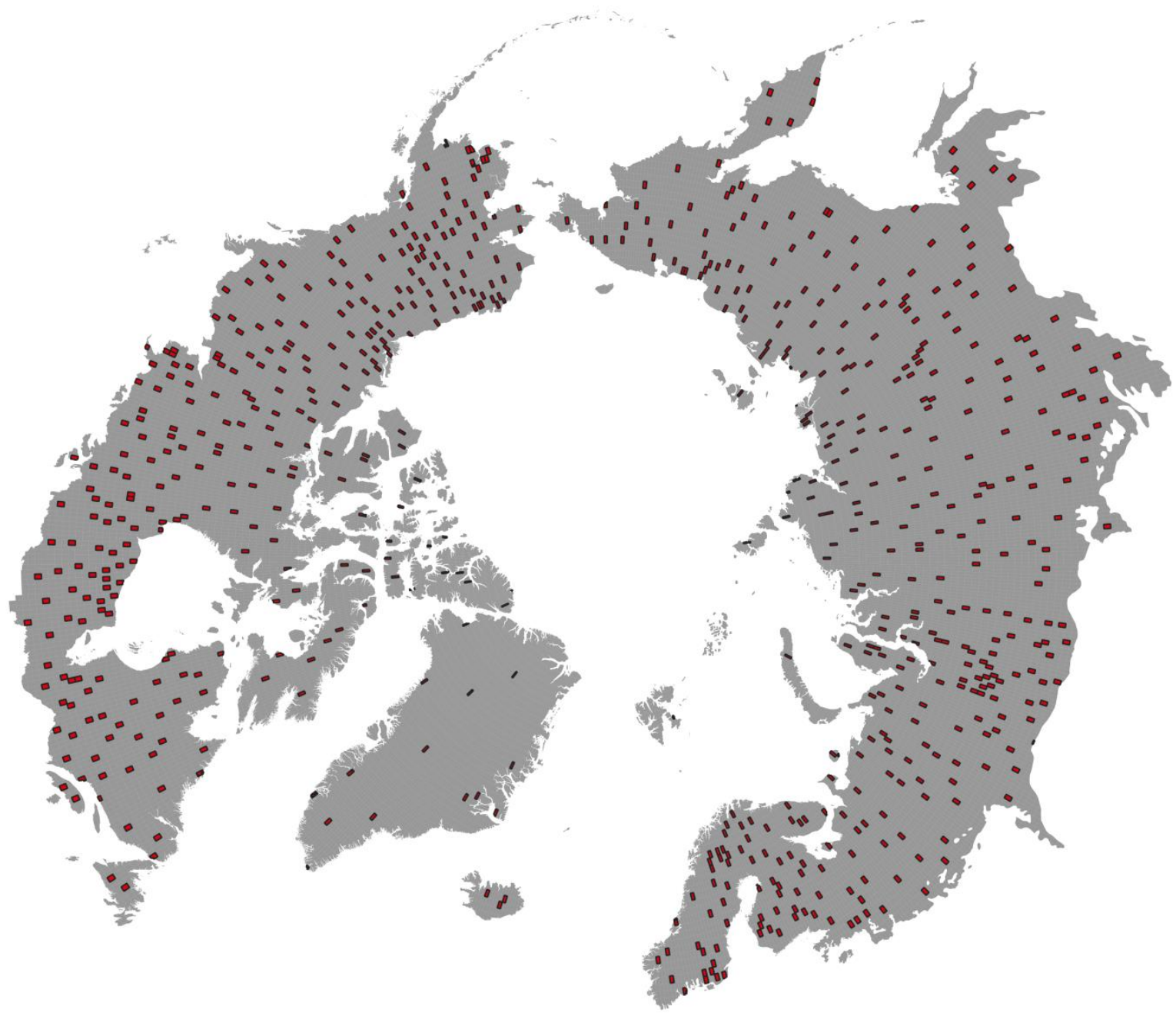

Figure S1. Spatial distribution of training cells where expert assessment of land cover composition was completed. 
Boreal Forest

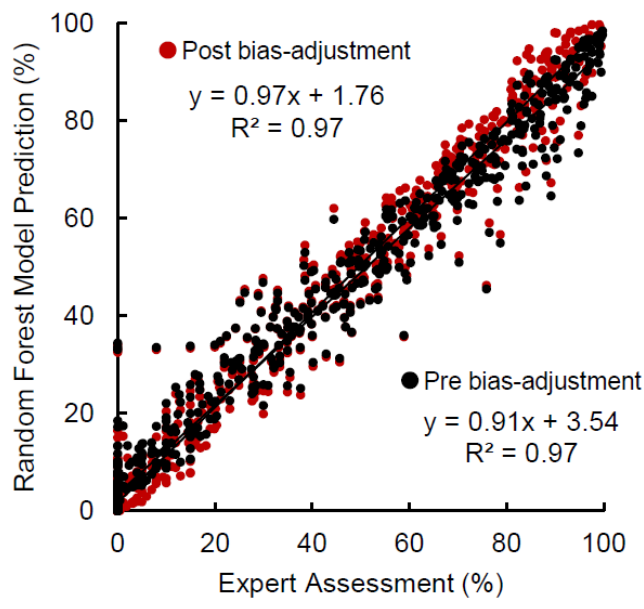

Midsize Peatland Lake

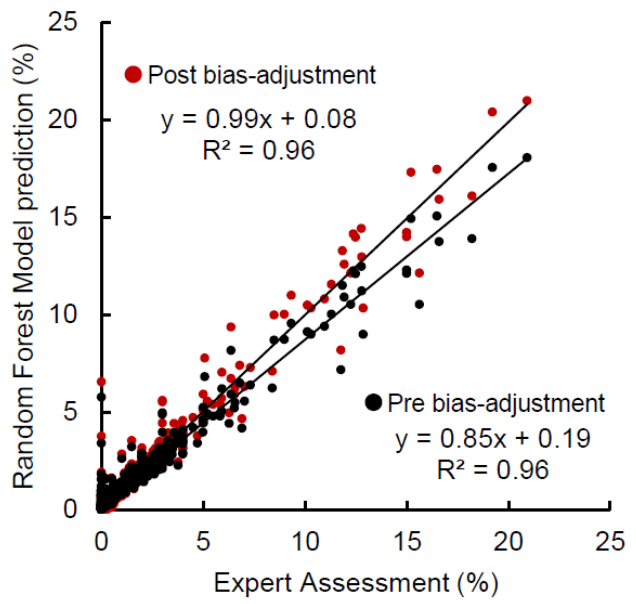

Permafrost Bog

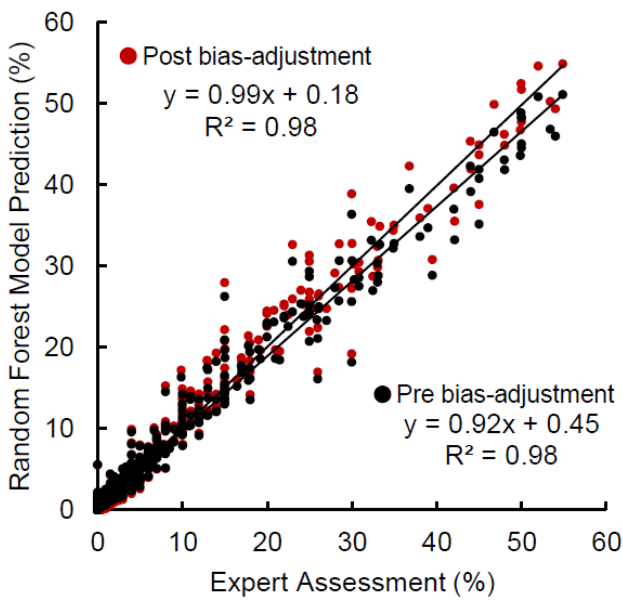

Marsh

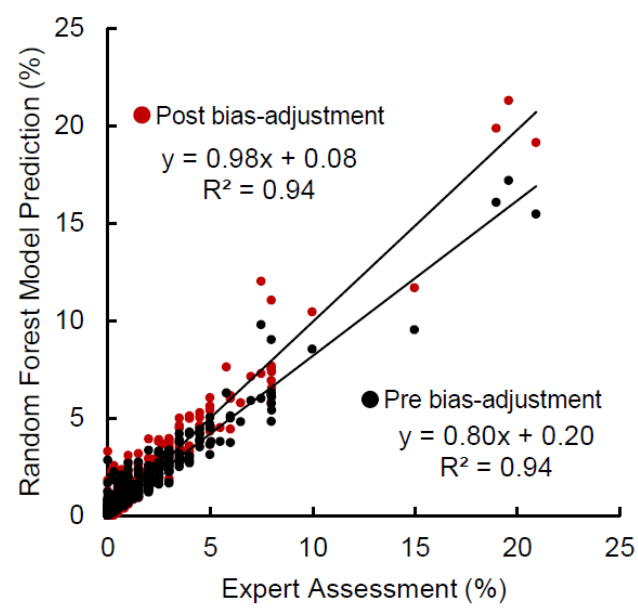

60 Figure S2. Examples of bias-adjustments of the random forest predictions for 4 of the 19 land-cover classes in BAWLD. 


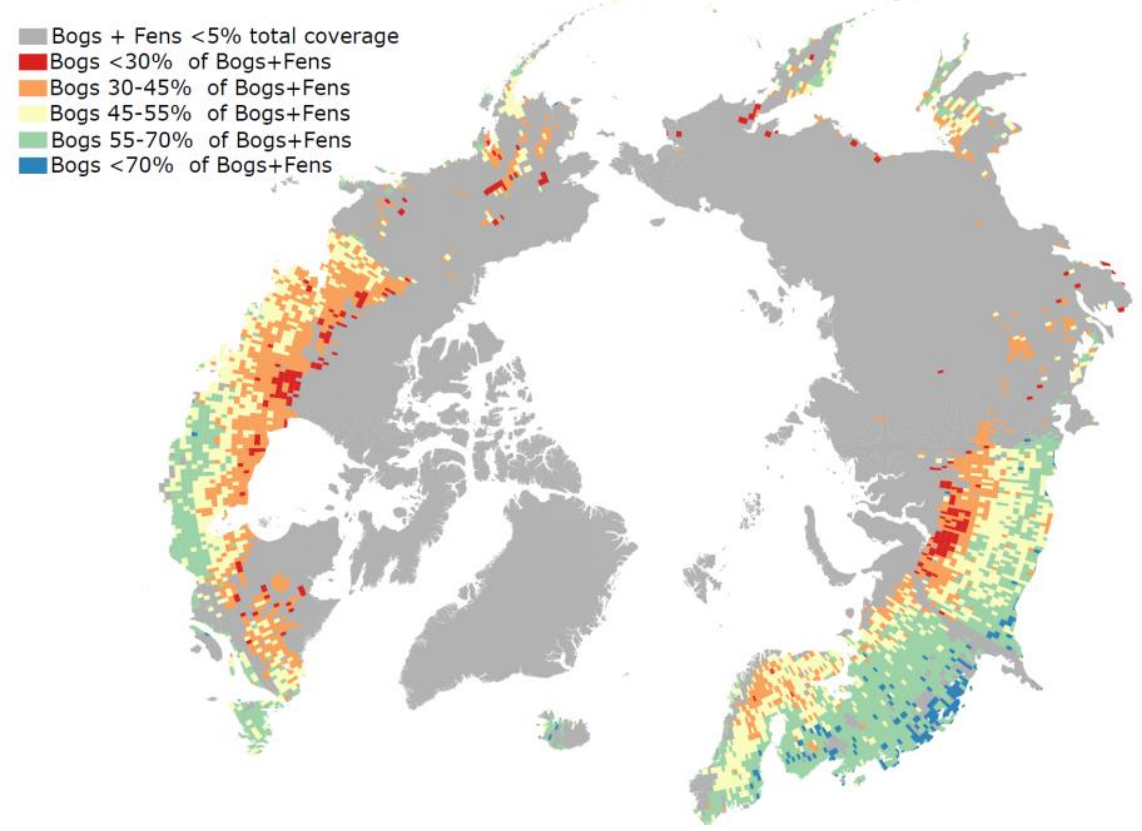

Figure S3. Predicted relative abundance of Bogs and Fens for grid cells within BAWLD where combined Bog and Fen cover was greater than $5 \%$ of the total grid cell area. 


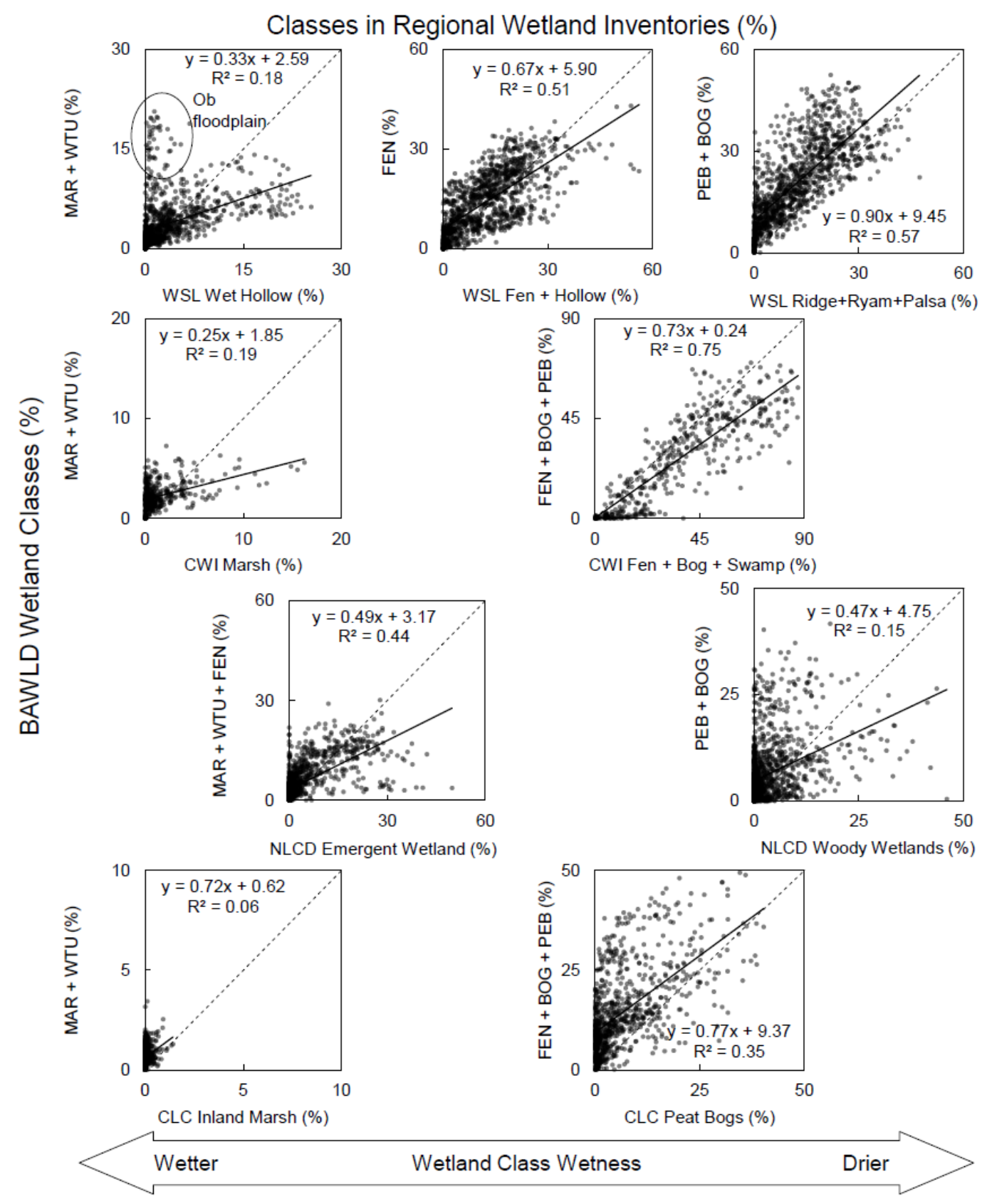

Figure S4. Comparison of the grid cell coverage of BAWLD wetland land cover classes with that of similar wetland land cover classes in four independent regional land cover datasets; the wetland mapping of the West Siberian Lowlands (WSL) (top row), the Canadian Wetland Inventory (CWI) (second row), the National Land Cover Database (NLCD) (third row), and the CORINE

70 Land Cover (CLC) dataset (fourth row). Abbreviations used for the BAWLD wetland classes: Marshes (MAR), Wetland Tundra (WTU), Fens (FEN), Bogs (BOG), and Permafrost Bogs (PEB). Several comparisons required combinations of wetland classes in order to ensure similar definitions. Relatively wetter wetland classes are compared on the left side of the figure, while drier wetland classes are compared on the right hand side. The ranking of relative wetness for BAWLD classes is MAR > WTU > FEN > BOG > PEB. 


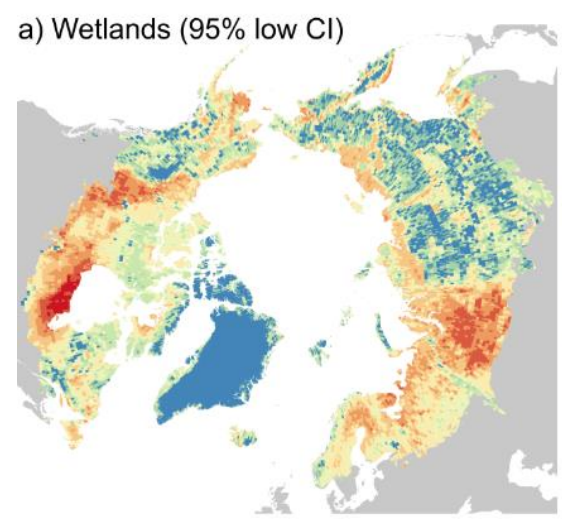

c) Lakes (95\% low CI)

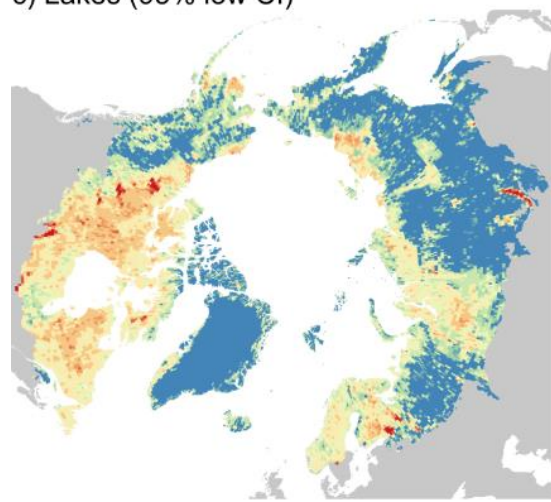

b) Wetlands ( $95 \%$ high $\mathrm{Cl}$ )

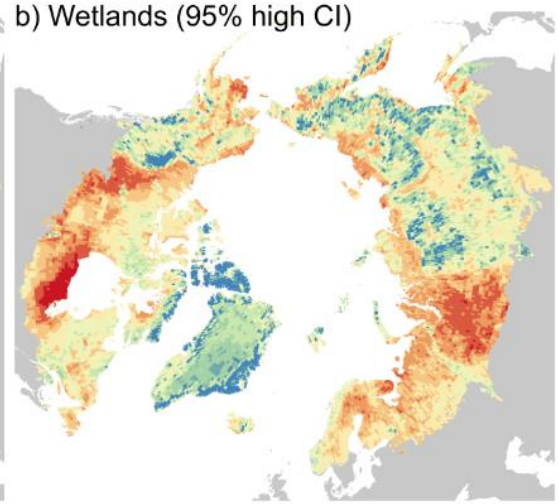

d) Lakes (95\% high $\mathrm{Cl}$ )

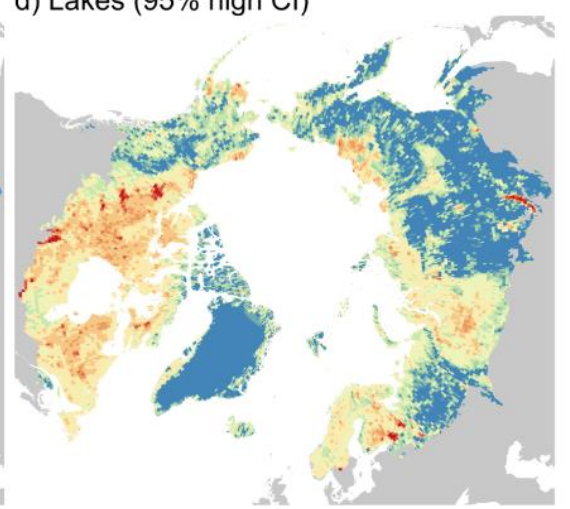

Proportional cover (\%)

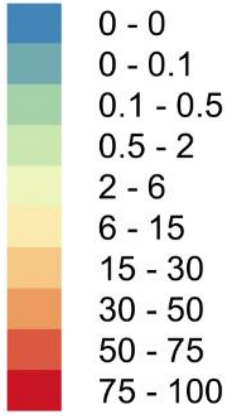

e) Rivers (95\% low $\mathrm{Cl}$ )

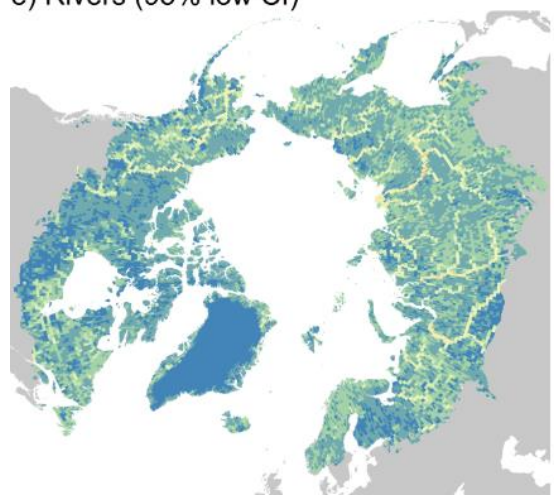

f) Rivers (95\% high Cl)

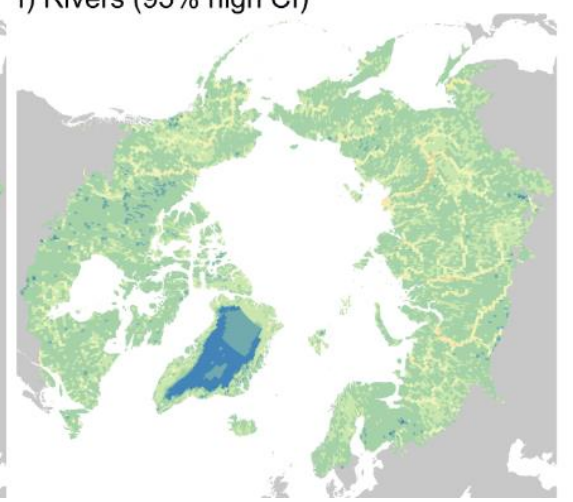

Figure S5. Low and High $95 \%$ confidence bounds for the fractional total coverage of wetland classes (sum of 5 classes) (a-b), lake classes (sum of 7 classes) (c-d) and river classes (sum of 3 classes) (e-f). 
a) Marshes (95\% low $\mathrm{Cl})$

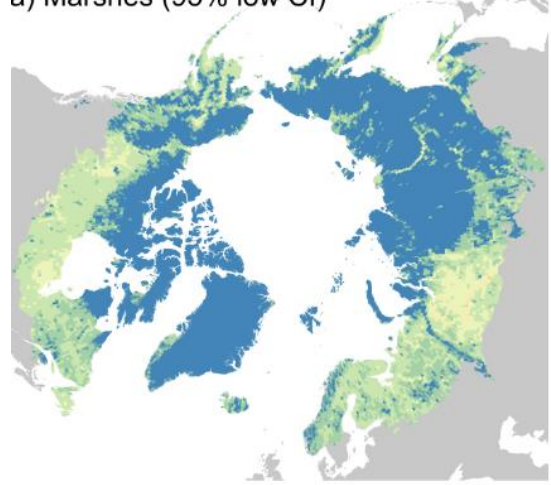

c) Small Peatland Lakes (95\% low Cl)

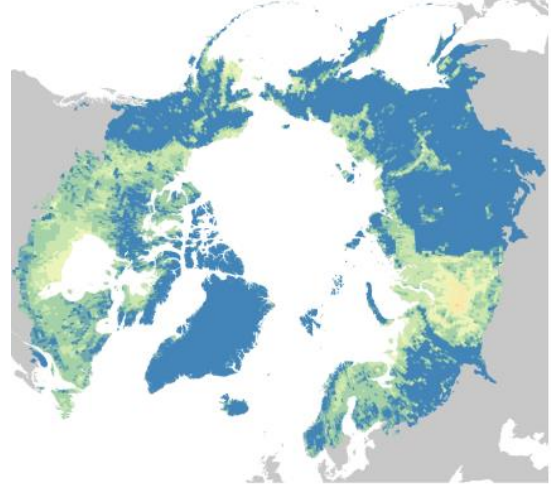

b) Marshes (95\% high $\mathrm{Cl})$

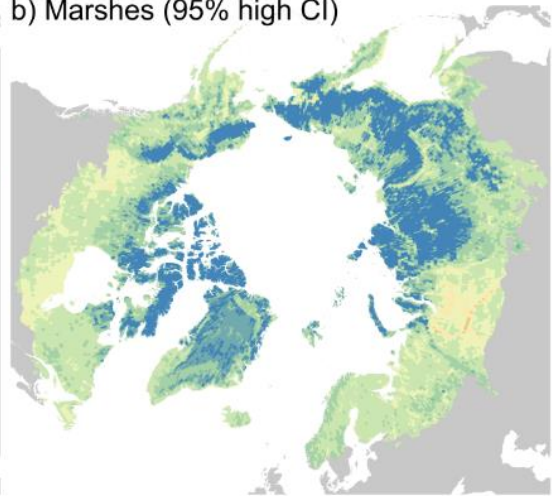

d) Small Peatland Lakes (95\% high Cl)

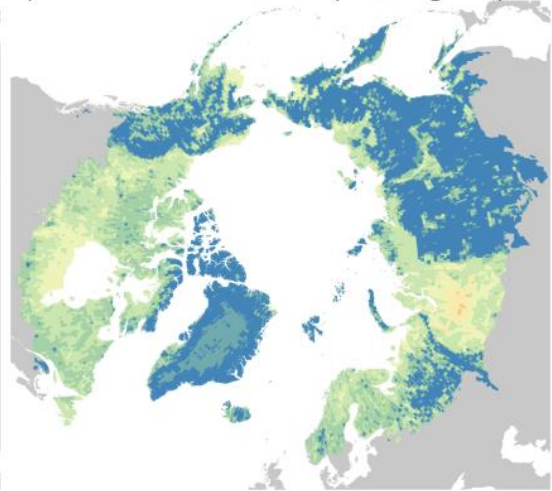

Proportional cover (\%)

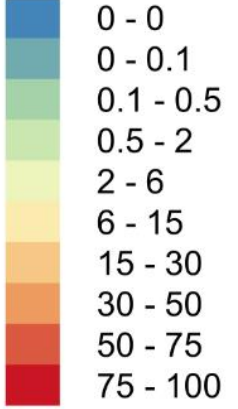

e) Small Organic-Rich Rivers (95\% low Cl) f) Small Organic-Rich Rivers (95\% high Cl)
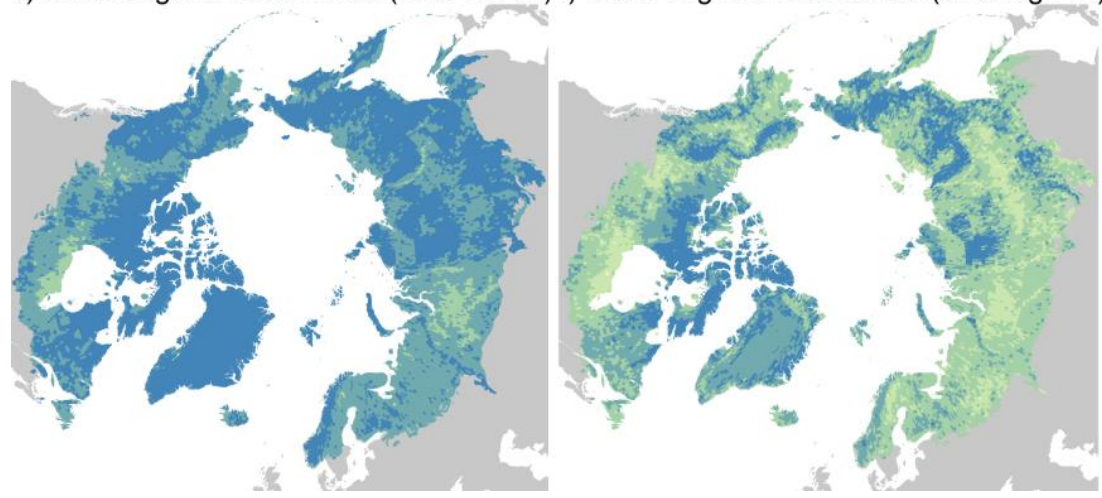

Figure S6. Examples of Low and High 95\% confidence bounds for the fractional coverage of 3 of the 19 land cover classes in

80 BAWLD; Marshes (a-b), Small Peatland Lakes (c-d), Small Organic-Rich Rivers (e-f). The chosen land cover classes have a relatively high uncertainty in BAWLD compared to other land cover classes, and are also considered classes with relatively high methane emissions. 

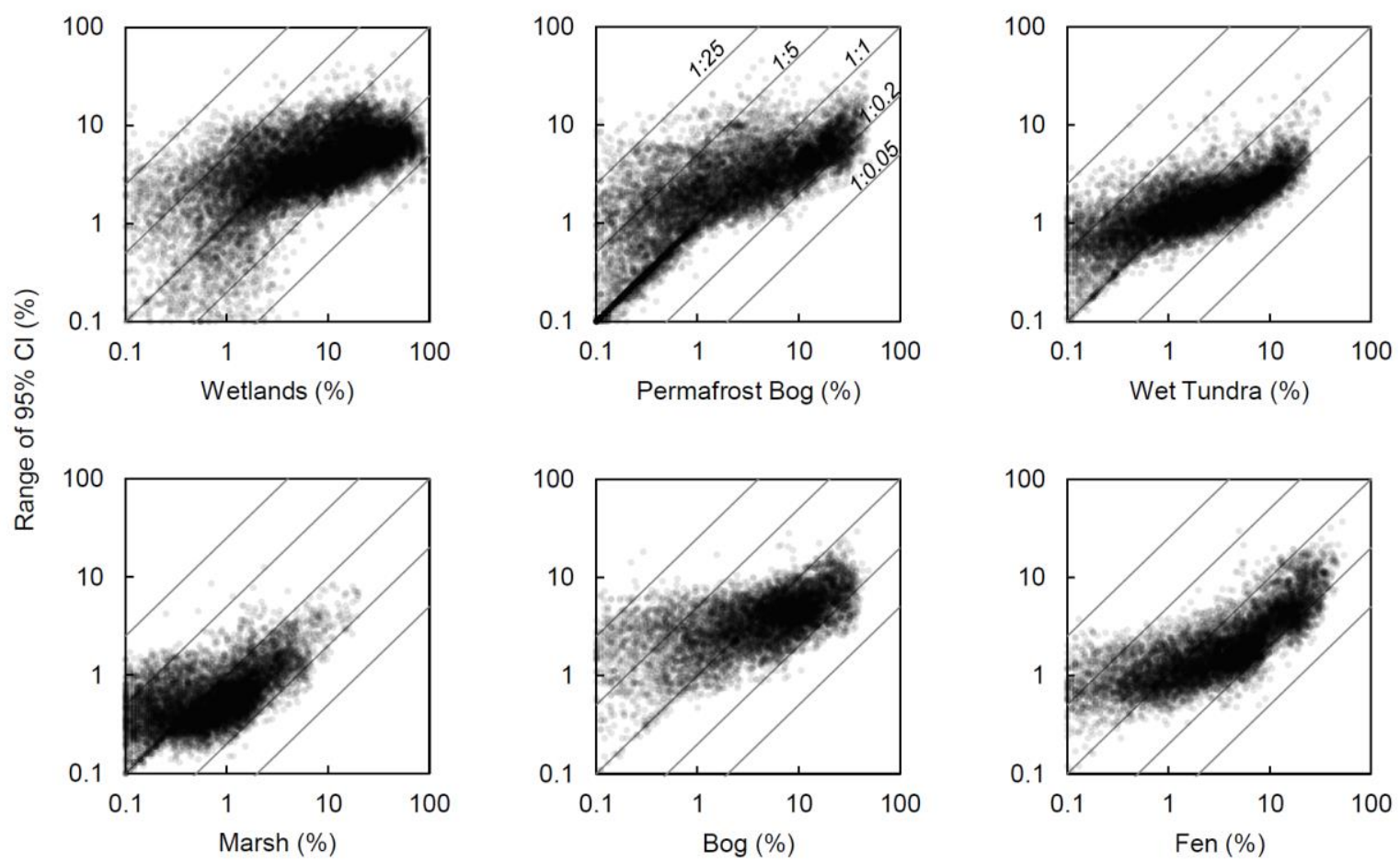

85 Figure S7. Scatterplots of central estimates vs the range of the $95 \%$ confidence intervals for wetland classes within individual BAWLD grid cells. Diagonal lines indicate the relative size range of the $95 \%$ confidence interval in comparison to the central estimate, ranging from the confidence interval being $2500 \%$ greater than the central estimate (1:25) to only representing $5 \%$ of the central estimate $(1: 0.05)$. Top left plate shows the total wetland estimates, while the remaining plates focus on individual wetland classes. 

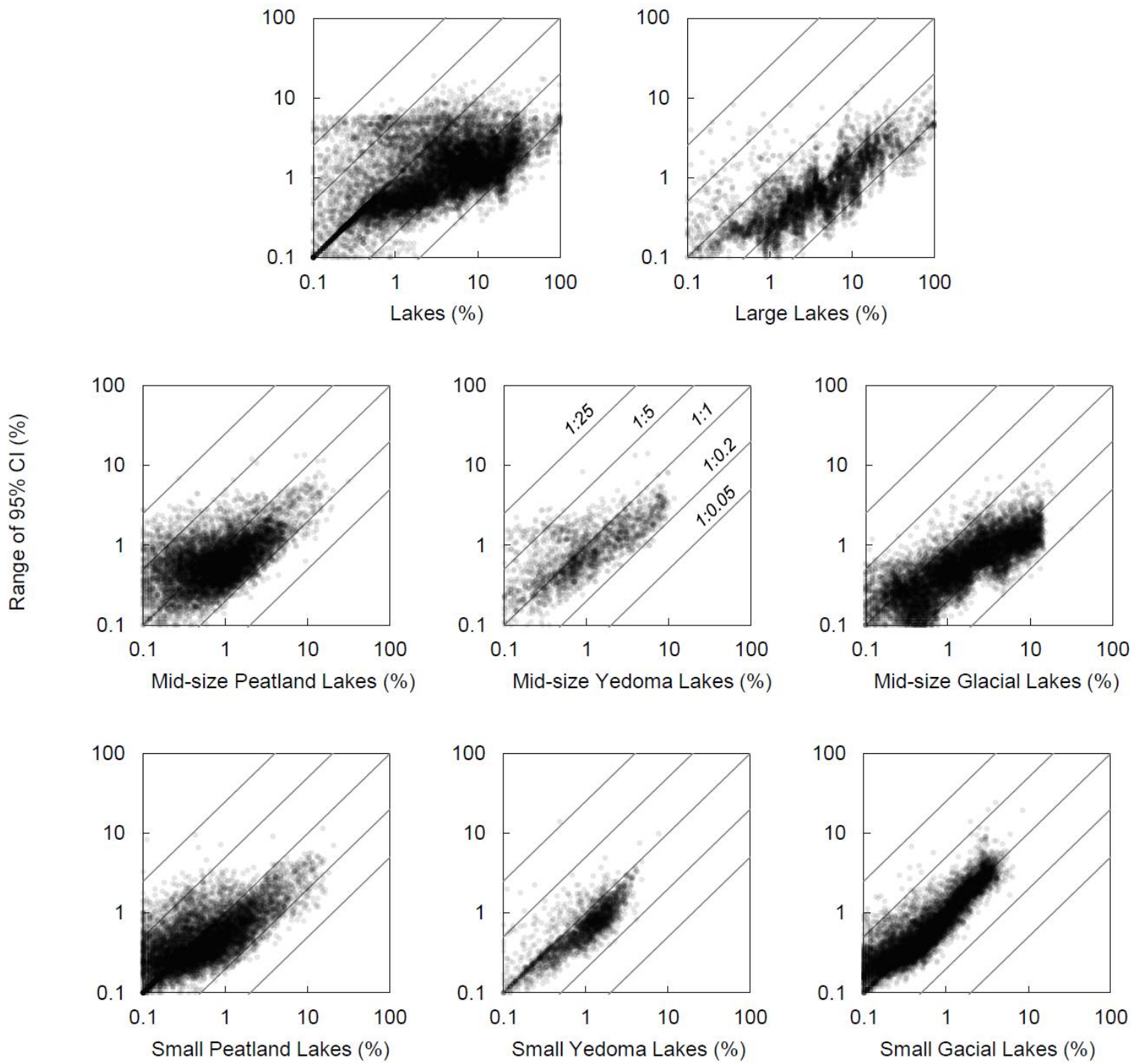

Figure S8. Scatterplots of central estimates vs the range of the $95 \%$ confidence intervals for lake classes within individual BAWLD grid cells. Diagonal lines indicate the relative size range of the $95 \%$ confidence interval in comparison to the central estimate, ranging from the confidence interval being $2500 \%$ greater than the central estimate $(1: 25)$ to only representing $5 \%$ of the central estimate (1:0.05). Top left plate shows the total lake estimates, while the remaining plates focus on individual lake classes. 

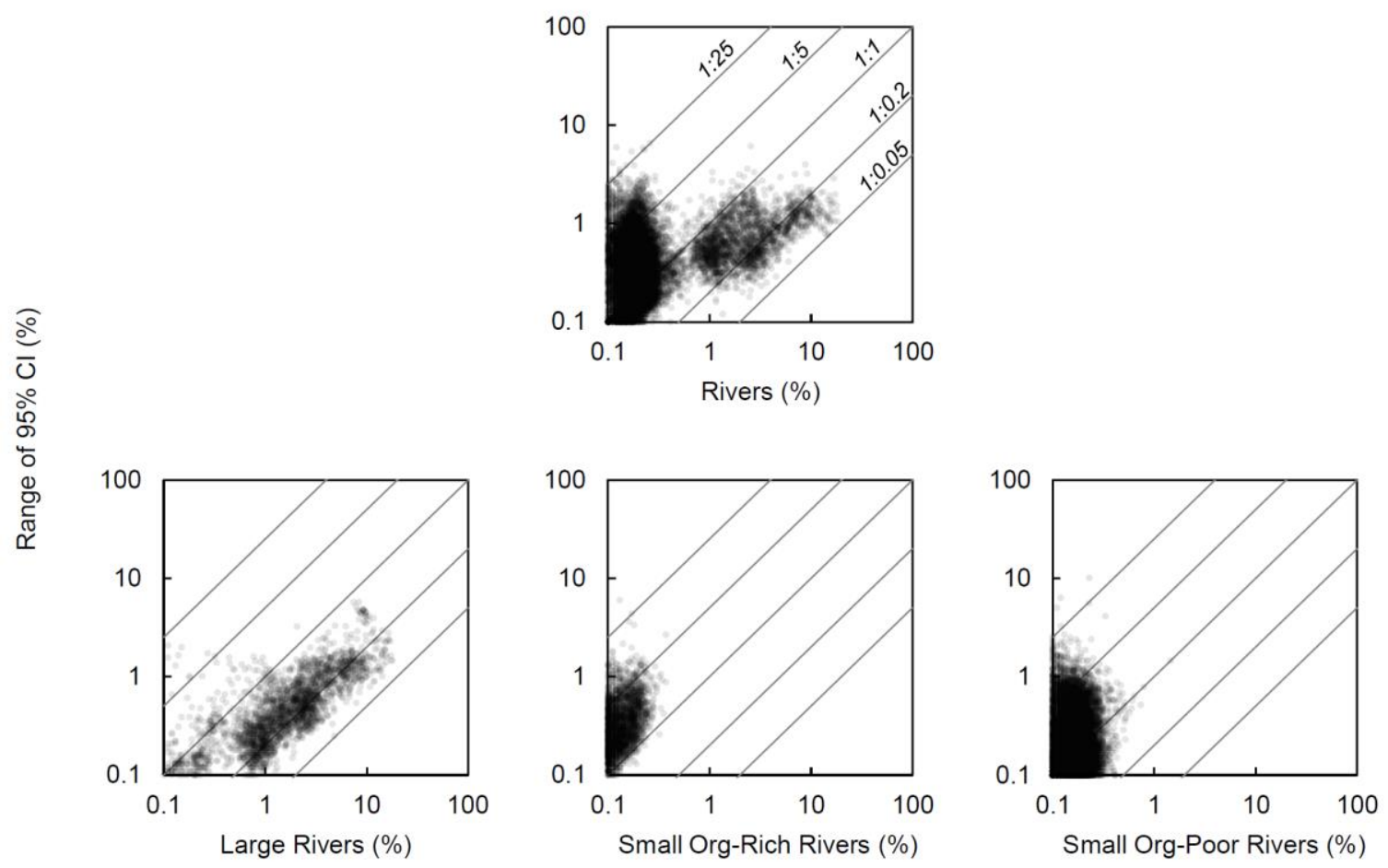

Figure S9. Scatterplots of central estimates vs the range of the $95 \%$ confidence intervals for river classes within individual BAWLD grid cells. Diagonal lines indicate the relative size range of the $95 \%$ confidence interval in comparison to the central estimate, ranging from the confidence interval being $2500 \%$ greater than the central estimate (1:25) to only representing $5 \%$ of the central estimate $(\mathbf{1 : 0 . 0 5})$. Top plate shows the total river estimates, while the remaining plates focus on individual river classes. 


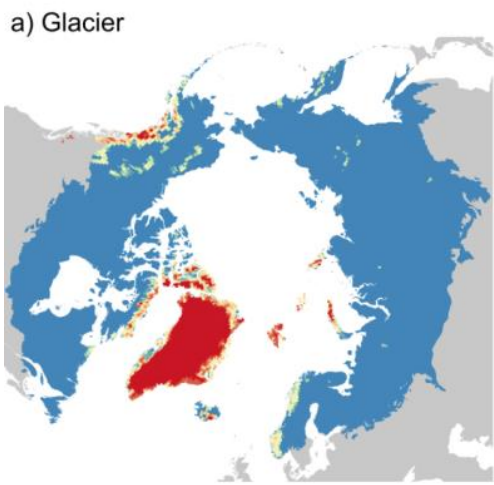

b) Rocklands

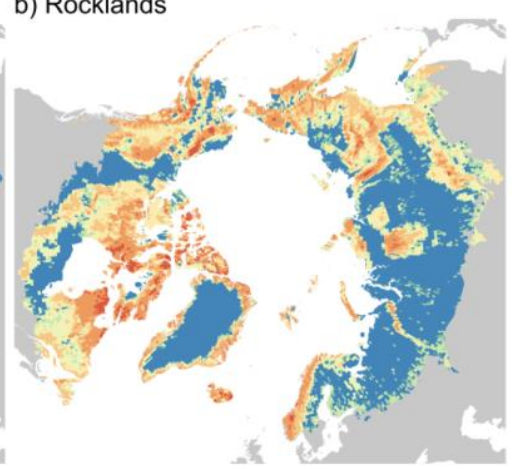

c) Tundra

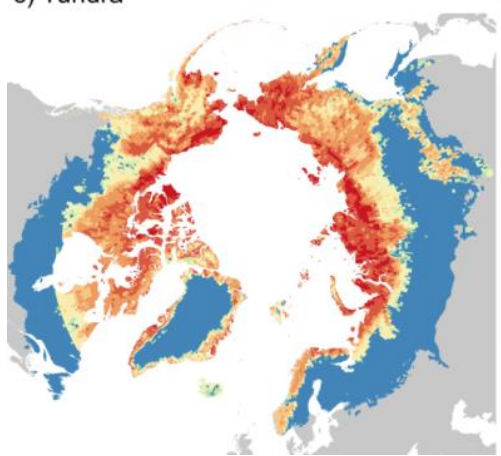

d) Boreal Forest

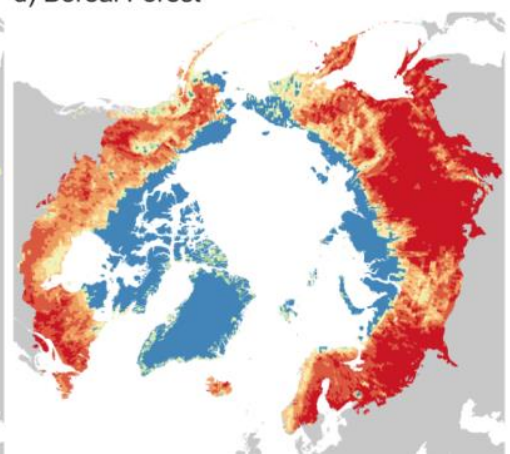

Proportional cover (\%)

$0-0$
$0-0.1$
$0.1-0.5$
$0.5-2$
$2-6$
$6-15$
$15-30$
$30-50$
$50-75$
$75-100$

Figure S10. Predicted distributions of a) Glaciers, b) Rocklands, c) Tundra, d) Boreal Forests in BALWD. 


\section{Expert Assessment Instructions}

Below we have compiled information from three files that were sent out to experts with instructions to complete the land cover fractional assessment. The first file has the step-by-step instructions for how to carry out the assessment. The second file has descriptions and examples of the 19 land cover classes that the experts were asked to assess fractional land coverage

110 of. Note that some of the class names were changed in the final version of BAWLD. The third file shows the available spatial datasets which could be used in combination with Google Earth satellite imagery and expert knowledge of the region to make the assessments. Experts also had access to this data in a .kml file that could be opened in Google Earth. 


\section{Suggested workflow for the expert assessment}

115 1. Check out the 20 grid cells we have assigned you for your assessment.

With this mail, we have attached 2 files; an excel file "Expert Assessment - LastName.xlsx" and a kml file "Expert Assessment - LastName.kml". In order to open the kml file, you will need to download Google Earth Pro on desktop, scroll down on this webpage for the download link if you don't already have it installed:

\section{https://www.google.com/earth/versions/}

120 In both the .xlsx and .kml files, you have the same 20 grid cells indicated for which we ask you to give your assessment of the relative coverage of 19 land cover classes. You should be able to cross-reference the cells based on their lat/long and their cell ID's.

Both files further include information for each cell from $\sim 50$ available data sources. This data is shown in column to the right in the .xlsx file, and should pop up when you click on a file in Google Earth.

125 Of the 20 cells, 10 have been randomly chosen in regions you specified familiarity with, and 10 have been chosen in the wider boreal-arctic domain. Each expert has been given 20 unique cells to assess.

Before you start to populate the .xlsx with your assessment, go through the steps below.

\section{Get to know the 19 land cover classes which will be in the final land cover database.}

These are presented and defined in the pdf file "1_Methane Land Cover Classes.pdf" which was sent to you in the last e-

130 mail. Let me know if you have any questions on the definitions.

\section{Get to know the $\sim \mathbf{5 0}$ available spatial data layers which you can use to guide your assessment.}

You assessment of the relative coverage of the methane classes in the assessment cells will be based on you knowledge of the region, visual assessment of satellite imagery provided by Google Earth, and already available spatial data from multiple sources. These $\sim 50$ available spatial data layers have been compiled into a common $0.5 \times 0.5^{\circ}$ grid cell framework. I have provided images of the data in each layer in a pdf file "2_Available data layers.pdf", you can explore all the data in detail in Google Earth if you open the kml file "3_Available data layers.kml", and each layer is described in "4_Available data layers.xlsx". You should have these files from my previous mail.

Let me know if you have any questions regarding the available data layers, .e.g. if you are not clear on what they indicate. At the bottom of this instruction are a few tips on how these layers may help your assessment of the 19 land cover classes.

140 4. Fill out your assessment in the "Expert assessment-LastName.xlsx" file.

For each of the 20 cells you have been assigned, give your assessment of the coverage of the 19 land cover classes. The unit is \%, and each row of 19 classes should add up to $100 \%$. Use up to two decimals for your assessment (e.g. 21.54\%). We use two decimals since it may be required for classes that have very small coverage - e.g. small rivers and marshes where I expect many cells to have $<0.10 \%$ coverage. Two decimals is also the precision of the available datasets, so you could directly transfer some data if you think it represents one of our land cover classes well (e.g. Large Lakes from the Hydrolakes Large Lake data layer). 
View of excel sheet:

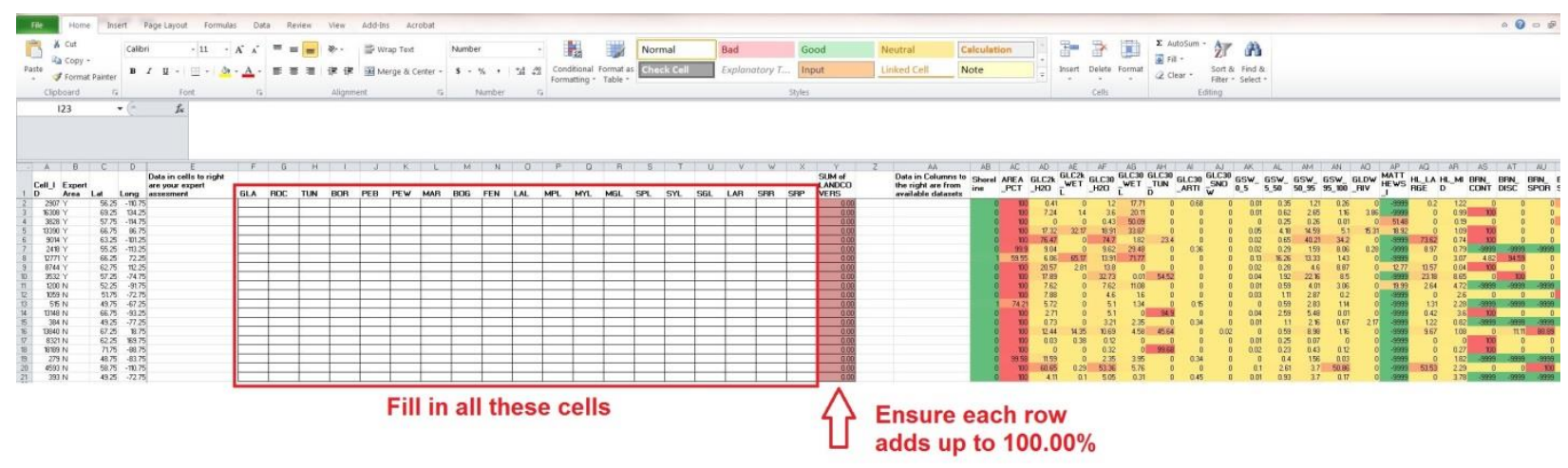

150 As mentioned above, in order to arrive at estimates, you can use your knowledge of the region, visual assessment of satellite imagery provided by Google Earth, and the available spatial data compiled into 50 data layers.

\section{Optional resources:}

If you are ambitious, and used to working in GIS, you can download a few of the key available datasets to see their original 155 data, rather than the data compiled into the $0.5 \times 0.5$ cells. For example, I found it useful sometimes to overlay the lake polygons in HydroLakes over the satellite imagery, in order to see how much of the visible smaller open water areas that were not included as lakes in the HydroLakes data:

https://www.hydrosheds.org/page/hydrolakes

Another dataset of potential interest is the Northers Circumpolar Soils Database V2, which is probably the most reliable

160 included datasource for distribution of peatland soils (both permafrost - histels, and non-permafrost - histosols): https://bolin.su.se/data/ncscd/shape.php

I also sometimes found it useful to look at the Global Surface Water data, which has an online explorer, as it often well indicates areas that are continuously vs temporarily inundated, and how much of open water areas (peatland pools) within wetland complexes that it captures:

165 https://global-surface-water.appspot.com/map

That said, using these additional resources is not required. 


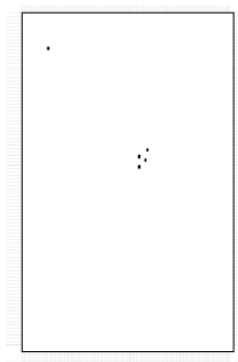

$0.05 \%$

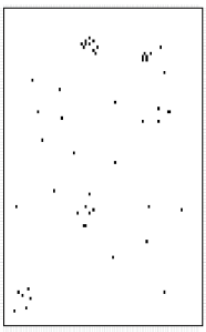

$0.5 \%$

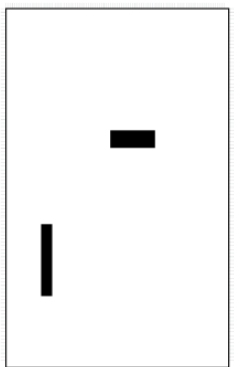

$2 \%$

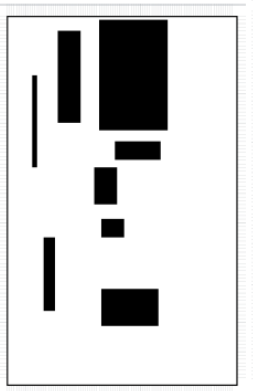

$20 \%$

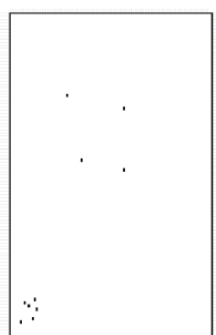

$0.1 \%$

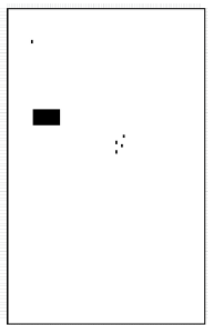

$0.75 \%$

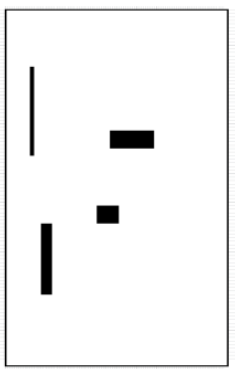

$3 \%$

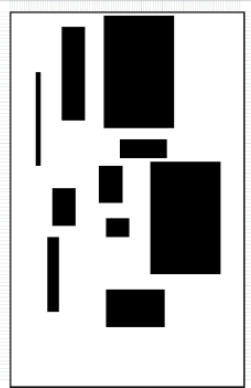

$30 \%$

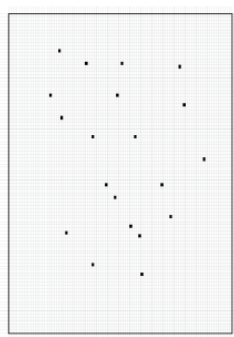

$0.2 \%$

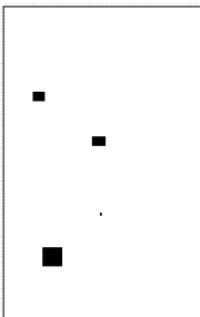

$1.00 \%$

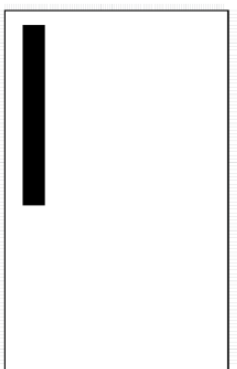

$5 \%$

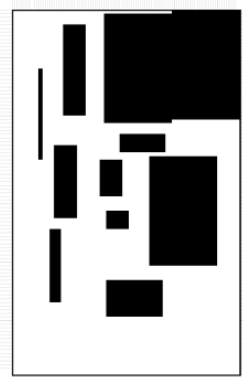

$40 \%$

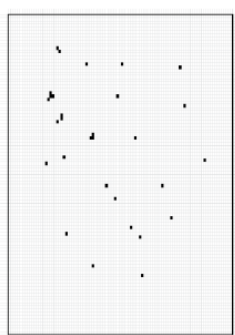

$0.3 \%$

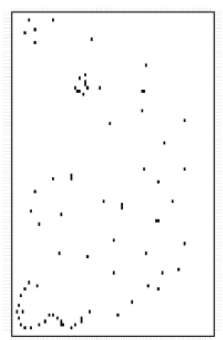

$0.75 \%$

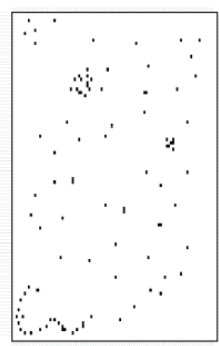

$1.00 \%$

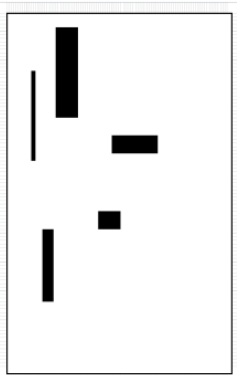

$7.5 \%$

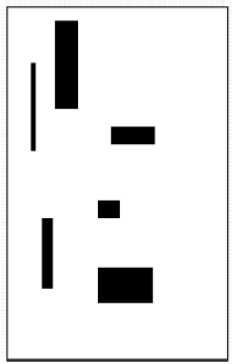

$10 \%$

Guide to assessing spatial cover within a $0.5 \times 0.5^{\circ}$ cell. 
170 Available spatial datasets that were be used to inform the expert assessment.

Available Dat
Grid_Cell_Data_v3_A
No Data
$0-0.01$
$0.01-0.05$
$0.05-0.1$
$0.1-0.25$
$0.25-0.5$
$0.5-1$
$1-2.5$
$2.5-5$
$5-10$
$10-25$
$25-50$
$50-90$
$90-100$
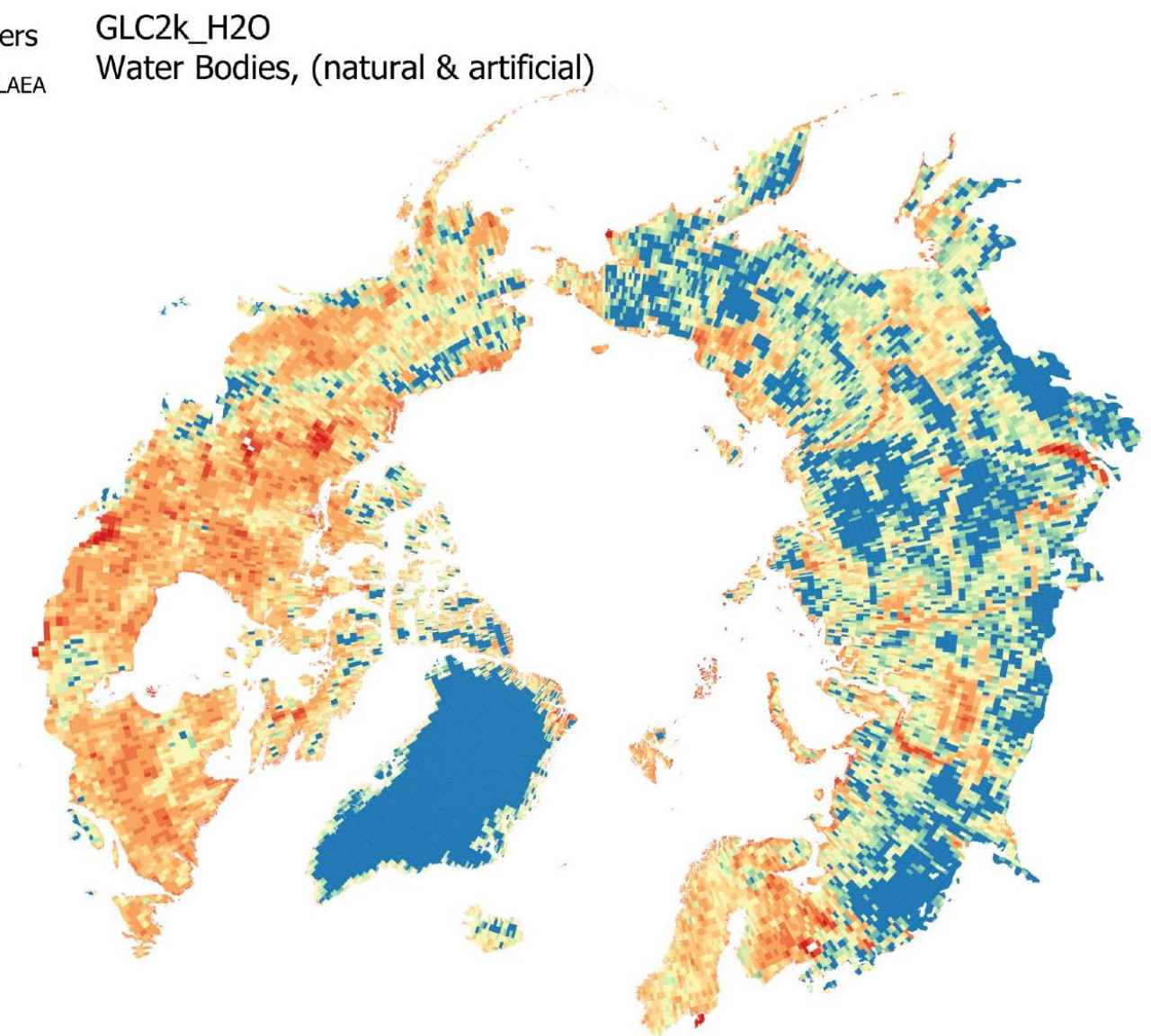
Available Datalayers

Grid_Cell_Data_v3_NPLAEA

\section{GLC2k_WETL}

Regularly flooded Shrub and/or Herbaceous Cover

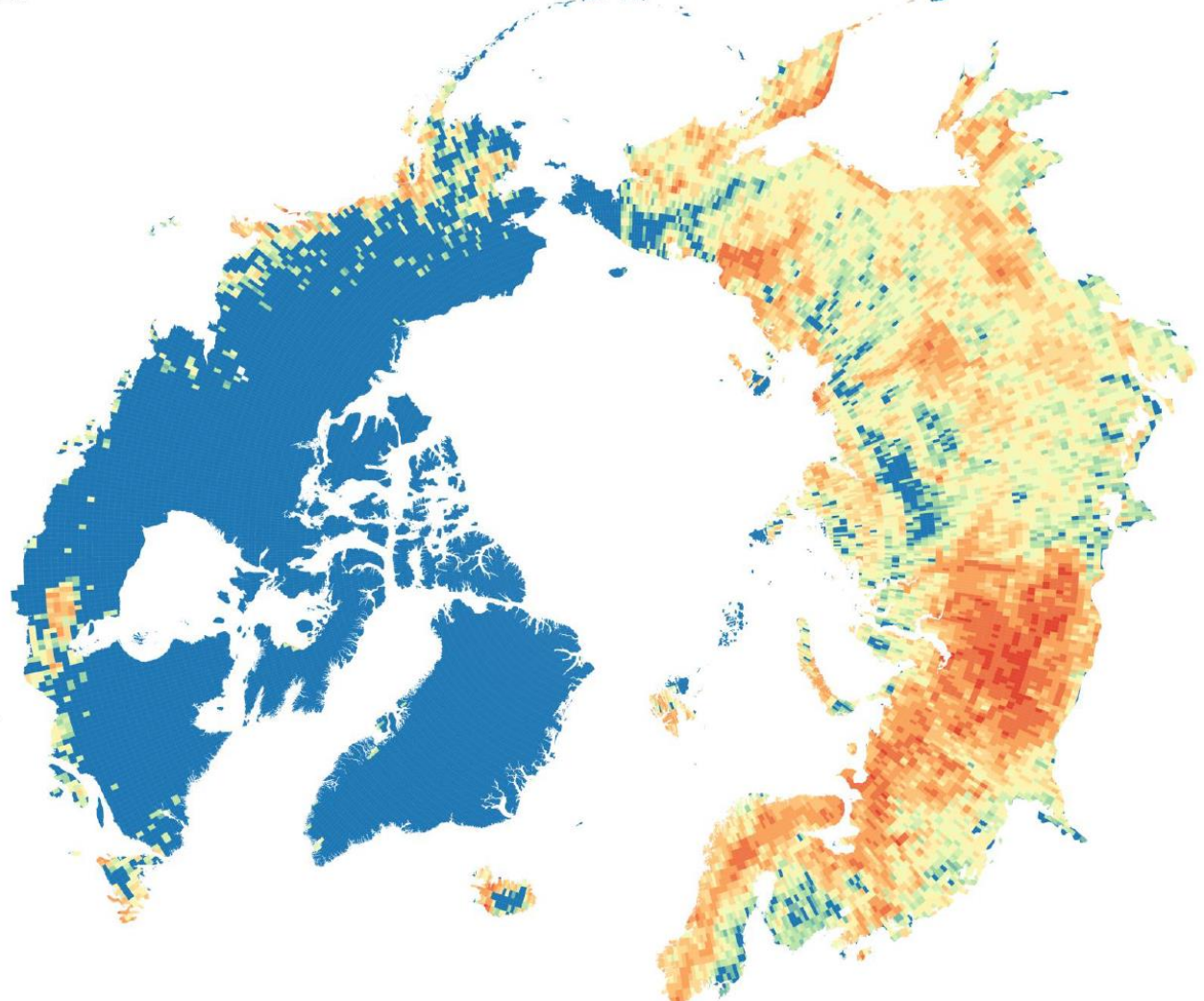


Available Datalayers

Grid_Cell_Data_v3_NPLAEA

No Data

$0-0.01$

$0.01-0.05$

$0.05-0.1$

$0.1-0.25$

$0.25-0.5$

$0.5-1$

$1-2.5$

$2.5-5$

$5-10$

$10-25$

$25-50$

$50-90$

$90-100$
GLC30_H2O

Water bodies. Water body in the land area, including river, lake, reservoir
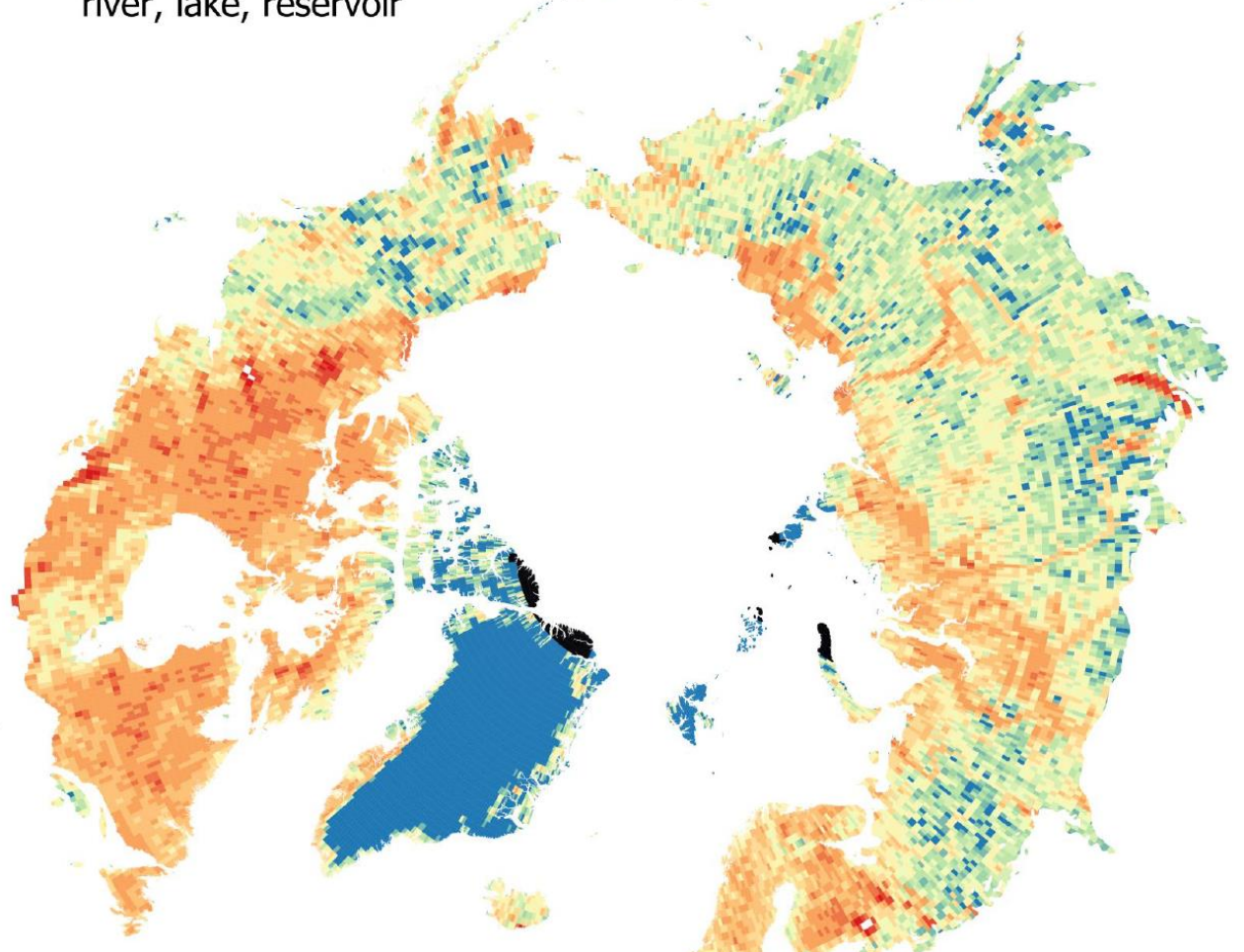
Available Datalayers

Grid_Cell_Data_v3_NPLAEA

No Data

$0-0.01$

$0.01-0.05$

$0.05-0.1$

$0.1-0.25$

$0.25-0.5$

$0.5-1$

$1-2.5$

$2.5-5$

- $5-10$

$10-25$

$25-50$

$50-90$

$90-100$
GLC30_WETL

Wetland. Lands covered with wetland plants and water bodies, including inland marsh, lake marsh, river floodplain wetland, forest/shrub wetland, peat bogs, mangrove and salt marsh

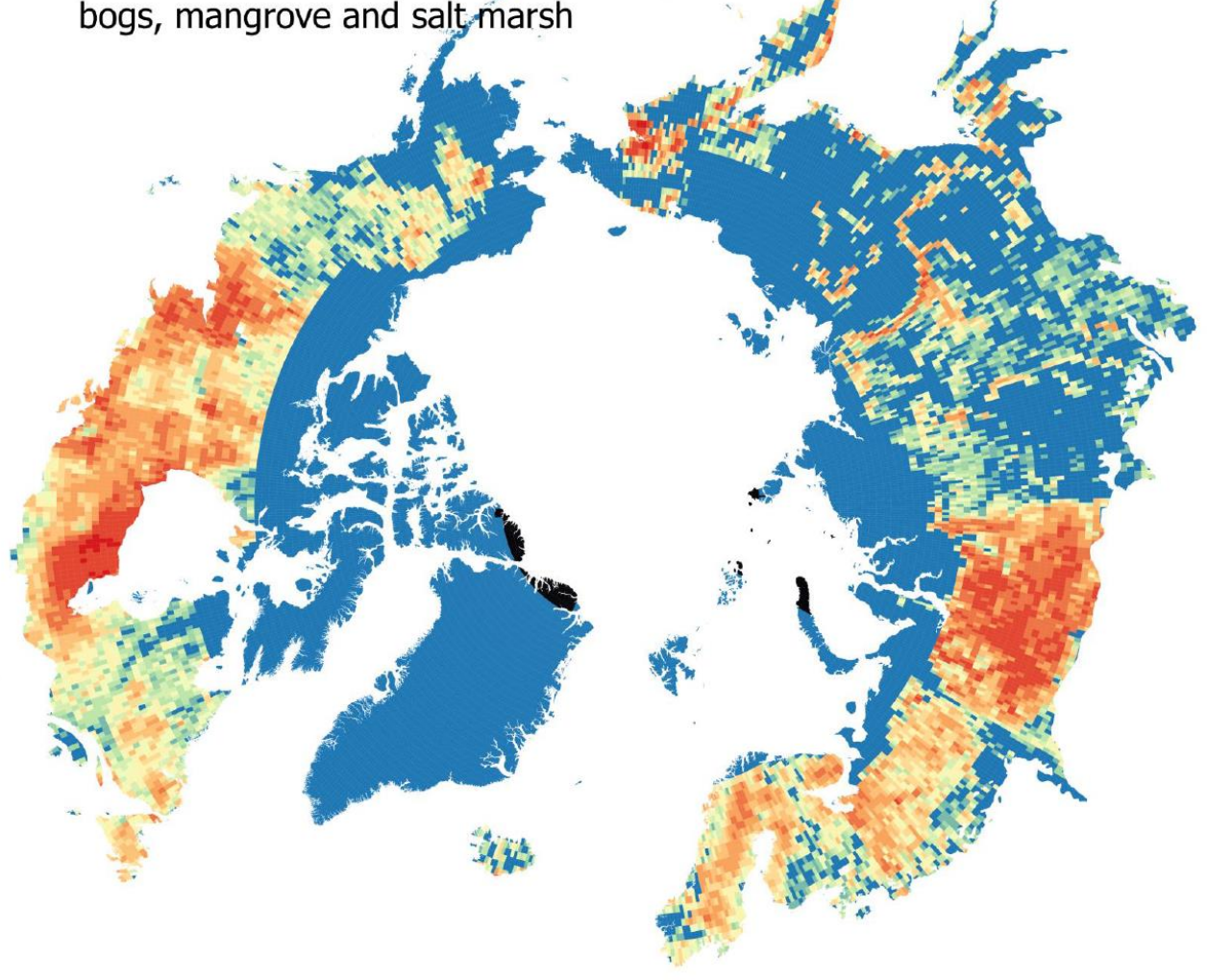


Available Datalayers

Grid_Cell_Data_v3_NPLAEA

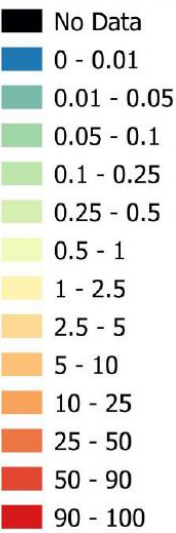

GLC30_TUND

Tundra. Lands covered by lichen, moss, hardy perennial herb and shrubs in the polar regions, including, shrúb tundra, herbaceous tundra, wet tundra and barren tundra

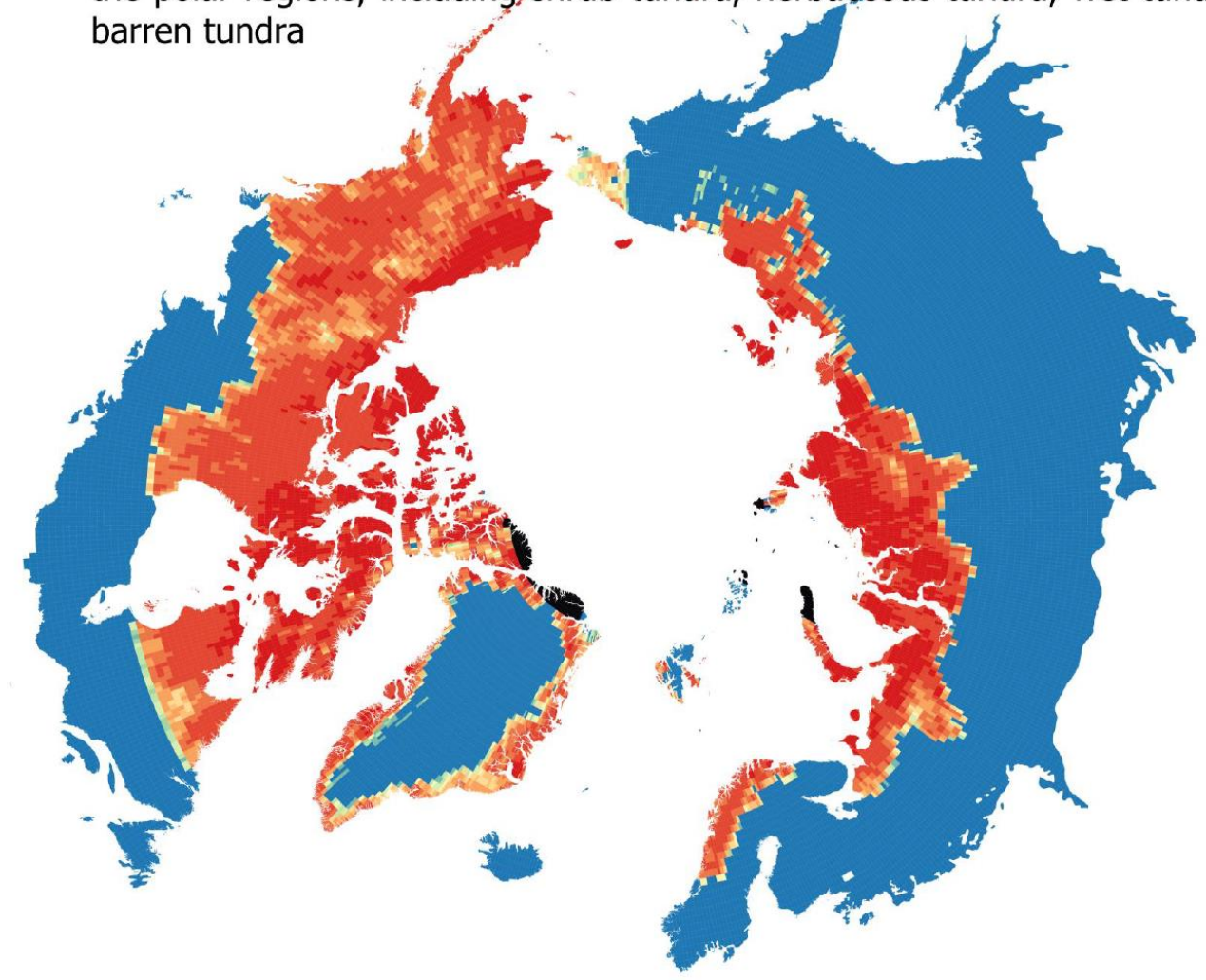


Available Datalayers

Grid_Cell_Data_v3_NPLAEA
No Data
$0-0.01$
$0.01-0.05$
$0.05-0.1$
$0.1-0.25$
$0.25-0.5$
$0.5-1$
$1-2.5$
$2.5-5$
- $5-10$
$10-25$
$25-50$
$50-90$
$90-100$

\section{GLC30_ARTI}

Artificial Surfaces. Lands modified by human activities, including all kinds of habitation, industrial and miníng area, transportation facilities, and interior urban green zones and water bodies

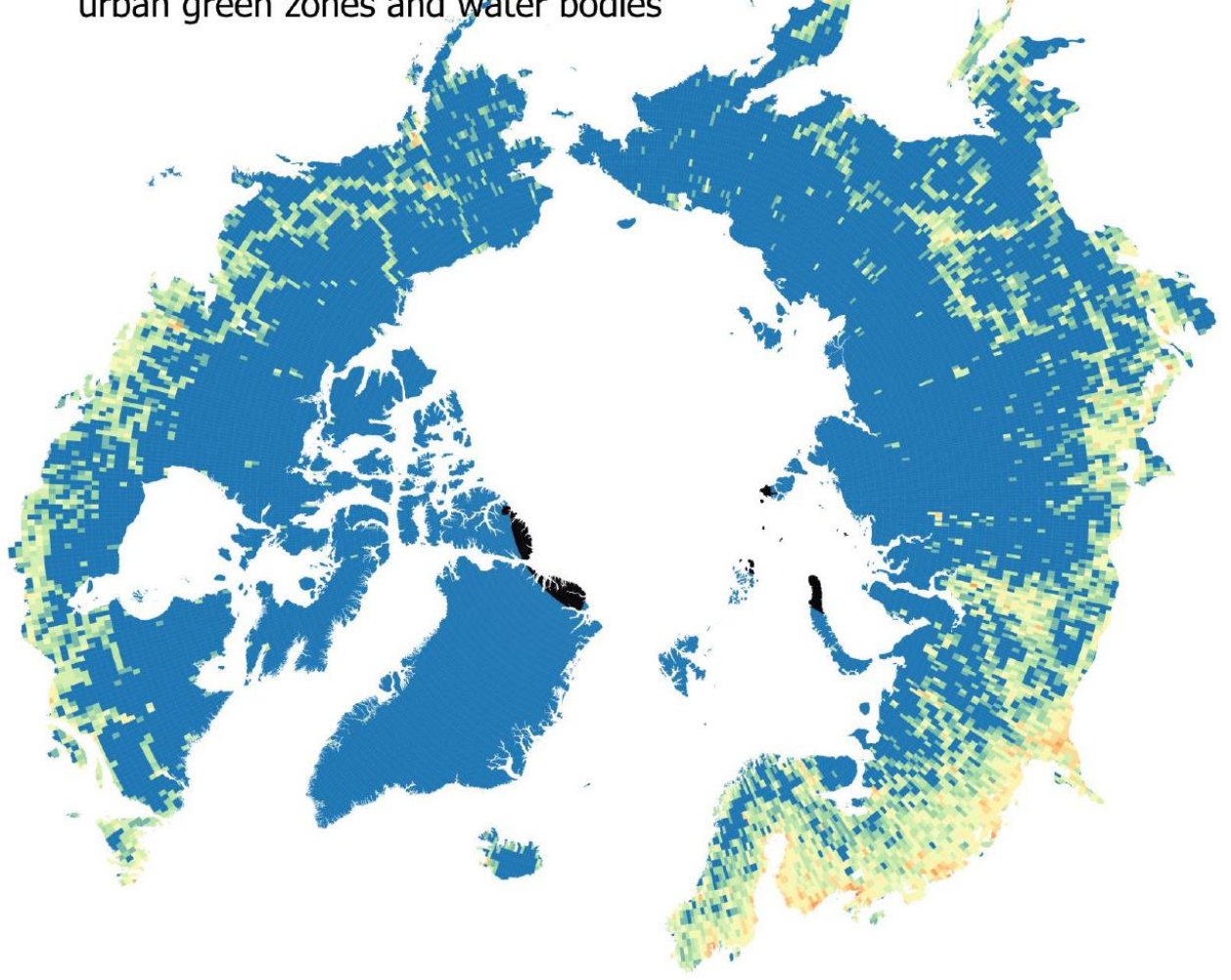


Available Datalayers

Grid_Cell_Data_v3_NPLAEA

\section{GLC30_SNOW}

Permanent snow and ice. Lands covered by permanent snow, glacier and icecap
0- 0.01
$0.01-0.05$
$0.05-0.1$
$0.1-0.25$
$0.25-0.5$
$0.5-1$
$1-2.5$
$2.5-5$
$\square-10$
$10-25$
$25-50$
- 50 - 90
$90-100$
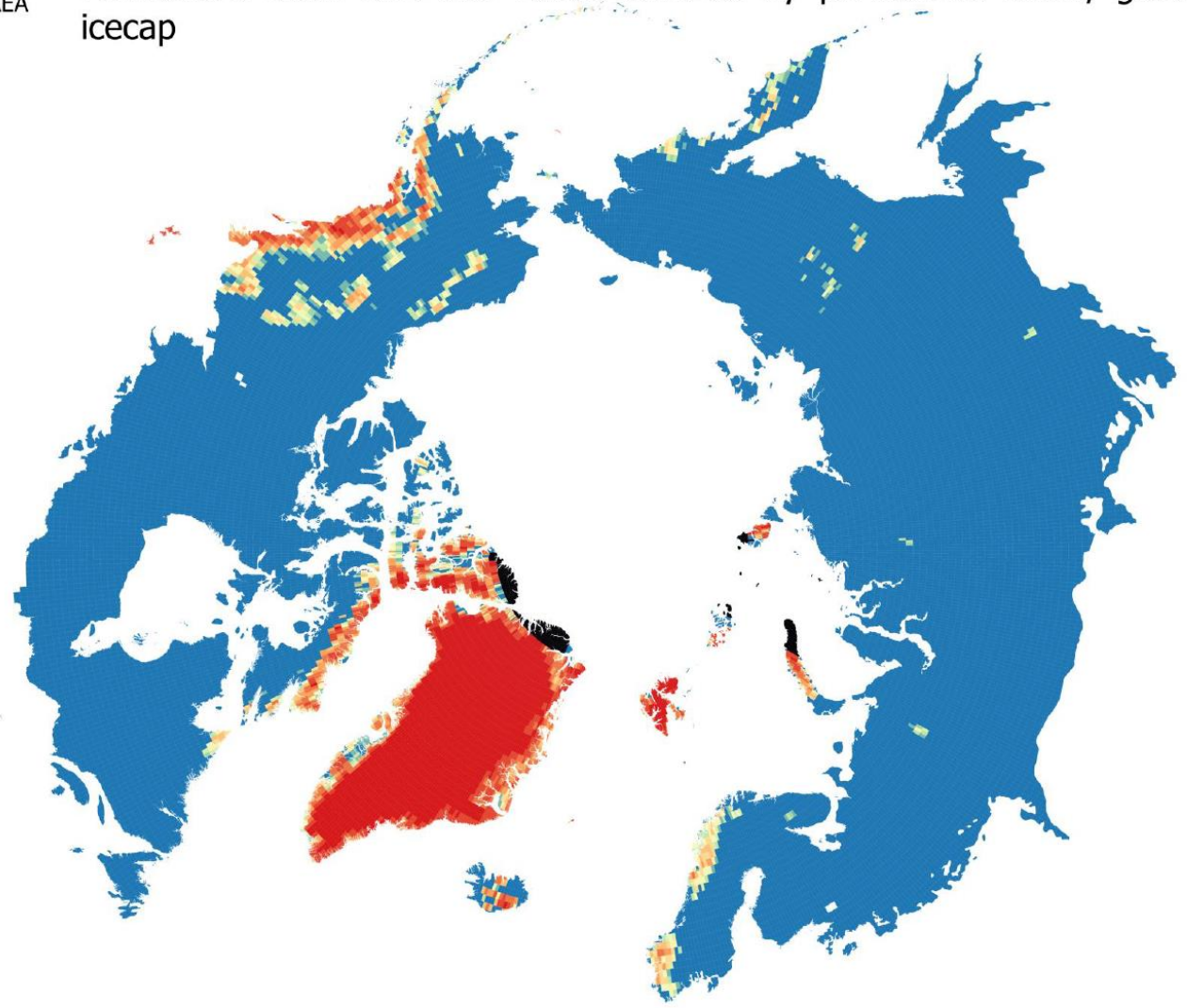
Available Datalayers

Grid_Cell_Data_v3_NPLAEA

$0-0.01$
$0.01-0.05$
$0.05-0.1$
$0.1-0.25$
$0.25-0.5$
$0.5-1$
$1-2.5$
$2.5-5$
$5-10$
$10-25$
$25-50$
$50-90$
$90-100$

GSW_0_5

Percent area with more than $0 \%$ and up to (and including) $5 \%$ occurrence of surface water between 1980 and 2018 .

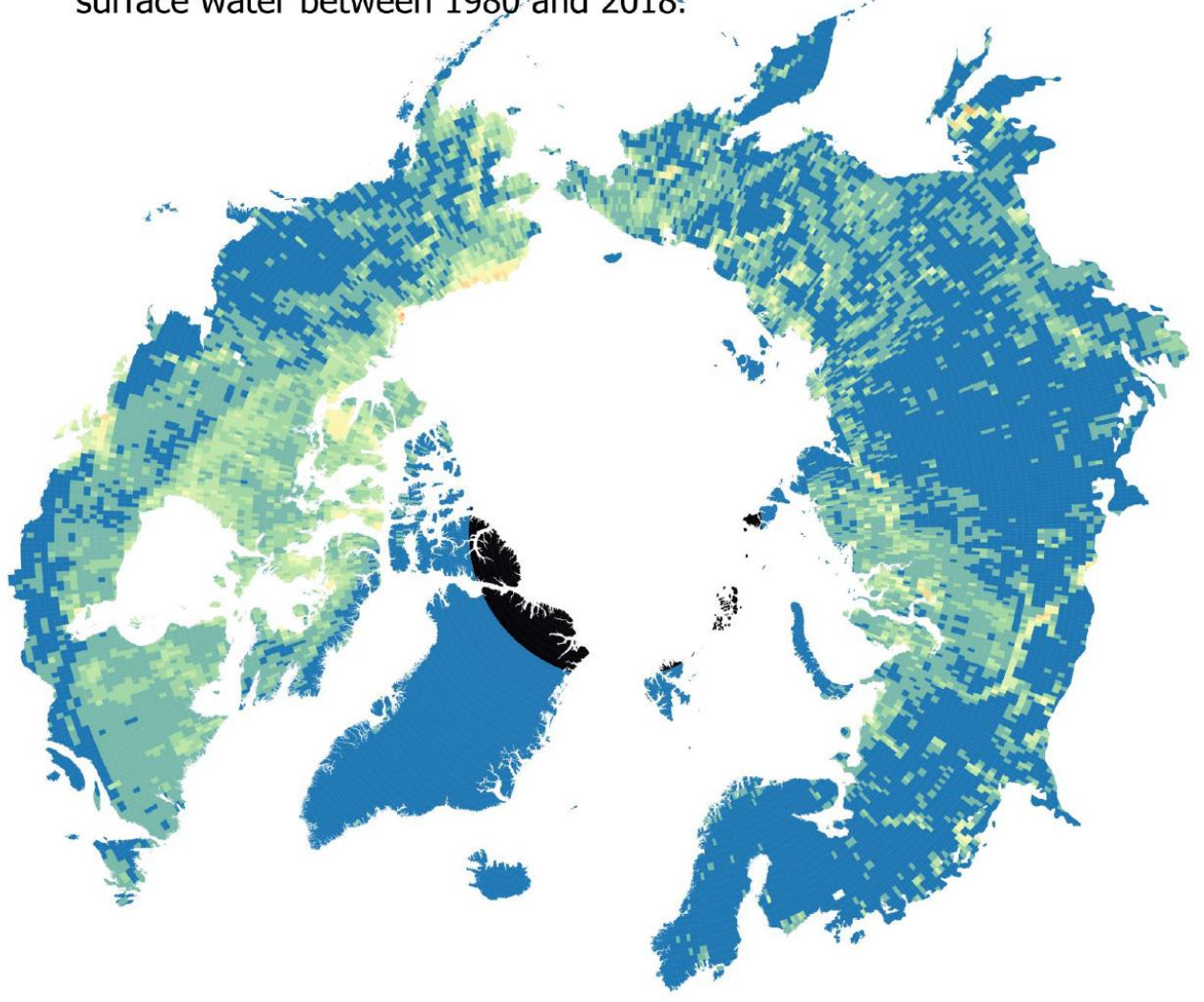


Available Datalayers

Grid_Cell_Data_v3_NPLAEA

No Data

$0-0.01$

$0.01-0.05$

$0.05-0.1$

$0.1-0.25$

$0.25-0.5$

$0.5-1$

$1-2.5$

$2.5-5$

$5-10$

$10-25$

$25-50$

$50-90$

$90-100$
GSW_5_50

Percent area with more than $5 \%$ and up to (and including) 50\% occurrence of surface water between 1980 and 2018.

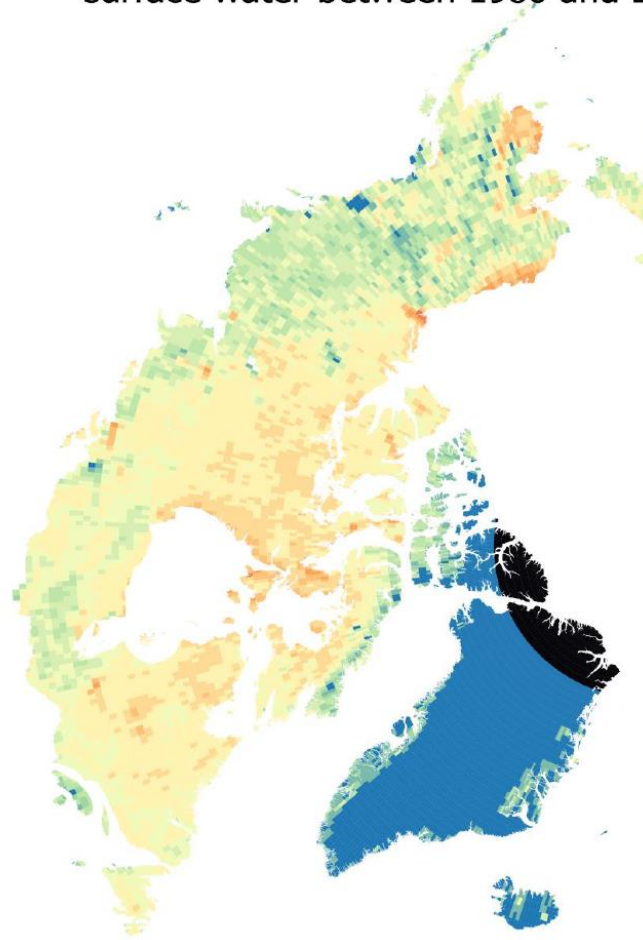

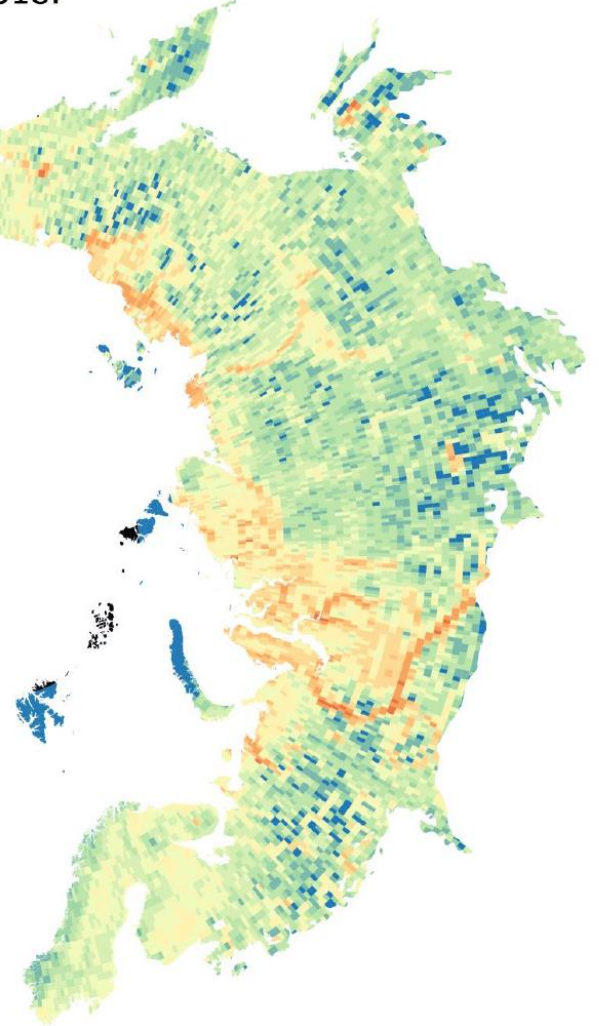


Available Datalayers

Grid_Cell_Data_v3_NPLAEA

No Data

$0-0.01$

$0.01-0.05$

$0.05-0.1$

$0.1-0.25$

$0.25-0.5$

$0.5-1$

$1-2.5$

$2.5-5$

- $5-10$

$10-25$

$25-50$

$50-90$

$90-100$

\section{GSW_50_95}

Percent area with more than $50 \%$ and up to (and including) 95\% occurrence of surface water between 1980 and 2018.

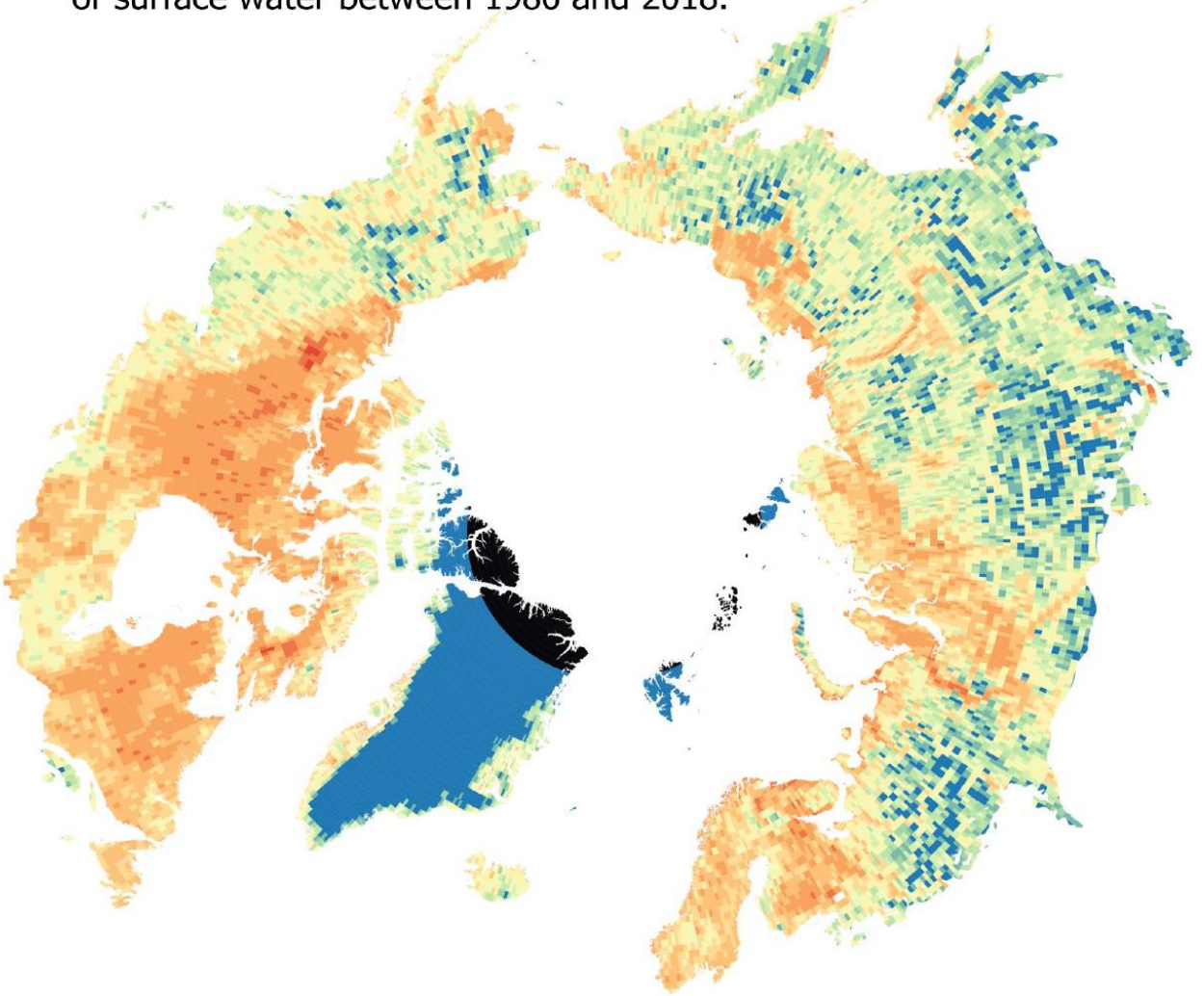


Available Datalayers

Grid_Cell_Data_v3_NPLAEA

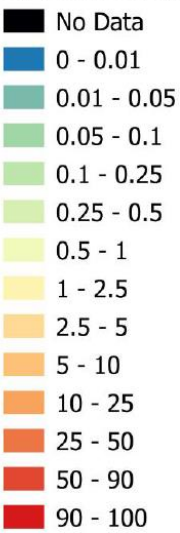

GSW_95_100

Percent area with more than $95 \%$ and up to (and including) $100 \%$ occurrence of surface water between 1980 and 2018.

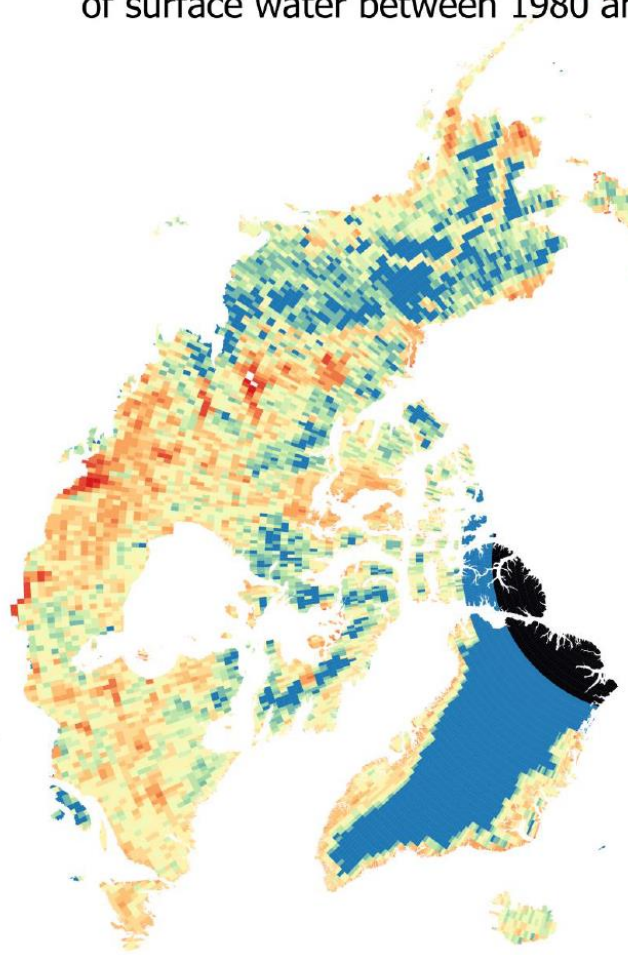

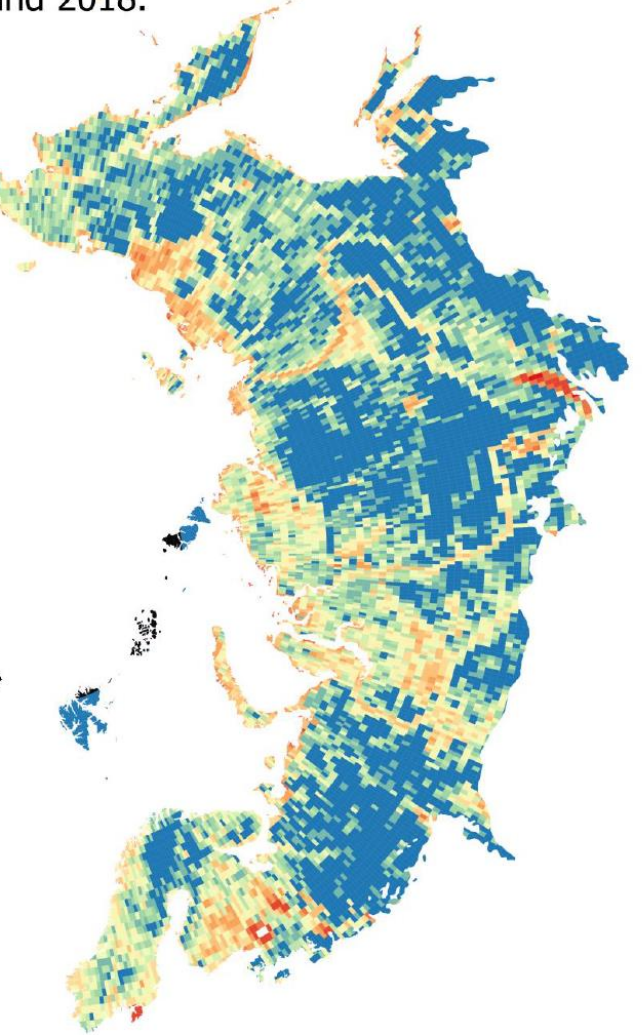


Available Datalayers

Grid_Cell_Data_v3_NPLAEA
GLDW_RIV

Rivers $>\sim 50 \mathrm{~m}$ width, $\sim 6$ th order and larger

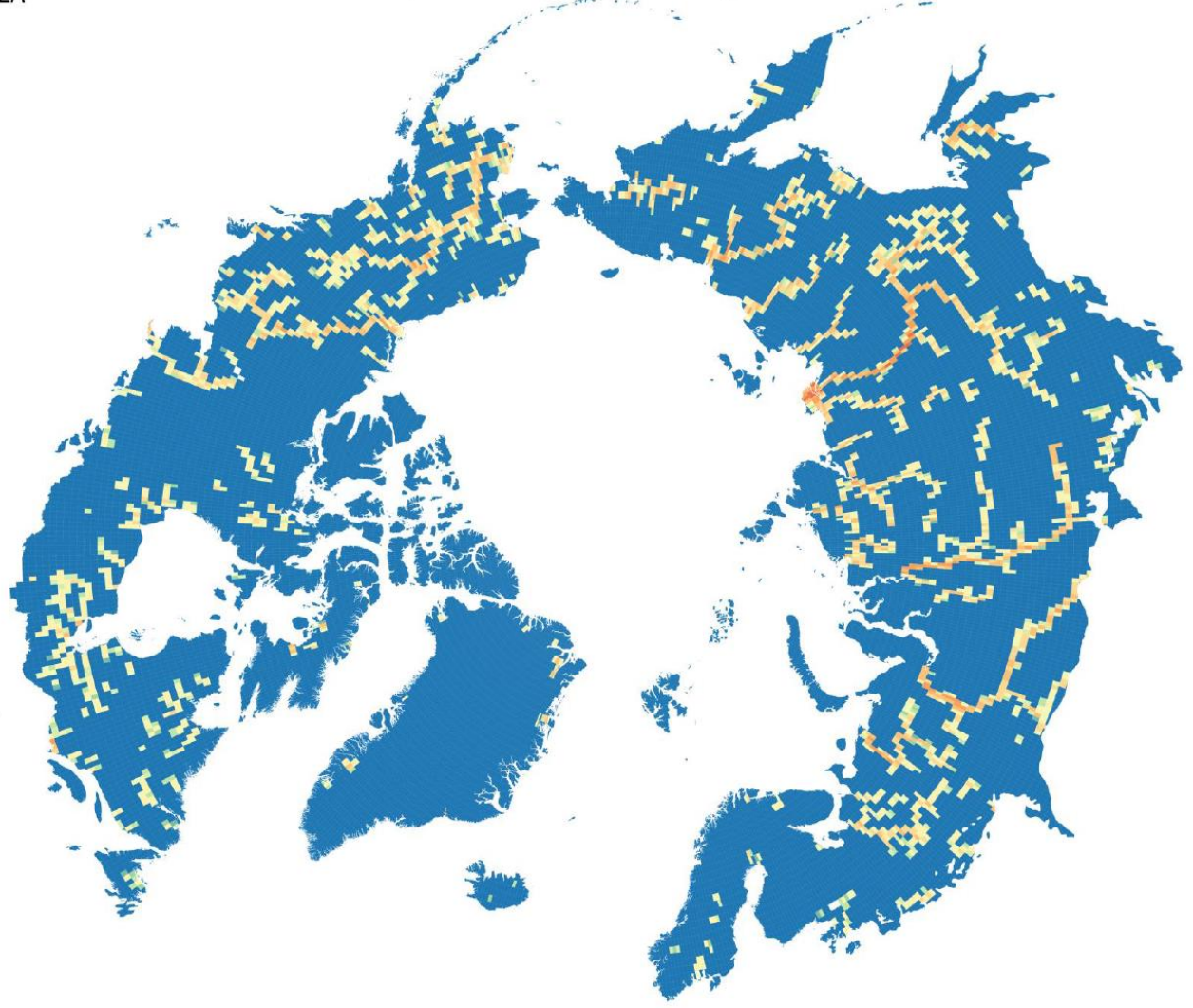


Available Datalayers

Grid_Cell_Data_v3_NPLAEA

No Data

$0-0.01$

$0.01-0.05$

$0.05-0.1$

$0.1-0.25$

$0.25-0.5$

$0.5-1$

$1-2.5$

$2.5-5$

- $5-10$

$10-25$

$25-50$

$50-90$

- $90-100$
Matthews and Fung 1987 Wetland coverage

No data should be interpreted as 0 .

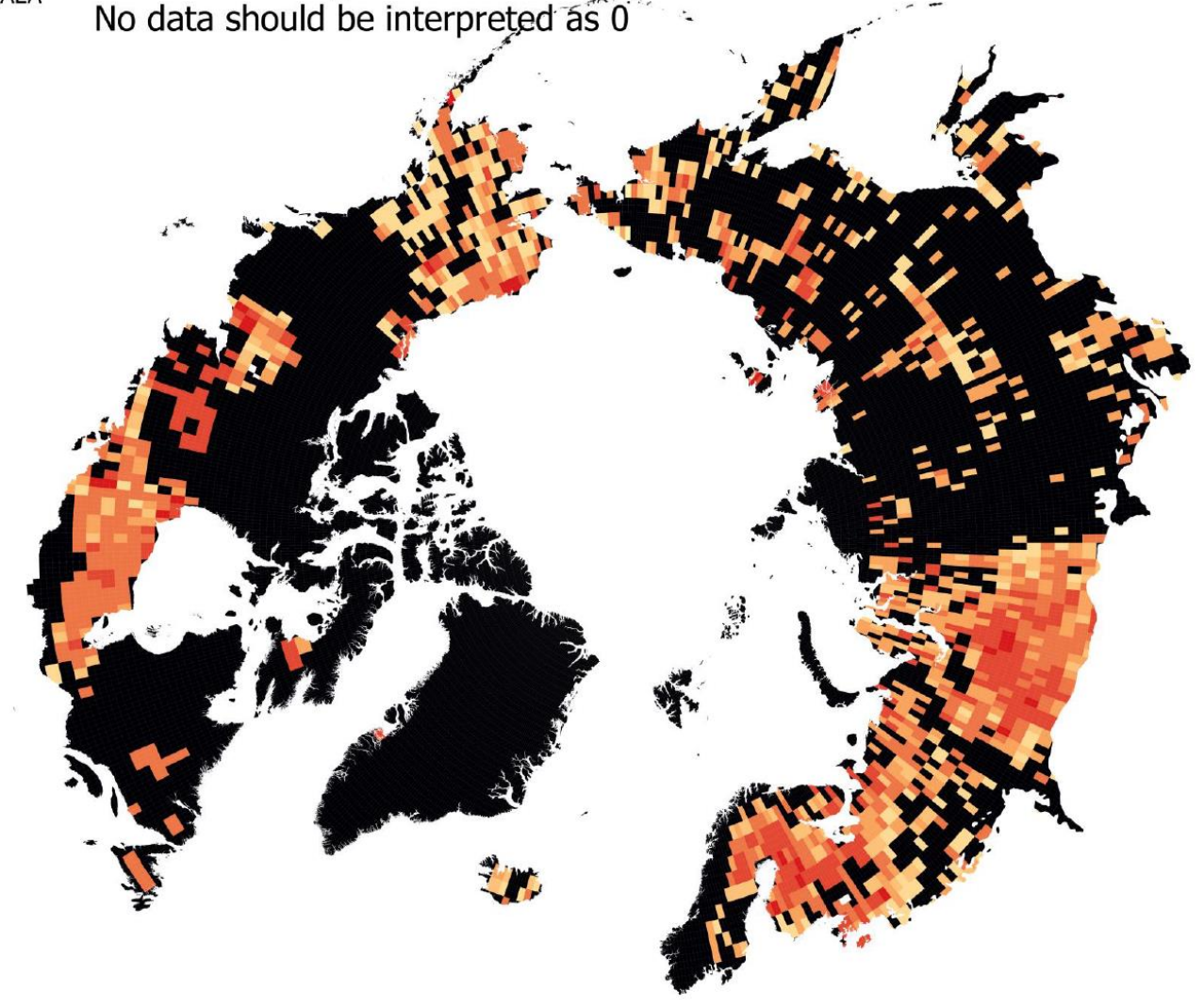


Available Datalayers

Grid_Cell_Data_v3_NPLAEA

\begin{tabular}{|l} 
No Data \\
$0-0.01$ \\
$0.01-0.05$ \\
$0.05-0.1$ \\
$0.1-0.25$ \\
$0.25-0.5$ \\
$0.5-1$ \\
$1-2.5$ \\
$2.5-5$ \\
$5-10$ \\
$10-25$ \\
$25-50$ \\
$50-90$ \\
$90-100$
\end{tabular}

\section{HL_LARGE}

HydroLAKES (v.10):\% lake area (large, > $10 \mathrm{~km} 2$ ) in grid cell

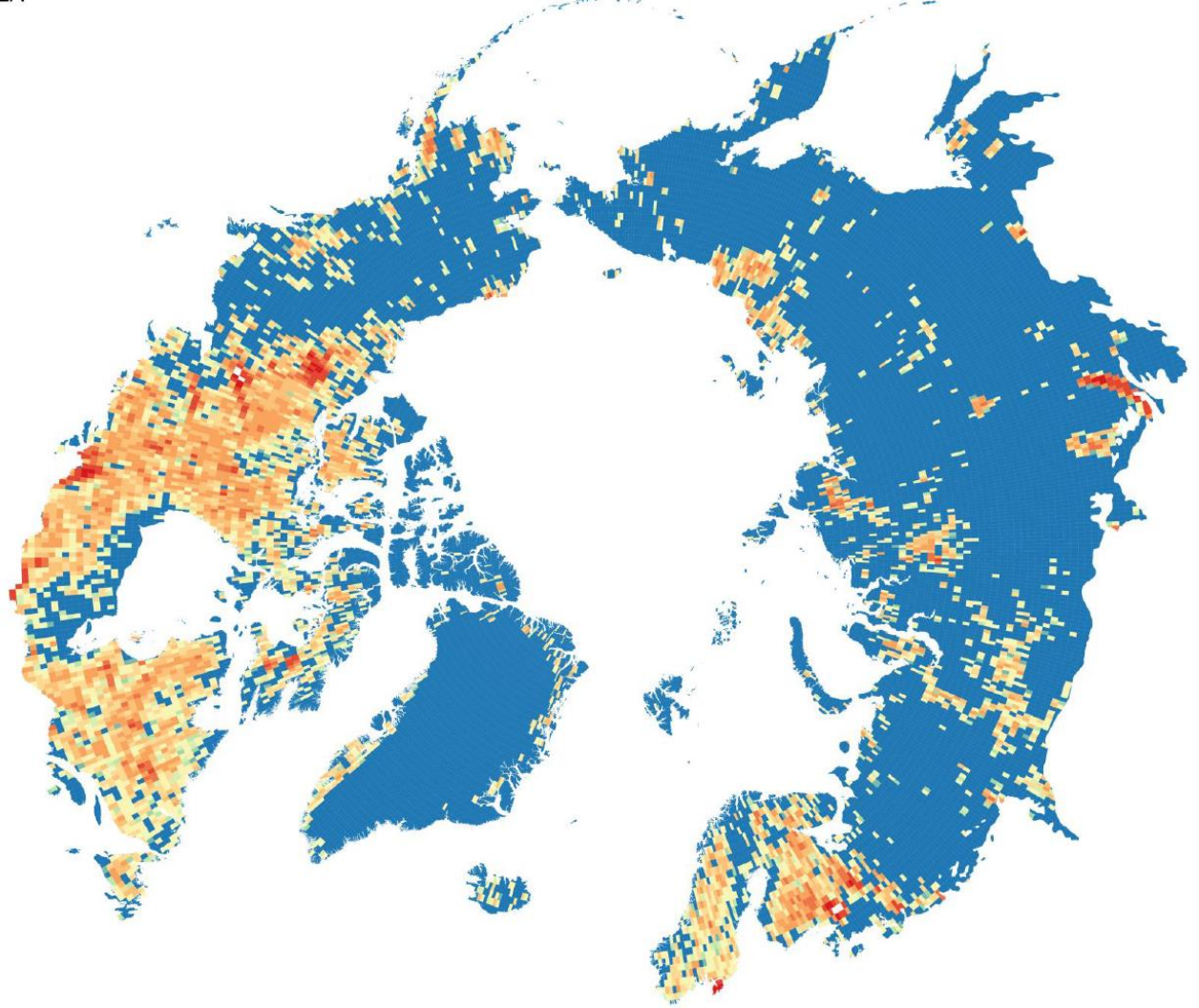


Available Datalayers

Grid_Cell_Data_v3_NPLAEA

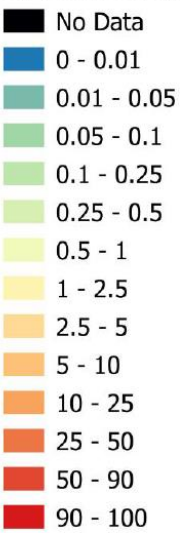

HL_MID

HydroLAKES (v.10):\% lake area (midsize, 0.1 to $10 \mathrm{~km} 2$ ) in grid cell

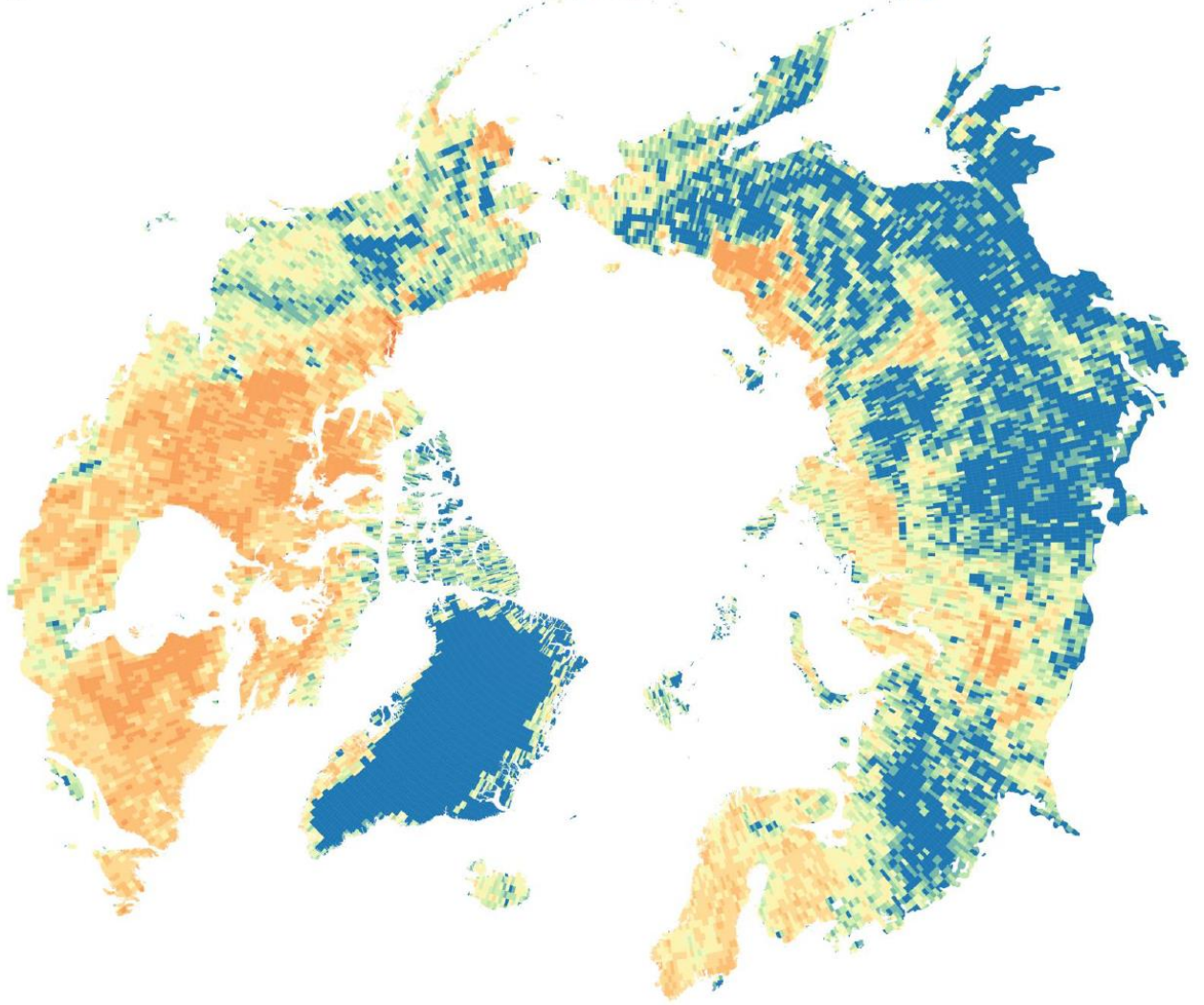


Available Datalayers

Grid_Cell_Data_v3_NPLAEA

\section{BRN_CONT}

Brown 1997: Continous permafrost (90-100\%)
$0-0$
$0-0.01$
$0.01-0.05$
$0.05-0.1$
$0.1-0.25$
$0.25-0.5$
$0.5-1$
$1-2.5$
$2.5-5$
- $5-10$
$10-25$
- $25-50$
$50-90$
$90-100$

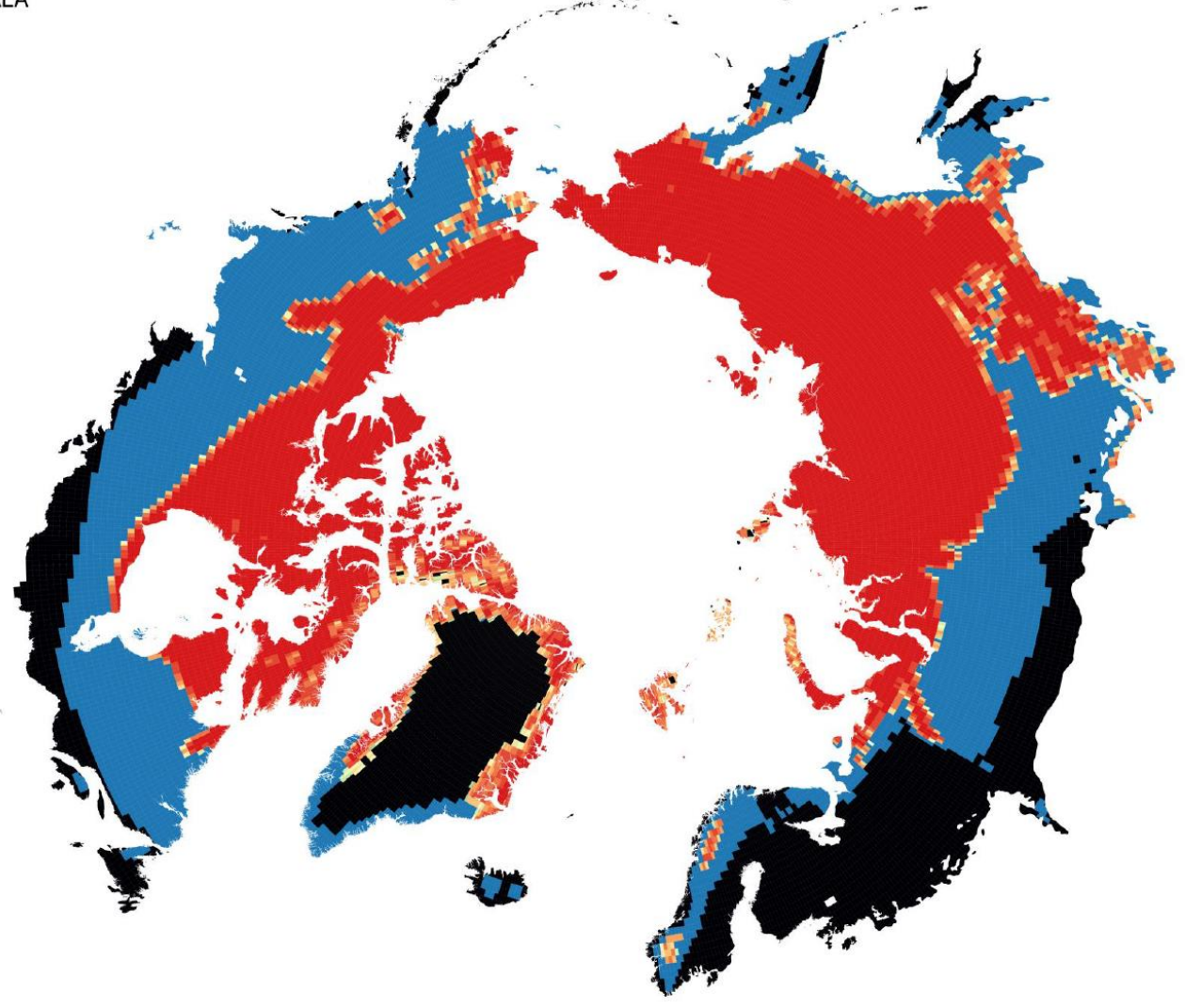


Available Datalayers

Grid_Cell_Data_v3_NPLAEA

\section{BRN_DISC}

Brown 1997: Discontinous permafrost (50-90\%)

$0-0.01$

$0.01-0.05$

$0.05-0.1$

$0.1-0.25$

$0.25-0.5$

$0.5-1$

$1-2.5$

$2.5-5$

$5-10$

$10-25$

$25-50$

$50-90$

$90-100$

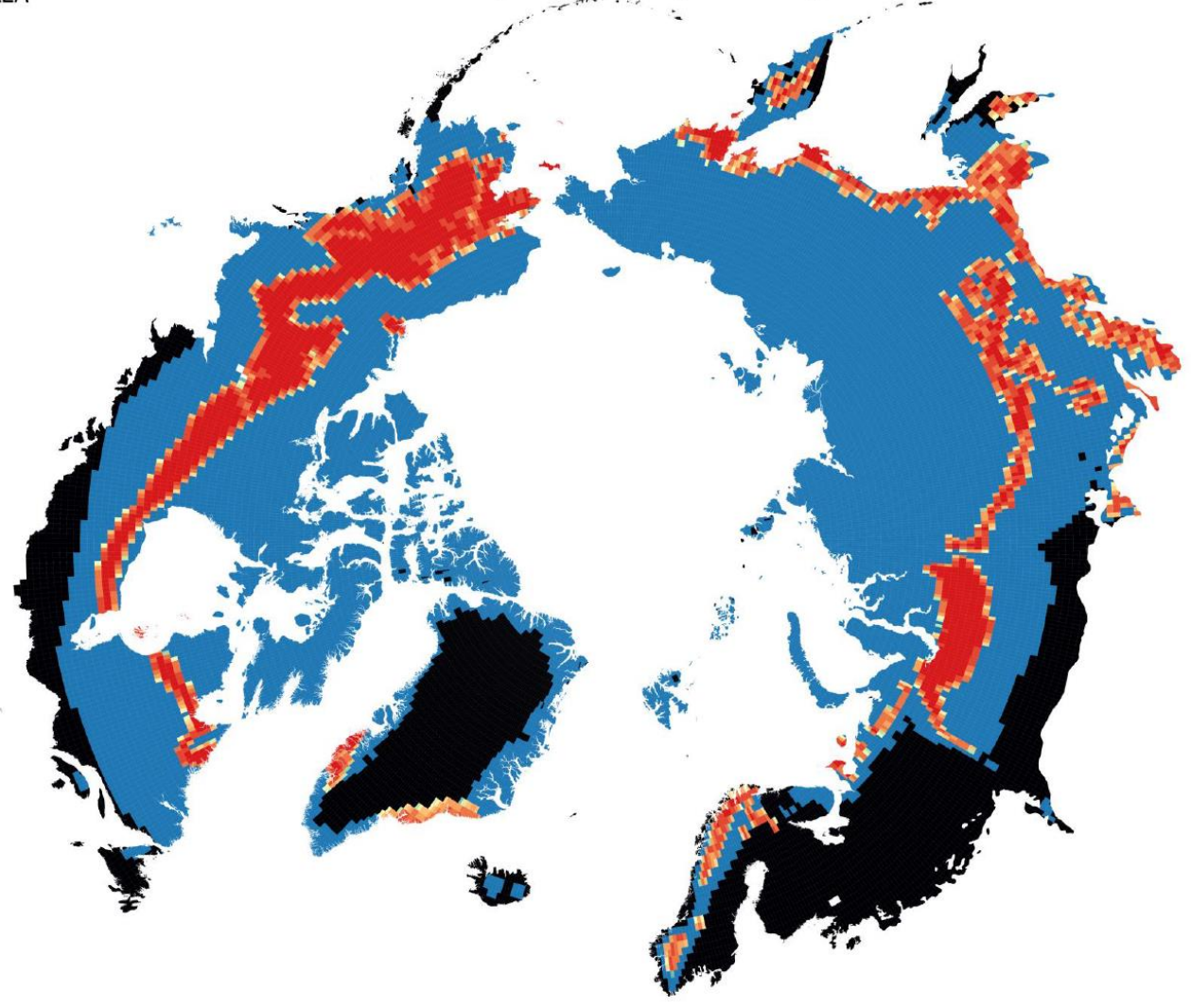


Available Datalayers

Grid_Cell_Data_v3_NPLAEA
BRN_SPOR

Brown 1997: Discontinous permafrost (10-50\%)

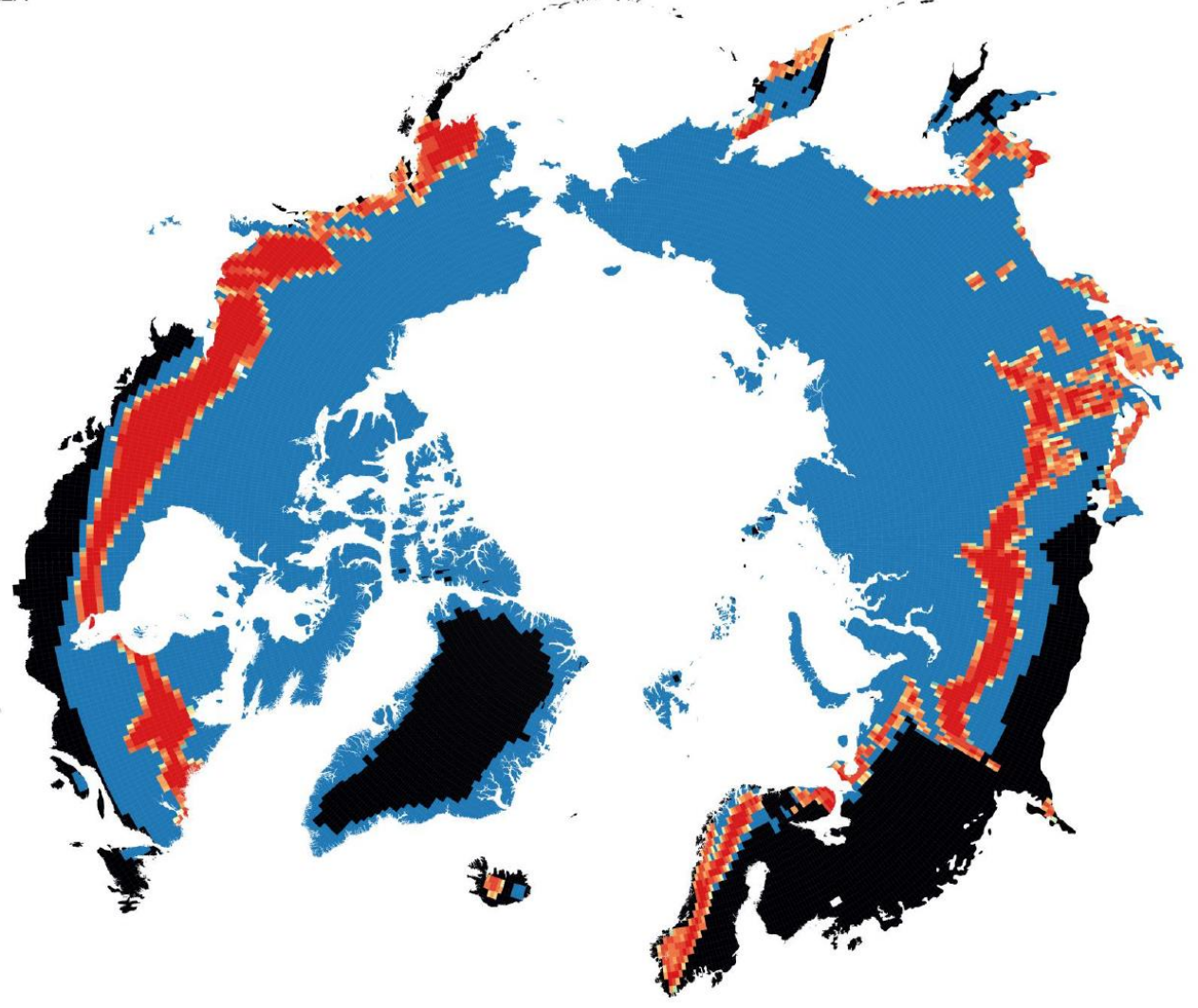


Available Datalayers

Grid_Cell_Data_v3_NPLAEA
BRN_ISOL

Brown 1997: Discontinous permafrost (0-10\%)

$0-0.01$

$0.01-0.05$

$0.05-0.1$

$0.1-0.25$

$0.25-0.5$

$0.5-1$

$1-2.5$

$2.5-5$

$5-10$

$10-25$

$25-50$

$50-90$

$90-100$

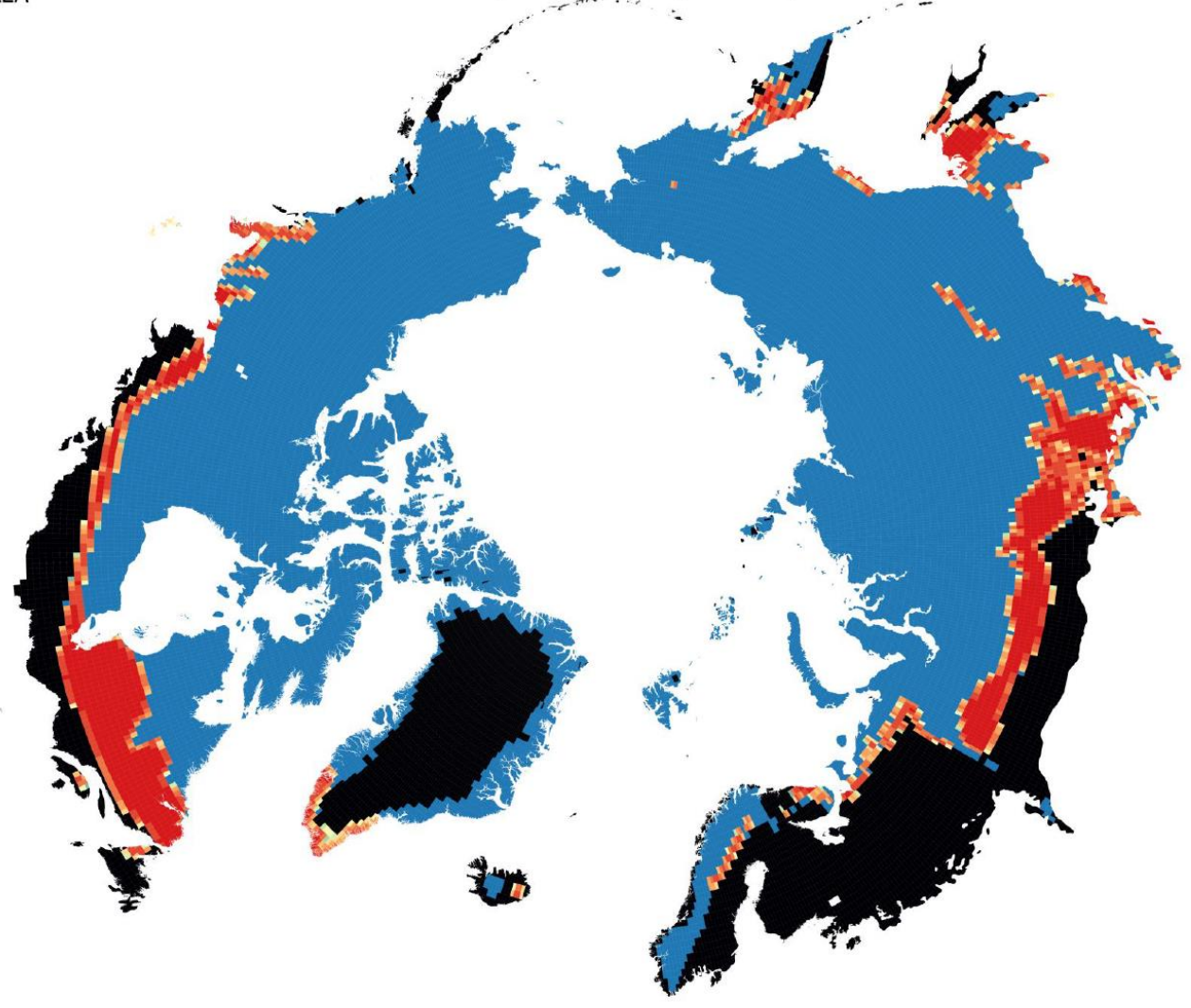


Available Datalayers

Grid_Cell_Data_v3_NPLAEA

\section{BRN_Xhf}

Brown 1997: Thick overburden cover (>5-10m), high ( $>20 \%$ ) ice content

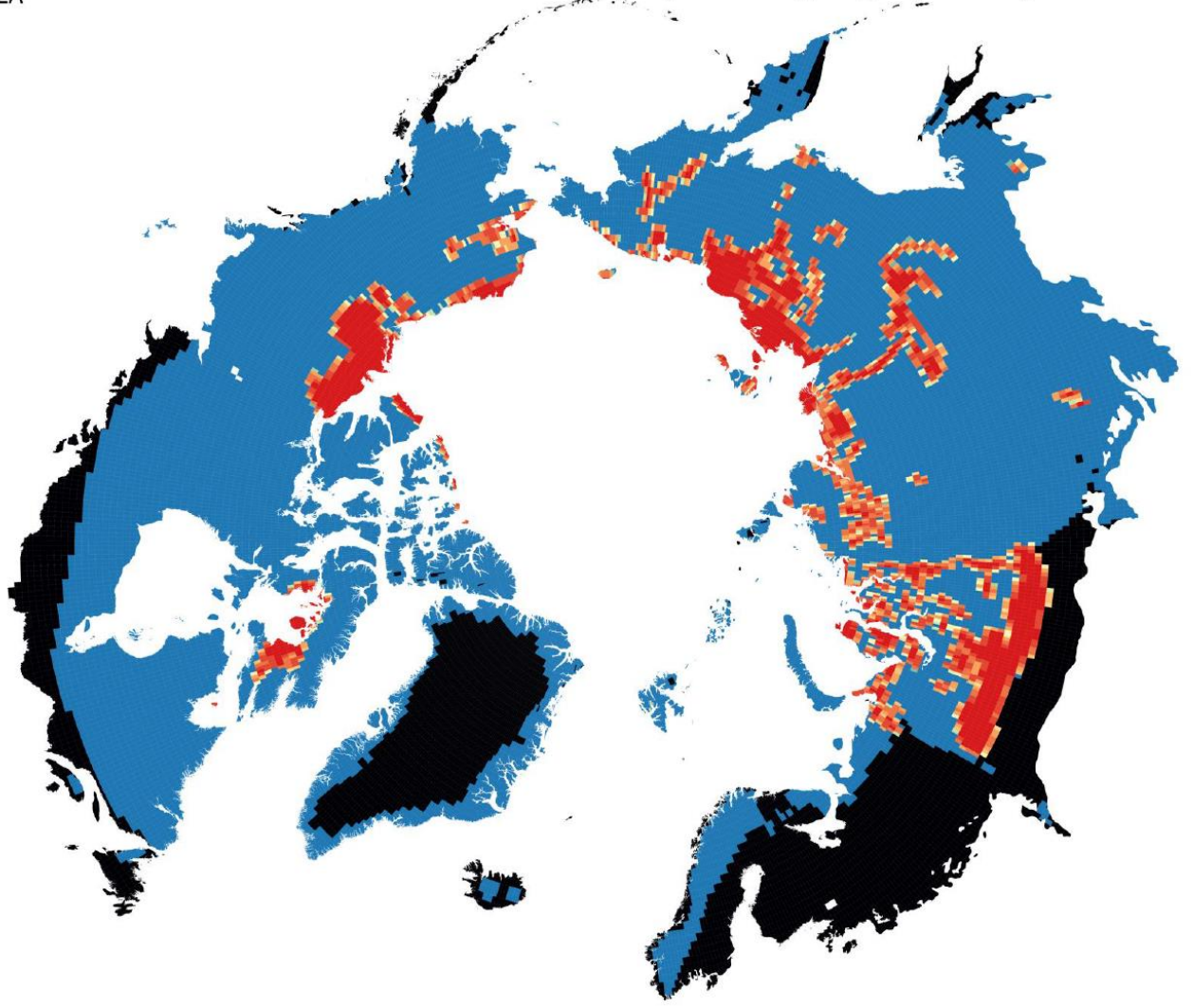


Available Datalayers

Grid_Cell_Data_v3_NPLAEA

No Data
$0-0.01$
$0.01-0.05$
$0.05-0.1$
$0.1-0.25$
$0.25-0.5$
$0.5-1$
$1-2.5$
$2.5-5$
$5-10$
$10-25$
$25-50$
$50-90$
$90-100$

\section{BRN_Xmf}

Brown 1997: Thick overburden cover $(>5-10 \mathrm{~m})$, medium $(10-20 \%)$ ice content

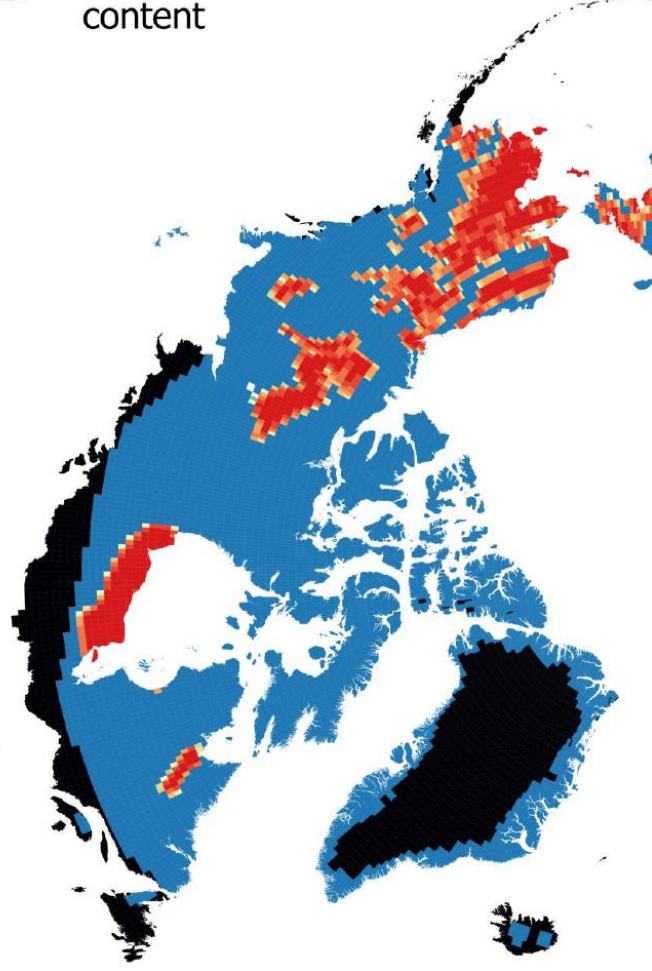

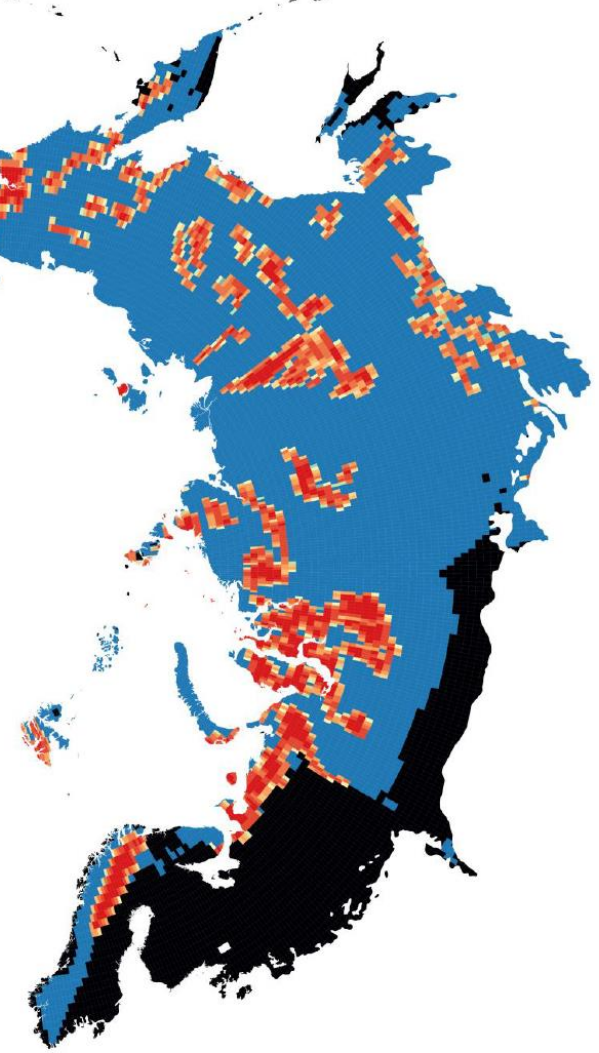


Available Datalayers

Grid_Cell_Data_v3_NPLAEA

\section{BRN_XIf}

Brown 1997: Thick overburden cover (>5-10m), low (0-10\%) ice content

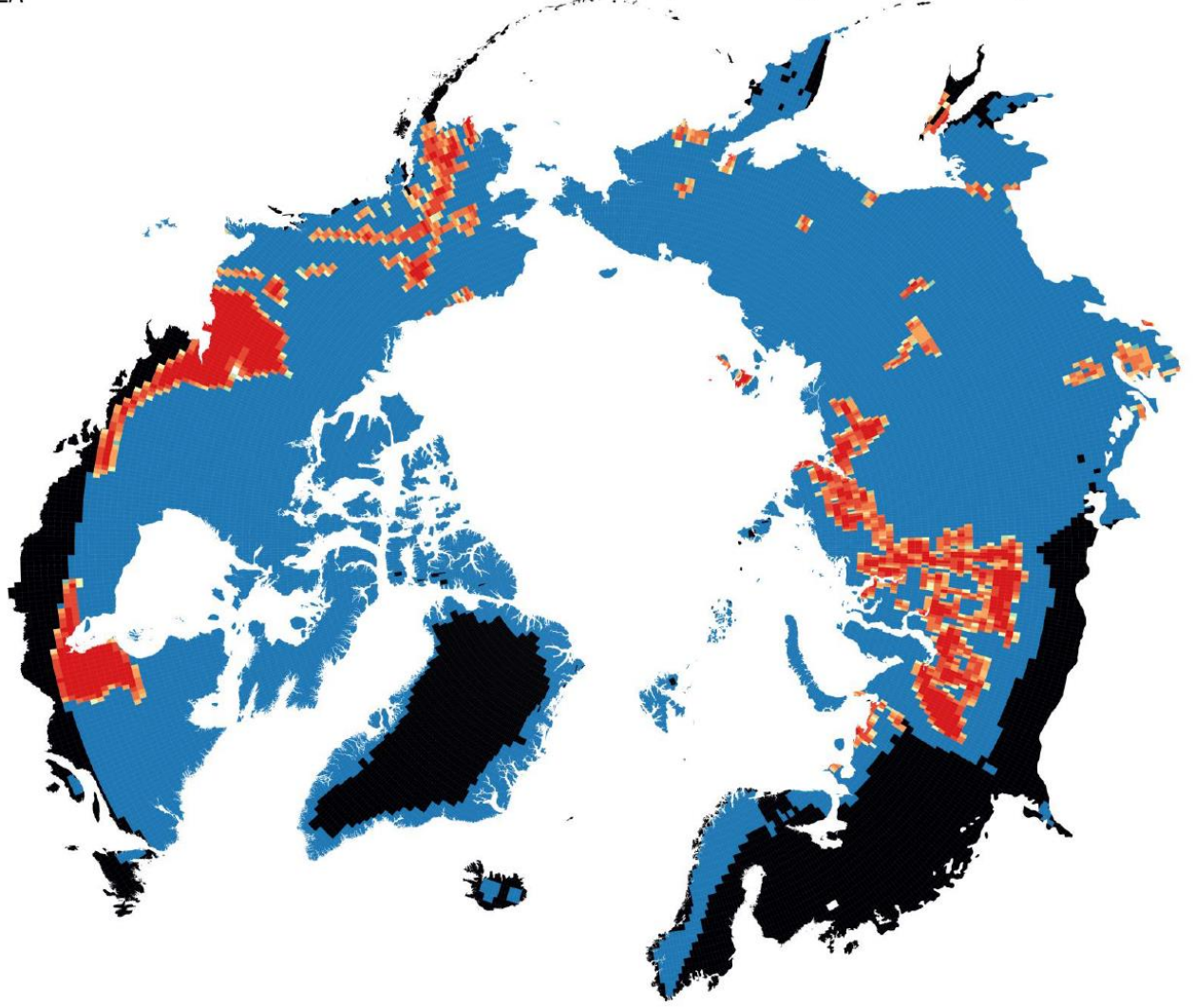


Available Datalayers

Grid_Cell_Data_v3_NPLAEA

$0-0.01$
$0.01-0.05$
$0.05-0.1$
$0.1-0.25$
$0.25-0.5$
$0.5-1$
$1-2.5$
$2.5-5$
$5-10$
$10-25$
$25-50$
$50-90$
$90-100$

BRN_Xhr

Brown 1997: Thin overburden cover $(<5-10 \mathrm{~m})$ and exposed bedrock, high to medium ( $>10 \%)$ ice content)

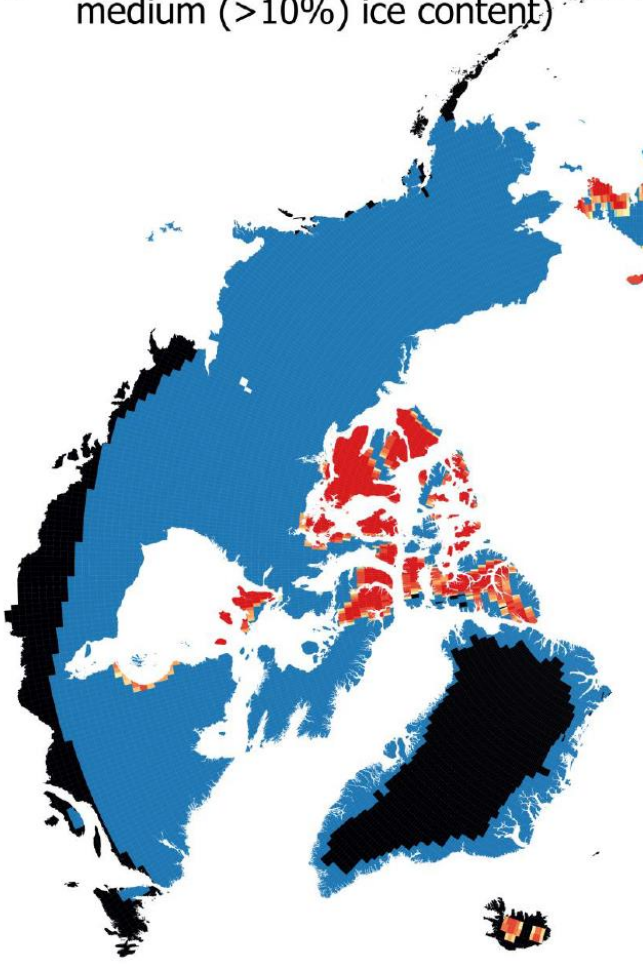

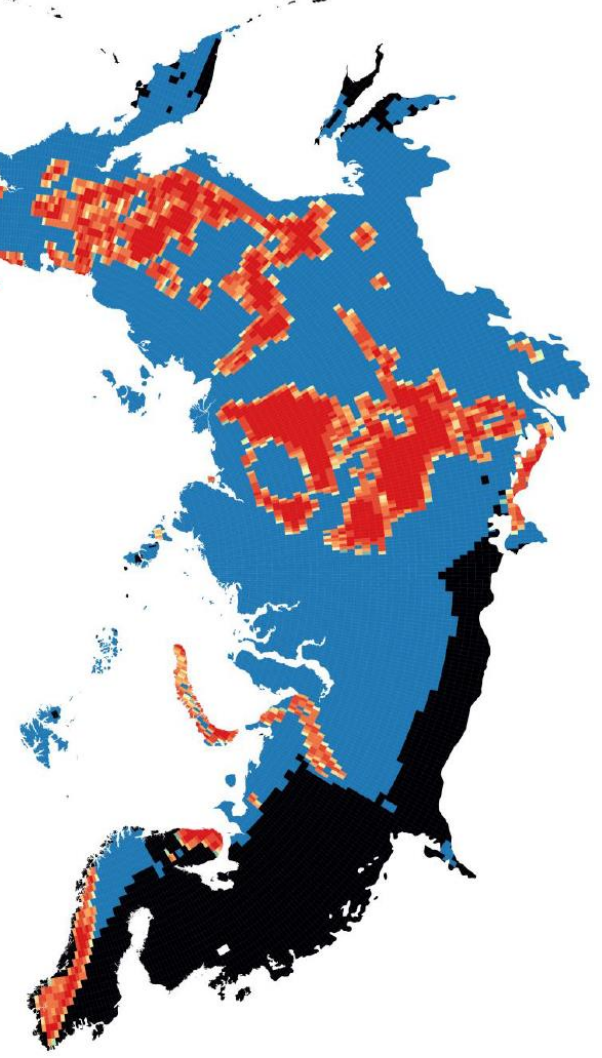


Available Datalayers

Grid_Cell_Data_v3_NPLAEA
No Data
$0-0.01$
$0.01-0.05$
$0.05-0.1$
$0.1-0.25$
$0.25-0.5$
$0.5-1$
$1-2.5$
$2.5-5$
$5-10$
$10-25$
$25-50$
- $50-90$
$90-100$

\section{BRN_XIr}

Brown 1997: Thin overburden cover $(<5-10 \mathrm{~m})$ and exposed bedrock, low (0-10\%) ice content)

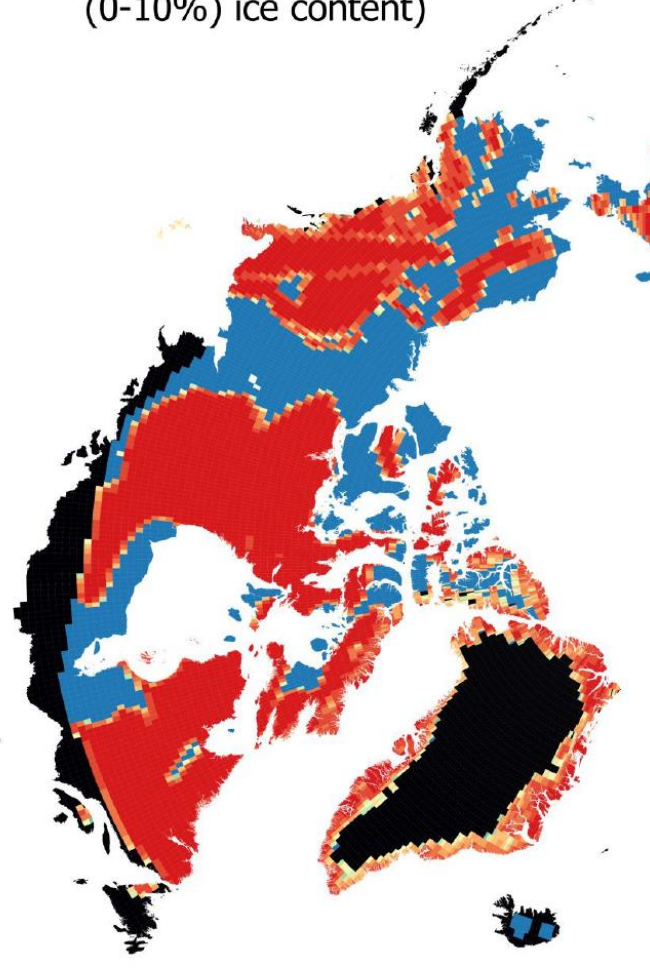

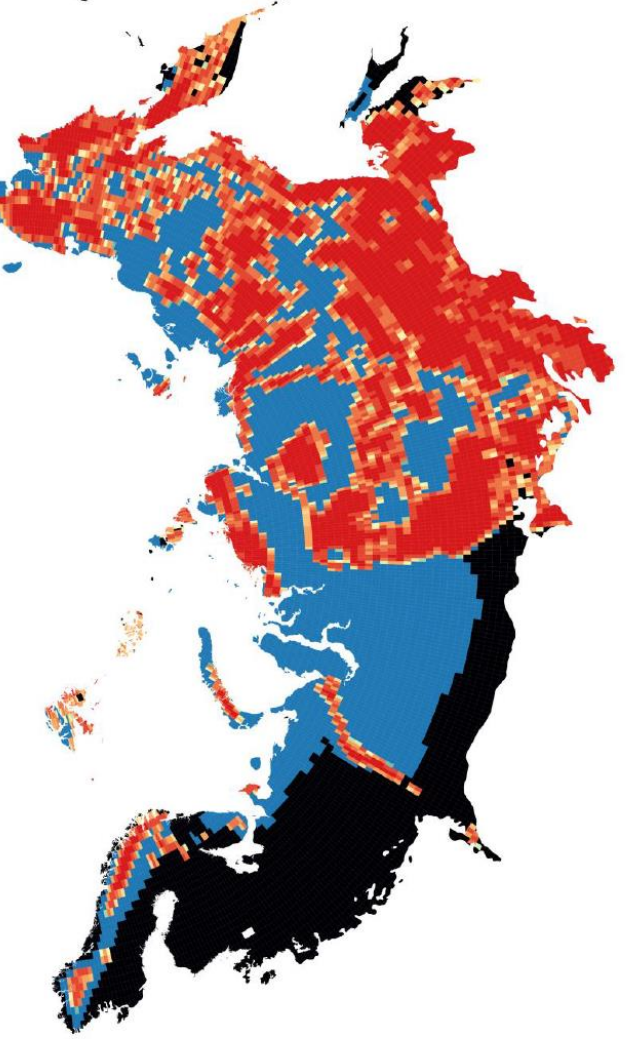


Available Datalayers

Grid_Cell_Data_v3_NPLAEA
BRN_RELI

Brown 1997: Relict permafrost.
No Data
0.0 .01
$0.01-0.05$
$0.05-0.1$
$0.1-0.25$
$0.25-0.5$
$0.5-1$
$1-2.5$
$2.5-5$
$5-10$
- $10-25$
$25-50$
$50-90$
$90-100$
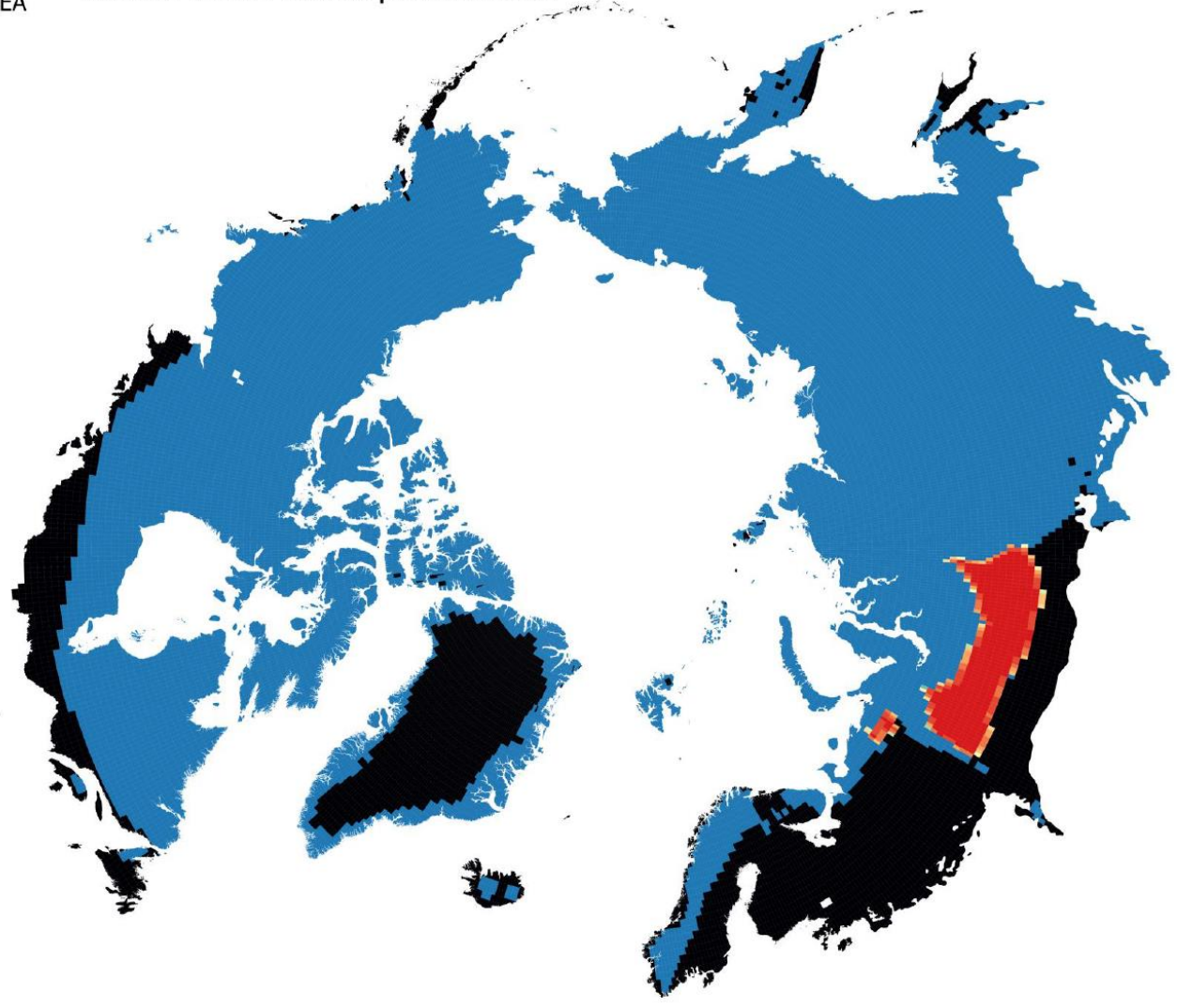
Available Datalayers

Grid_Cell_Data_v3_NPLAEA

\section{SOIL_HISTO}

NCSCD: Histosol coverage

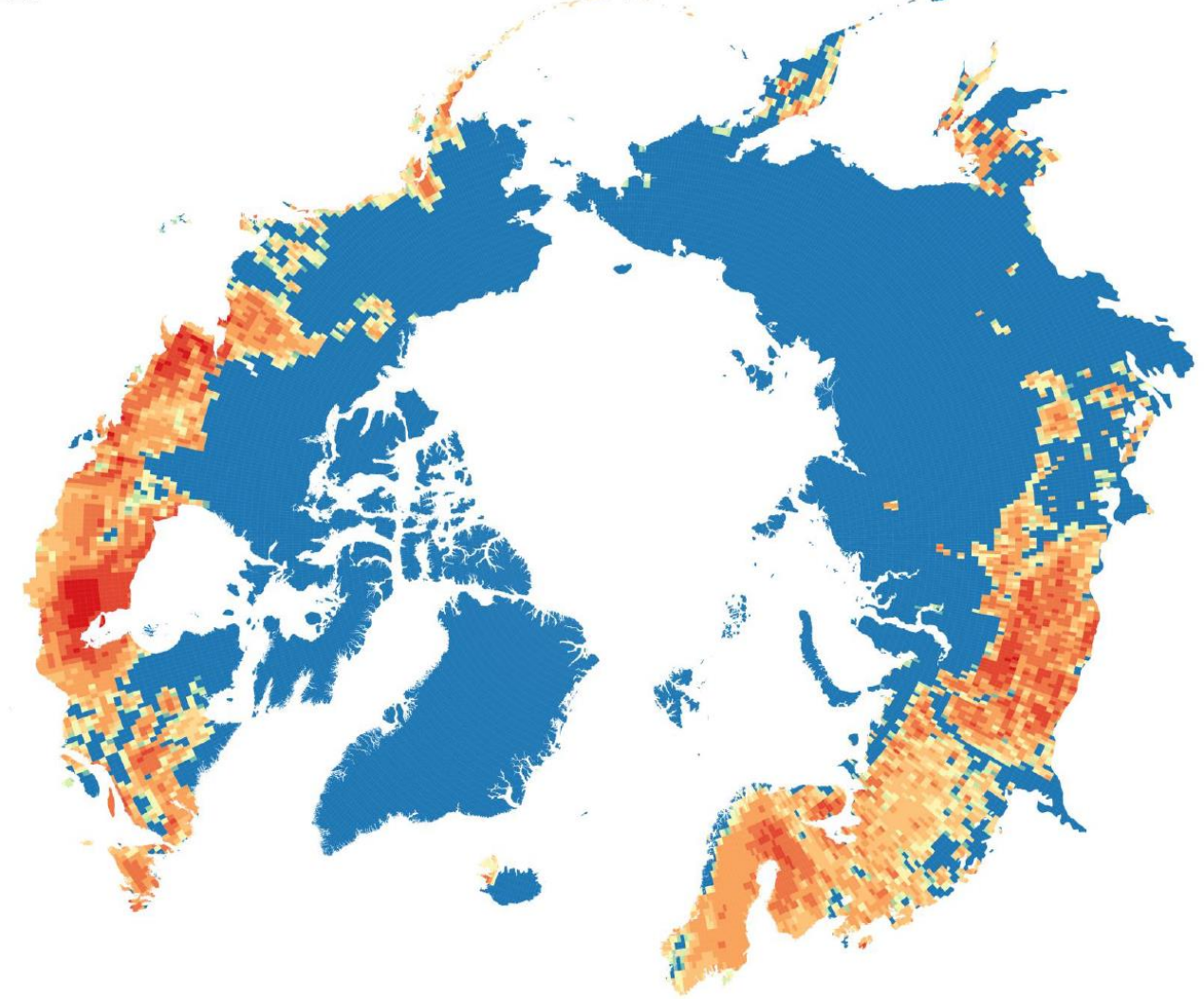


Available Datalayers

Grid_Cell_Data_v3_NPLAEA

\section{SOIL_HISTE}

NCSCD: Histel soil coverage (permafrost organic soils)

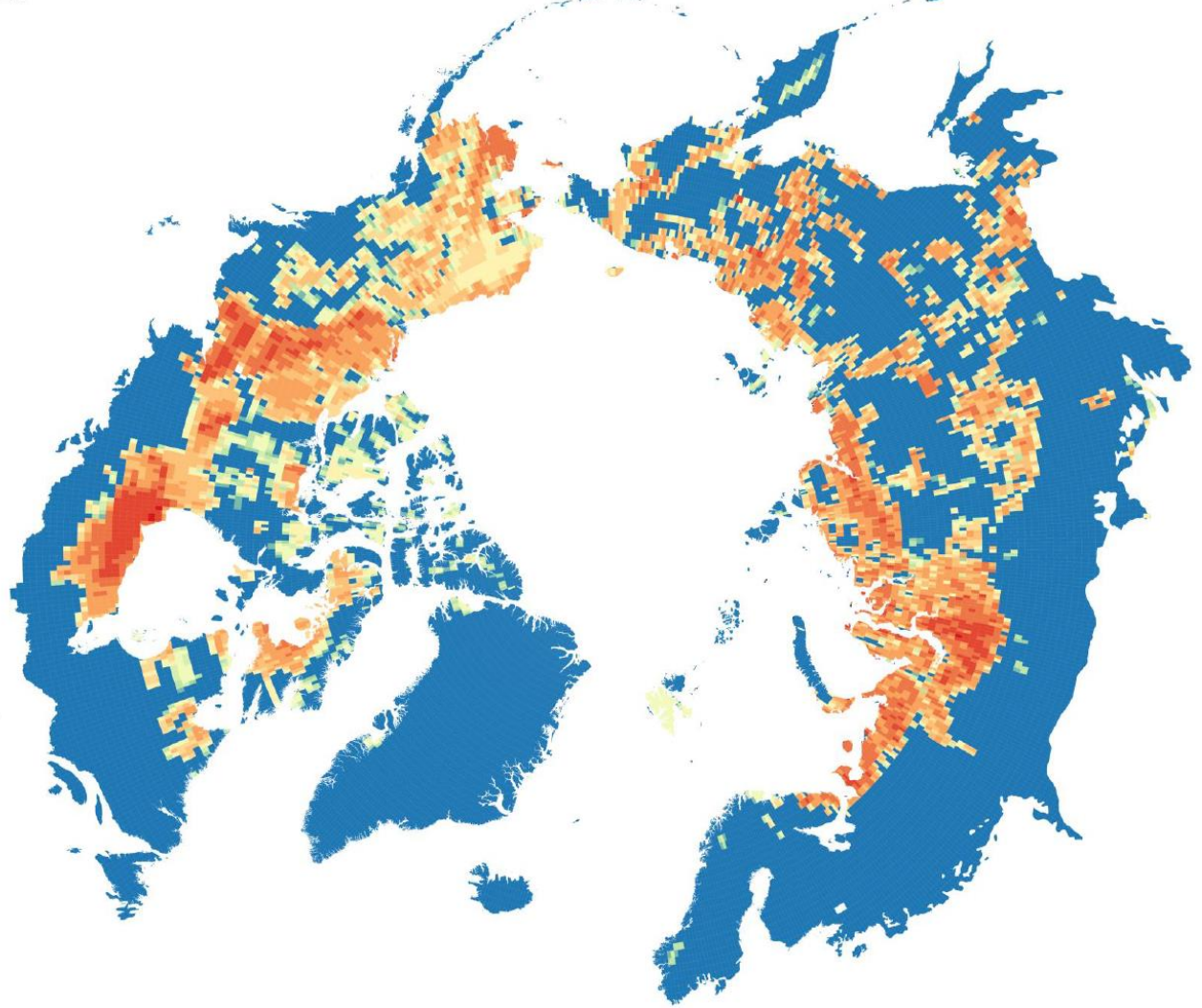


Available Datalayers

Grid_Cell_Data_v3_NPLAEA

\section{SOIL_AQU}

NCSCD: Aqu soil coverage (hydric soils, non peatland)

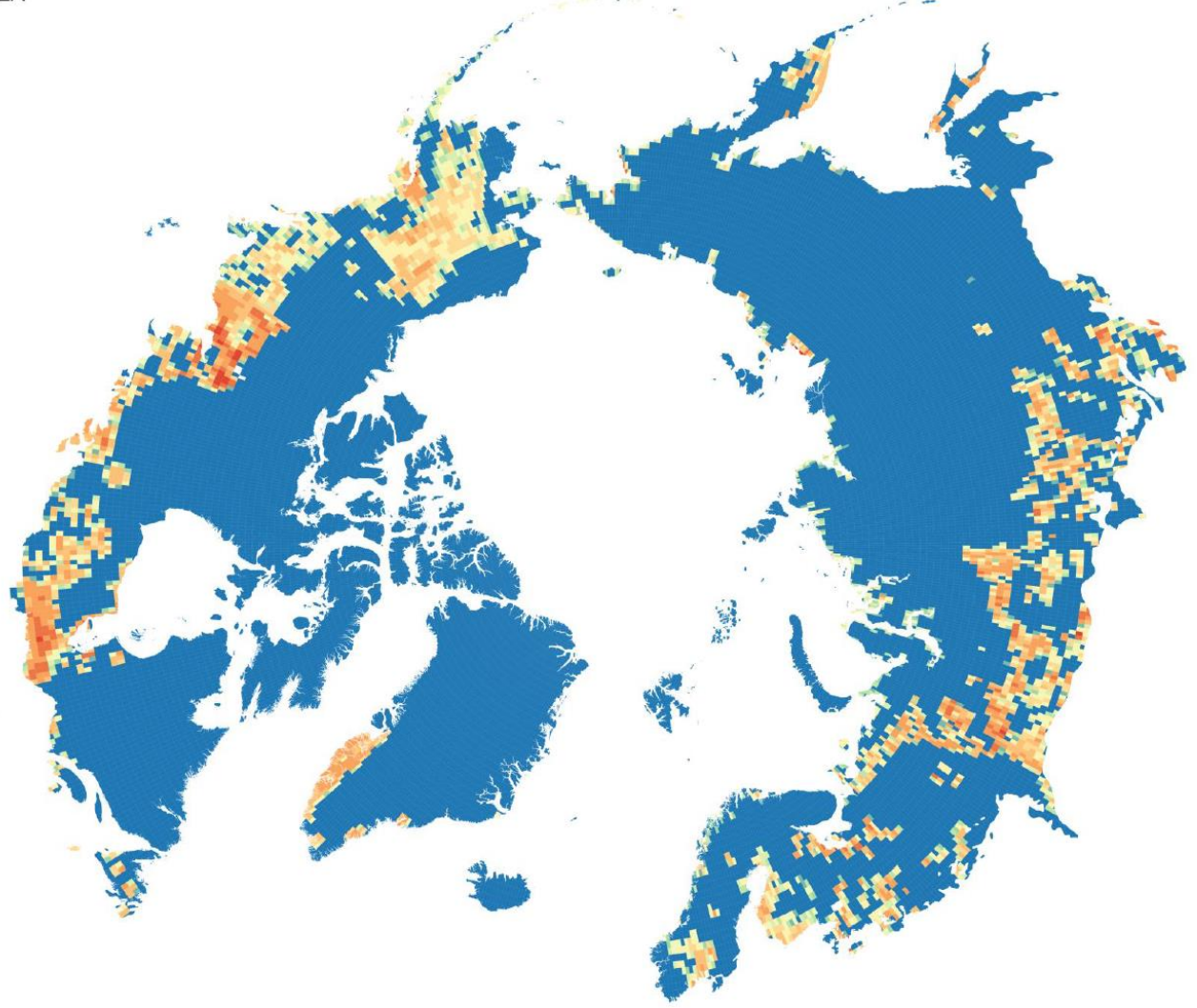


Available Datalayers

Grid_Cell_Data_v3_NPLAEA

No Data

$0-0.01$

$0.01-0.05$

$0.05-0.1$

$0.1-0.25$

$0.25-0.5$

$0.5-1$

$1-2.5$

$2.5-5$

$5-10$

$10-25$

$25-50$

$50-90$

$90-100$
SOIL_ROCKL

NCSCD: Rockland

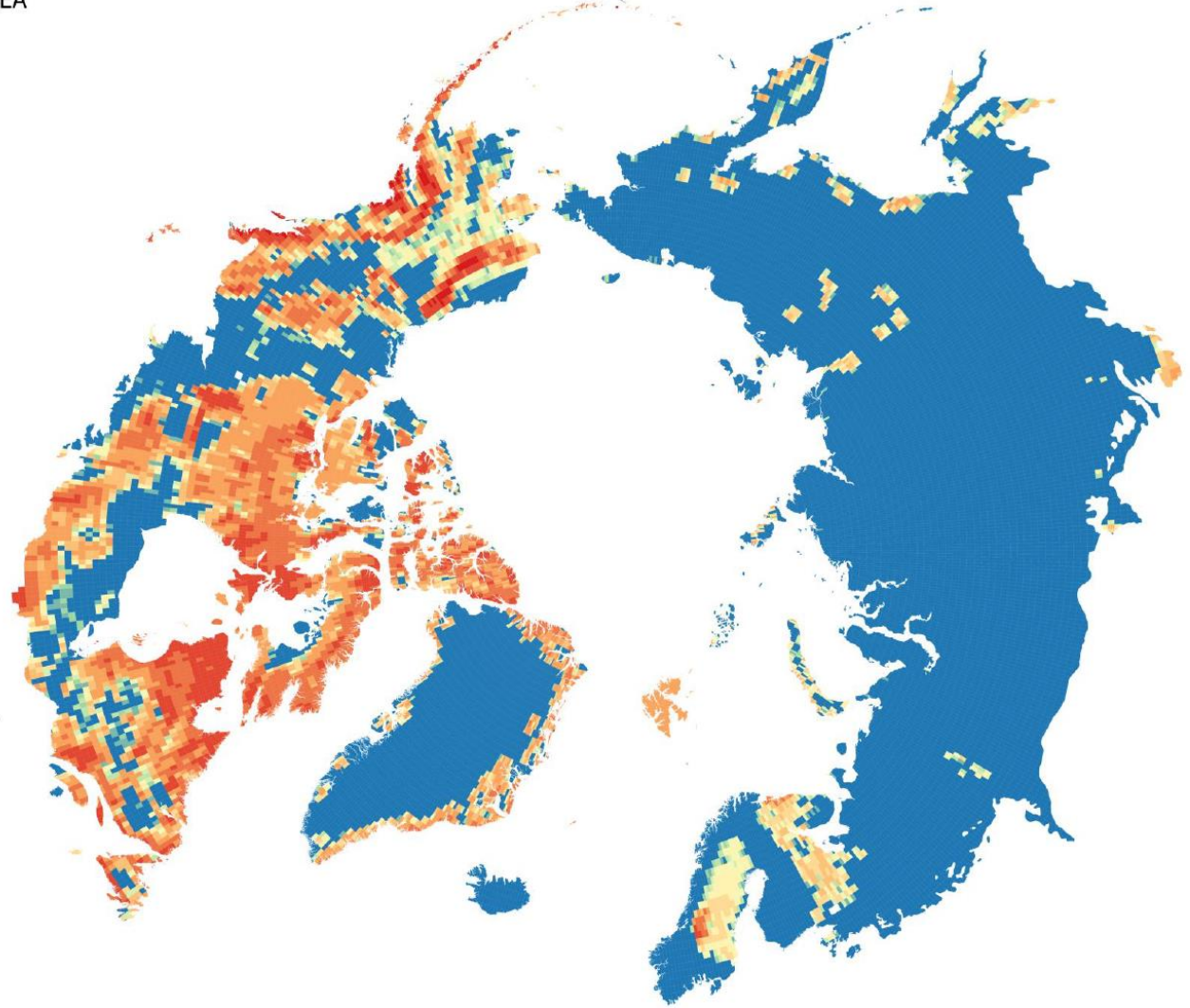


Available Datalayers

Grid_Cell_Data_v3_NPLAEA

No Data

$0-0.01$

$0.01-0.05$

$0.05-0.1$

$0.1-0.25$

$0.25-0.5$

$0.5-1$

$1-2.5$

$2.5-5$

$5-10$

$10-25$

$25-50$

$50-90$

$90-100$
SOIL_GLACI

NCSCD: Glaciers

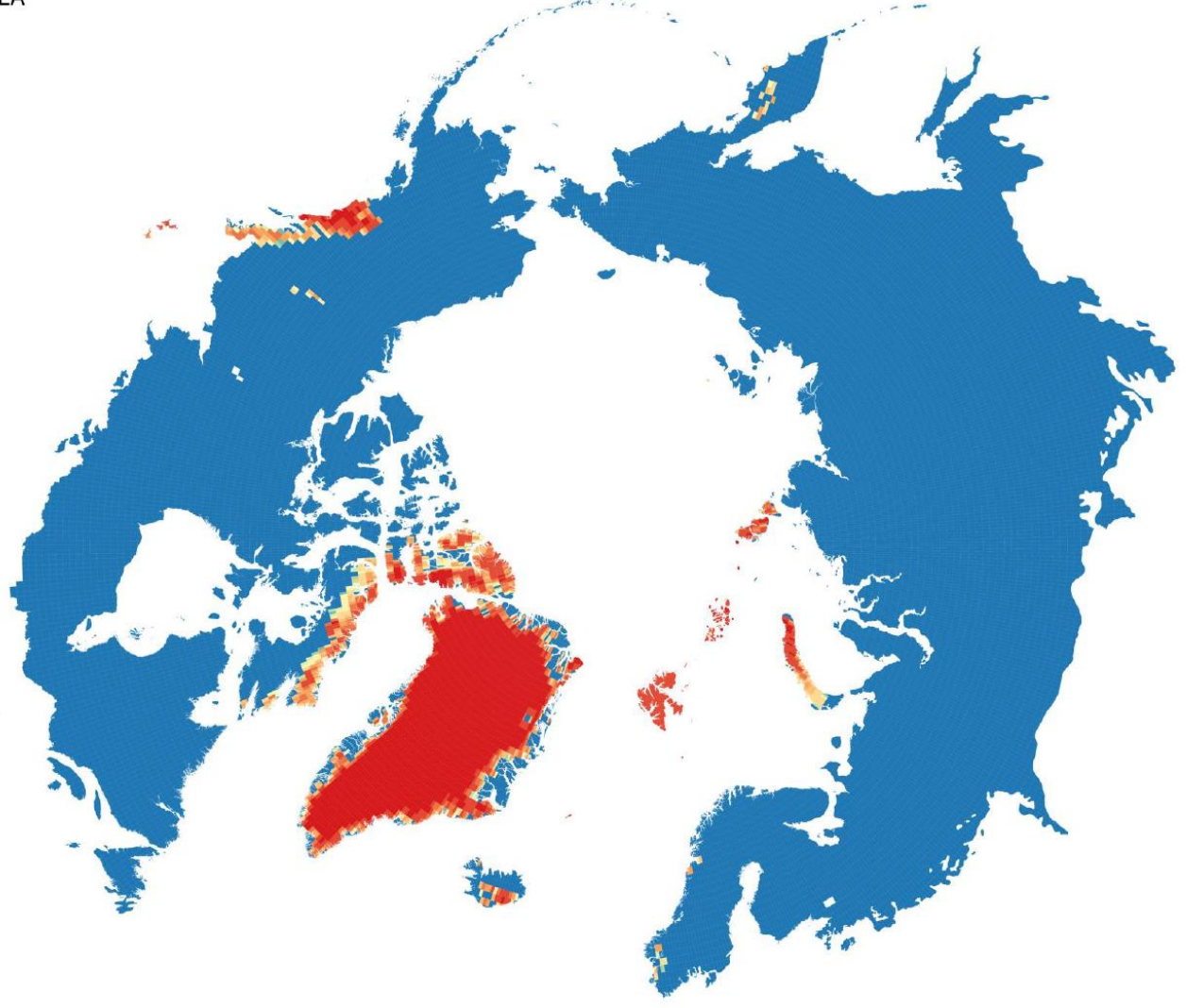




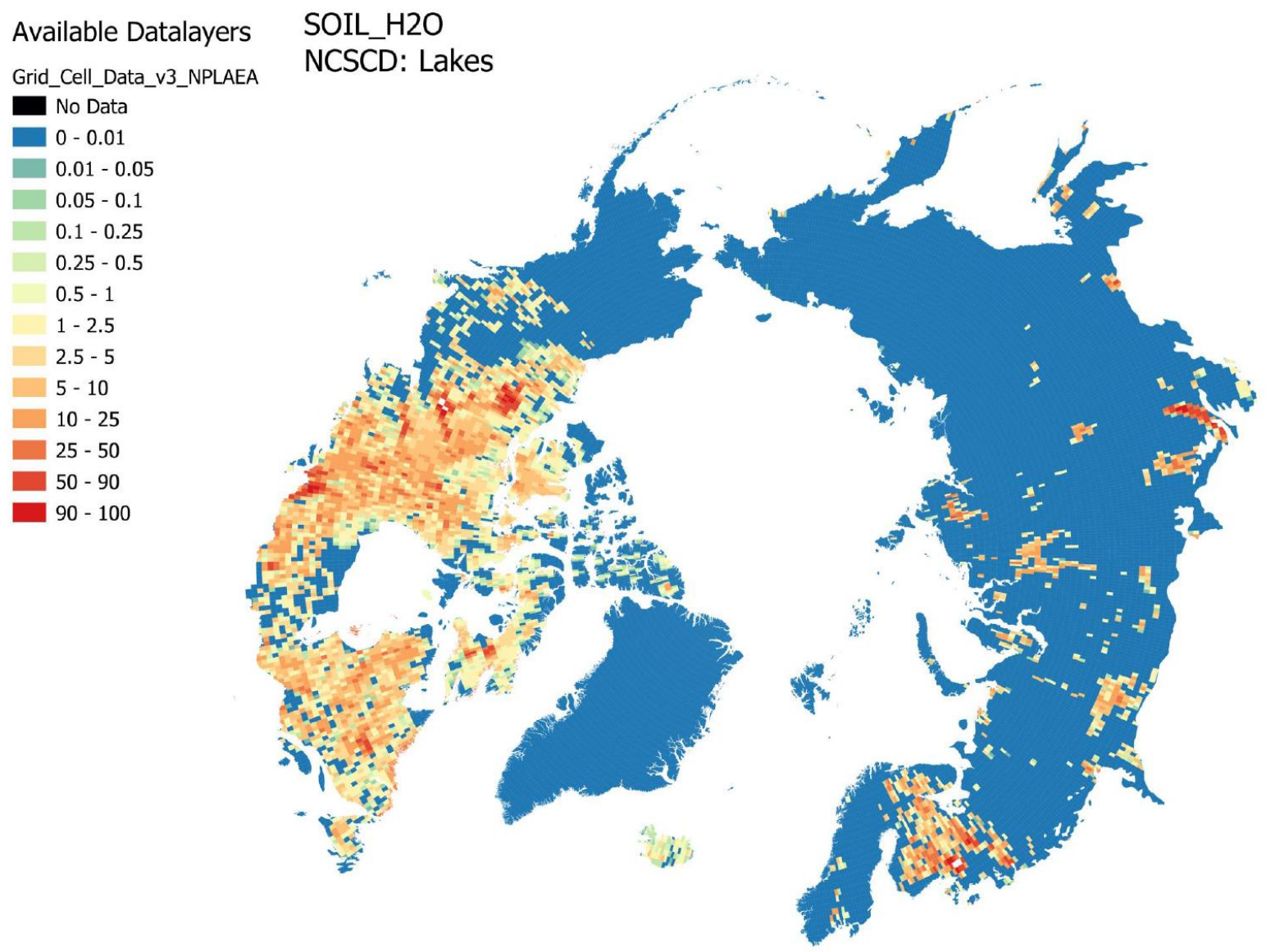


Available Datalayers

\section{TOPO_FLAT}

Grid_Cell_Data_v3_NPLAEA

Gruber 2012: Flat topography

\begin{tabular}{|l|}
\hline \\
$0-0.01$ \\
$0.01-0.05$ \\
$0.05-0.1$ \\
$0.1-0.25$ \\
$0.25-0.5$ \\
$0.5-1$ \\
$1-2.5$ \\
$2.5-5$ \\
$5-10$ \\
$10-25$ \\
$25-50$ \\
$50-90$ \\
$90-100$
\end{tabular}
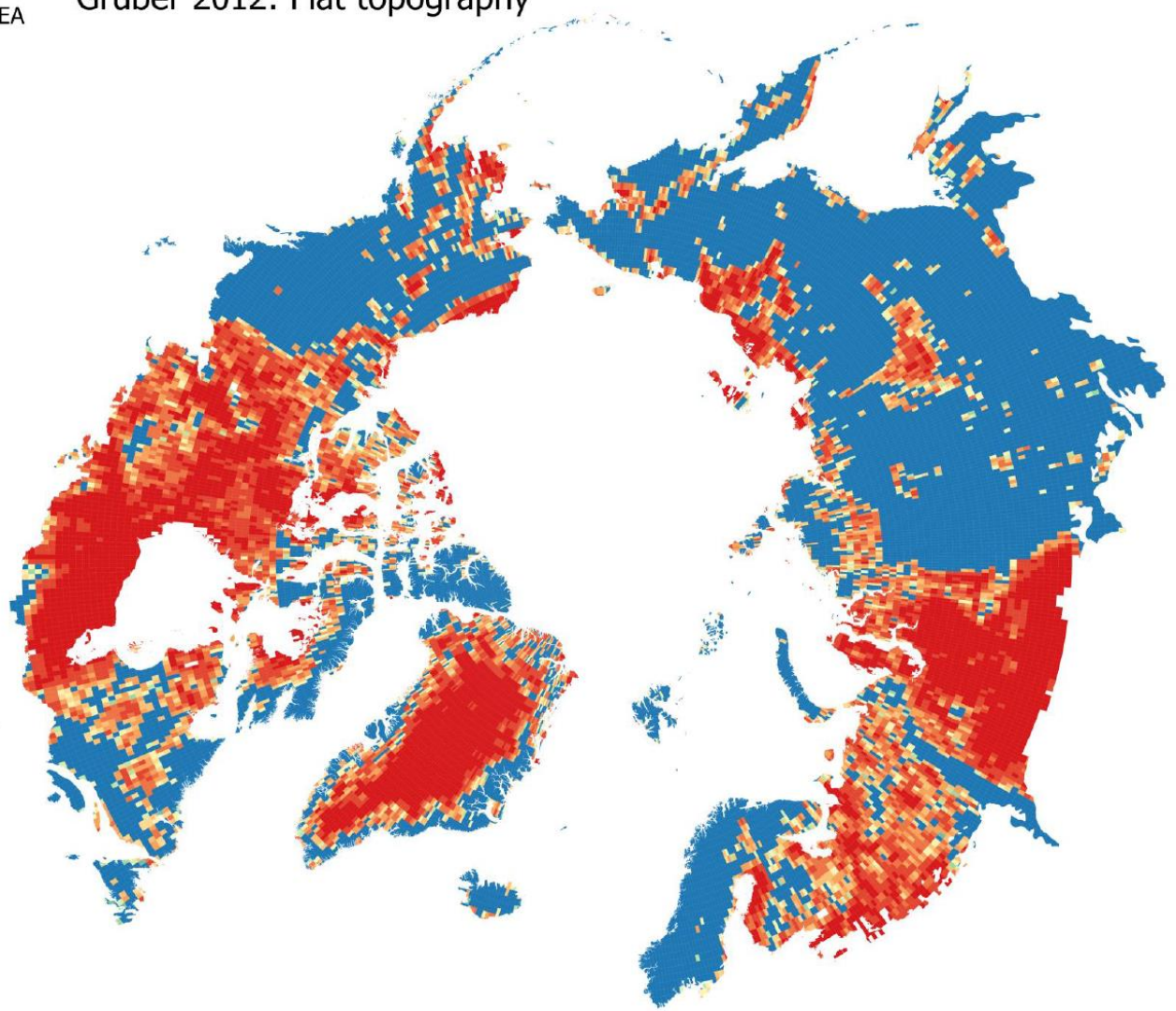
Available Datalayers

TOPO_UNDUL

Grid_Cell_Data_v3_NPLAEA

Gruber 2012: Undulating topography

\begin{tabular}{|l|}
\hline \\
$0-0.01$ \\
$0.01-0.05$ \\
$0.05-0.1$ \\
$0.1-0.25$ \\
$0.25-0.5$ \\
$0.5-1$ \\
$1-2.5$ \\
$2.5-5$ \\
$5-10$ \\
$10-25$ \\
$25-50$ \\
$50-90$ \\
$90-100$
\end{tabular}

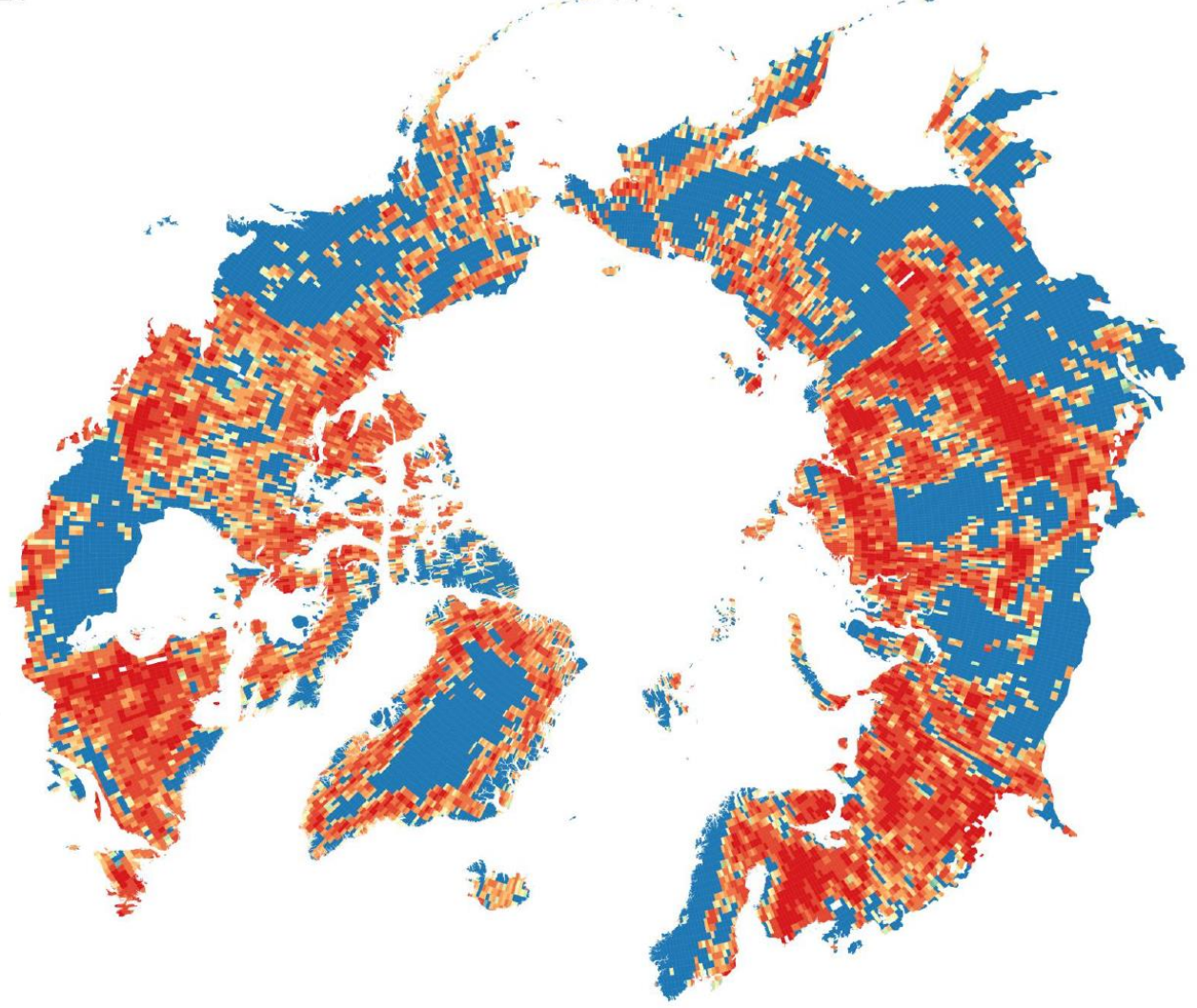


Available Datalayers

TOPO_HILLY

Grid_Cell_Data_v3_NPLAEA

Gruber 2012: Hilly topography

No Data
$0-0.01$
$0.01-0.05$
$0.05-0.1$
$0.1-0.25$
$0.25-0.5$
$0.5-1$
$1-2.5$
$2.5-5$
$5-10$
$10-25$
$25-50$
$50-90$
$90-100$

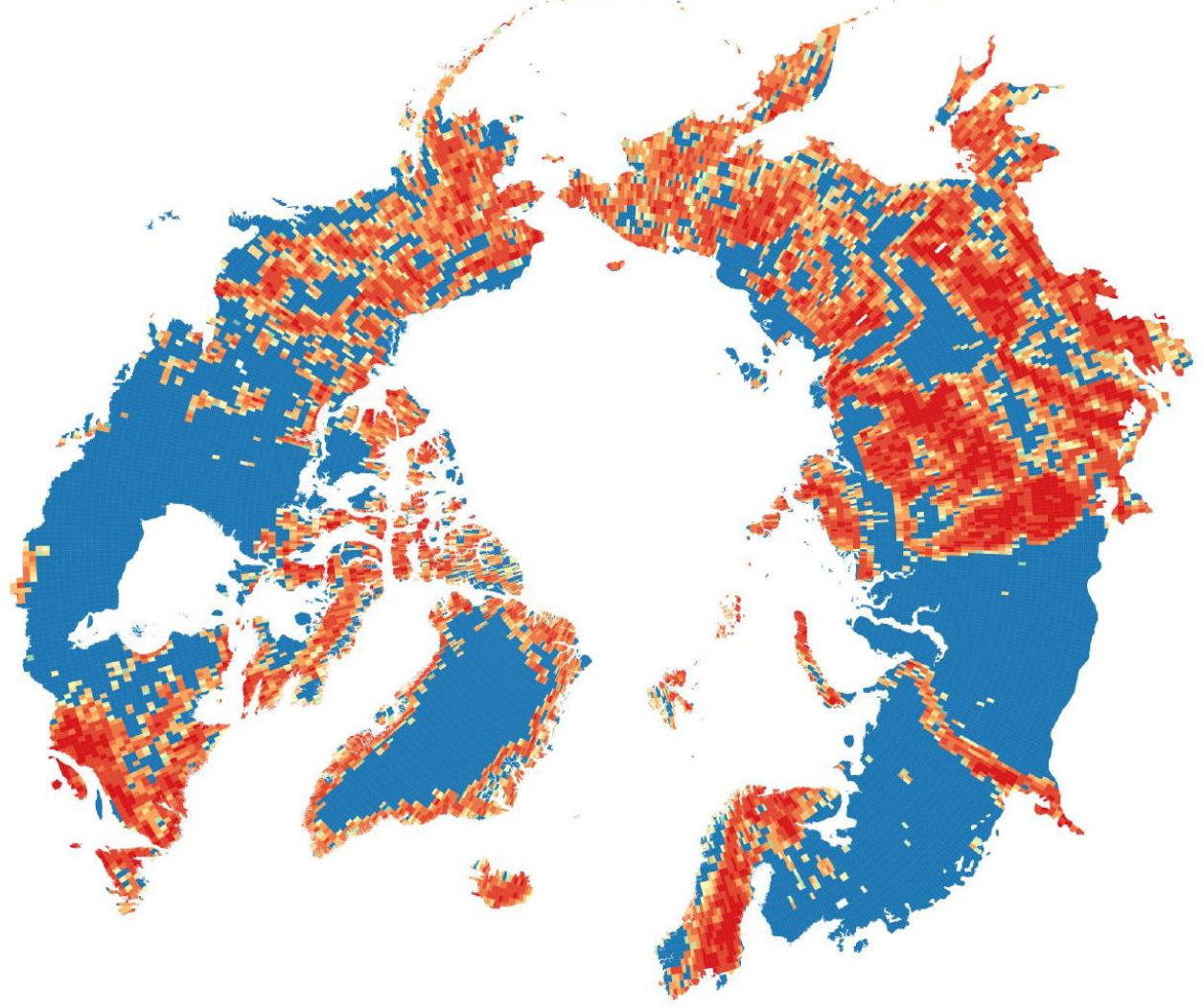




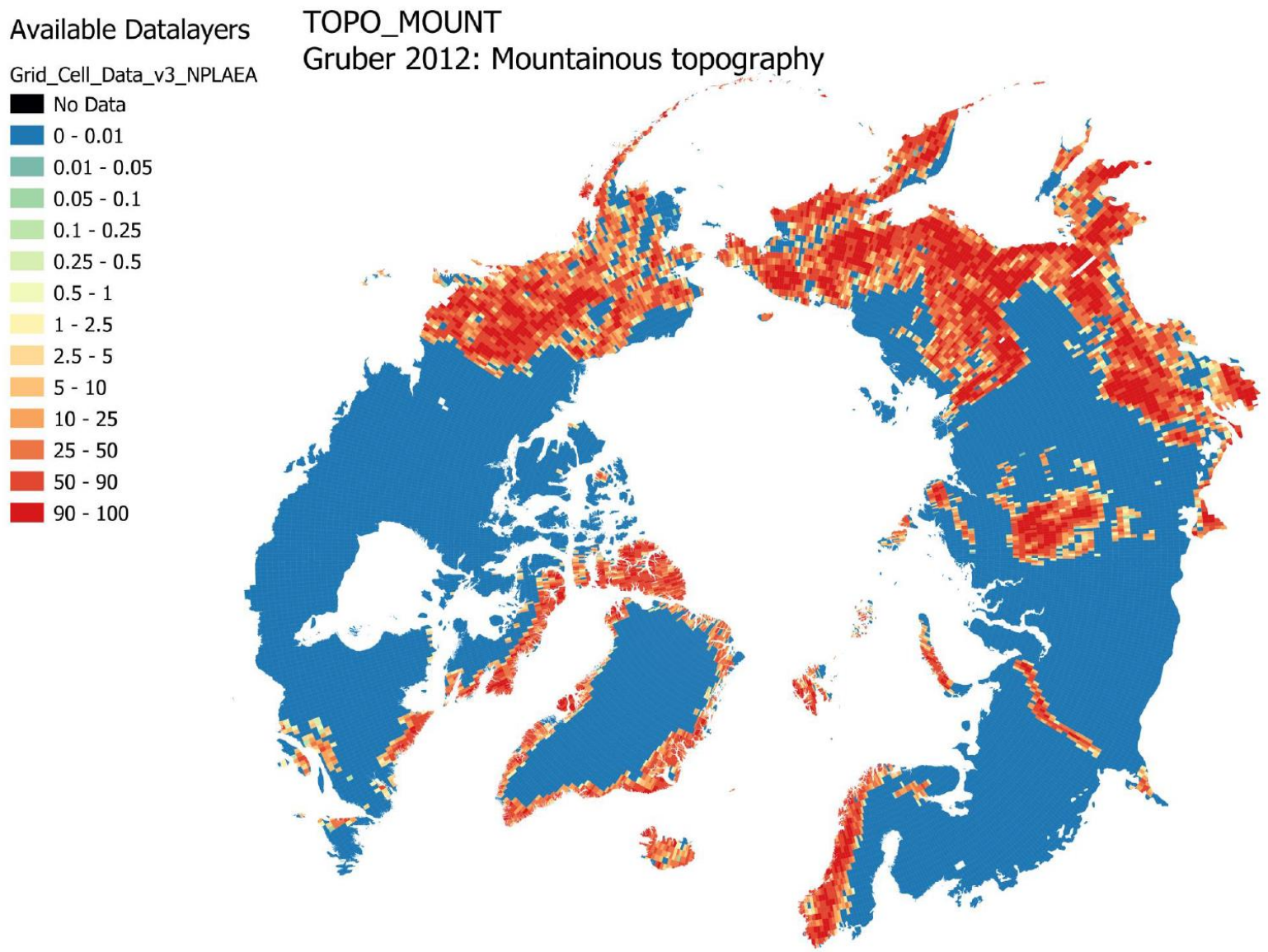


Available Datalayers

TOPO_RUGGE

Grid_Cell_Data_v3_NPLAEA

Gruber 2012: Rugged topography

\begin{tabular}{|l} 
No Data \\
$0-0.01$ \\
$0.01-0.05$ \\
$0.05-0.1$ \\
$0.1-0.25$ \\
$0.25-0.5$ \\
$0.5-1$ \\
$1-2.5$ \\
$2.5-5$ \\
$5-10$ \\
$10-25$ \\
$25-50$ \\
$50-90$ \\
$90-100$
\end{tabular}

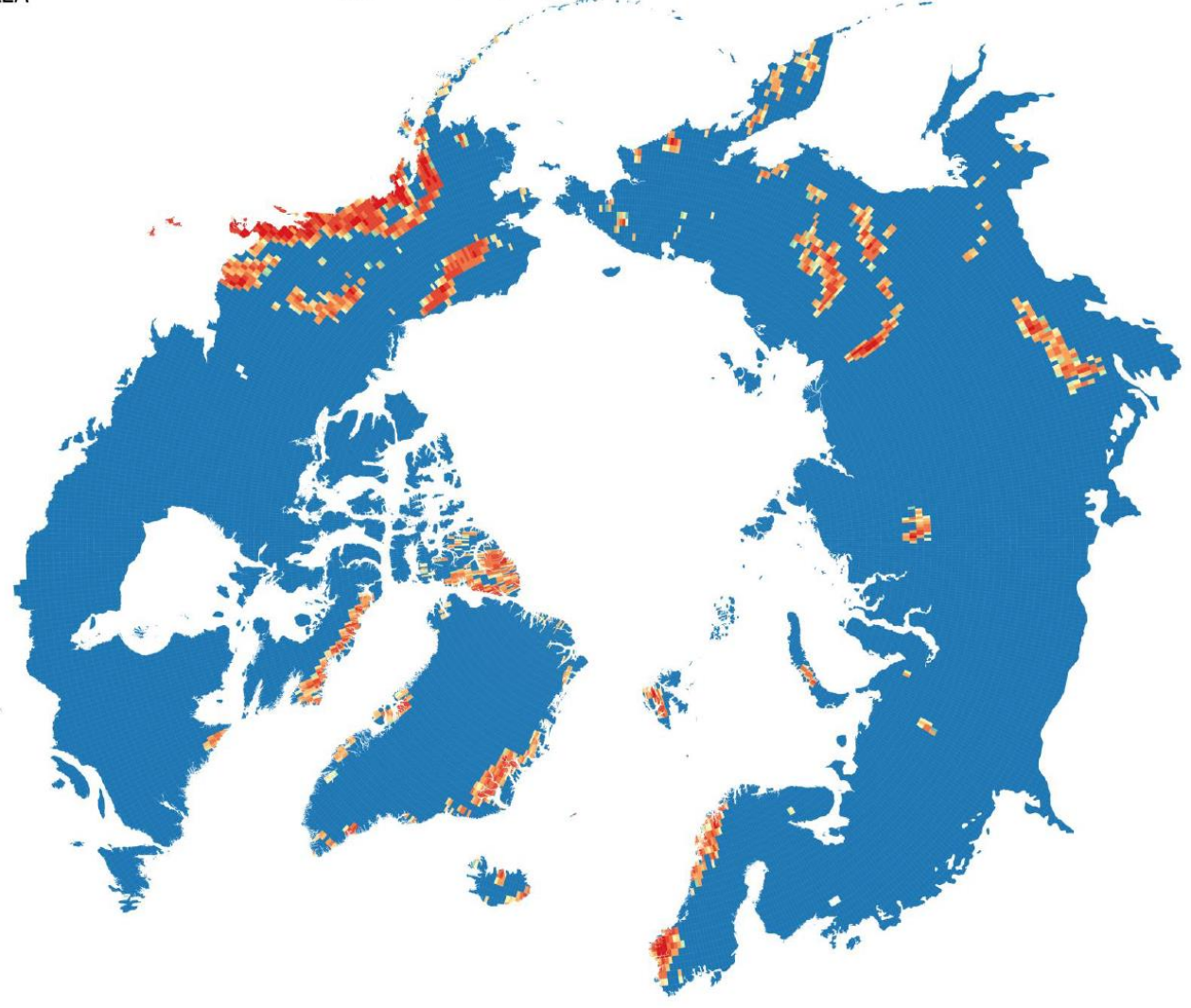


Available Datalayers

Grid_Cell_Data_v3_NPLAEA
WWF_BOREAL

Boreal Forests/Taiga

$0-0.01$

$0.01-0.05$

$0.05-0.1$

$0.1-0.25$

$0.25-0.5$

$0.5-1$

$1-2.5$

$2.5-5$

- $5-10$

$10-25$

$25-50$

$50-90$

- $90-100$

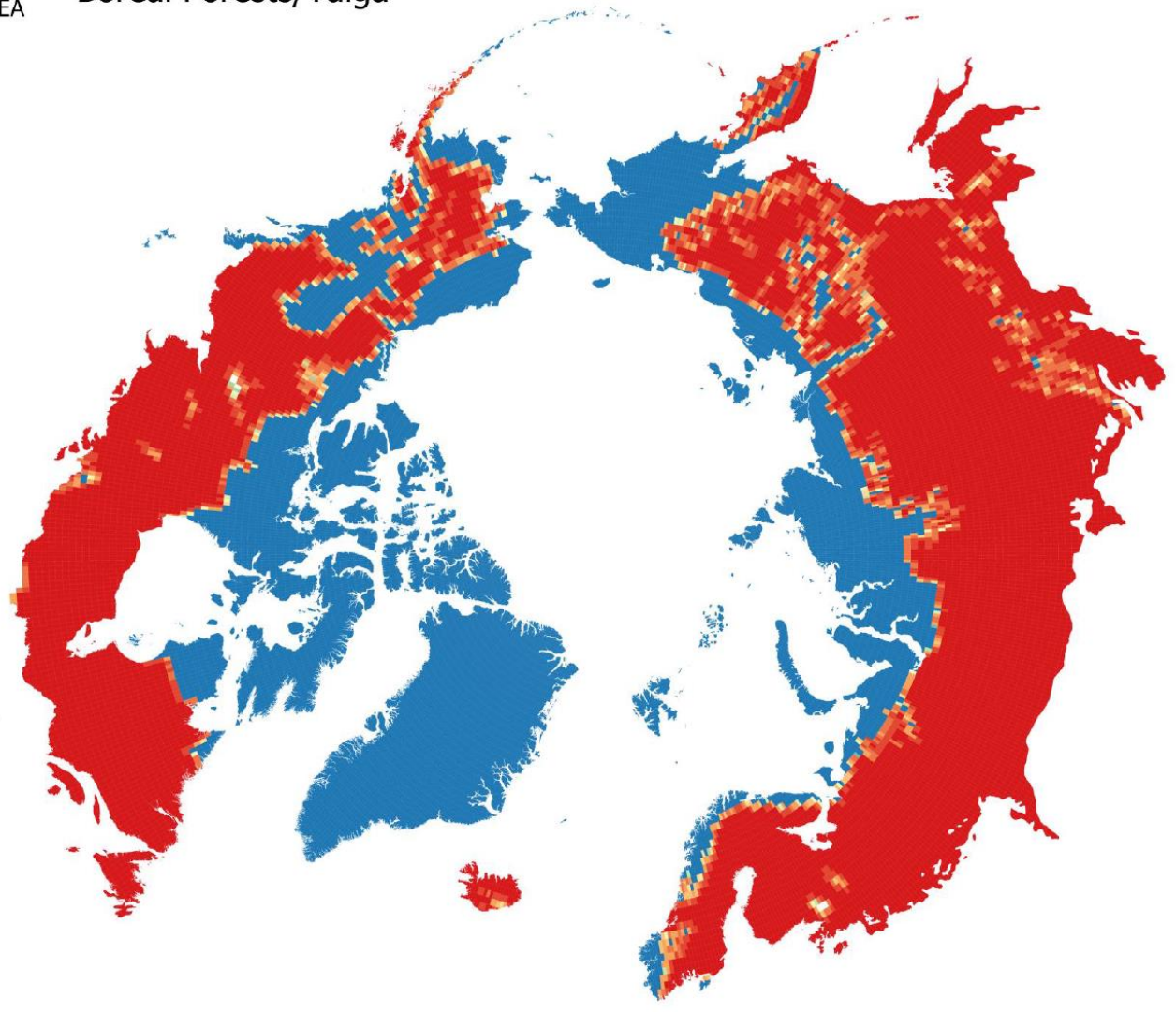


Available Datalayers

WWF_TUNDRA

Grid_Cell_Data_v3_NPLAEA

Tundra

\begin{tabular}{|l|l|}
\hline & No Data \\
0 & -0.01 \\
$0.01-0.05$ \\
$0.05-0.1$ \\
$0.1-0.25$ \\
$0.25-0.5$ \\
$0.5-1$ \\
$1-2.5$ \\
$2.5-5$ \\
$5-10$ \\
$10-25$ \\
$25-50$ \\
$50-90$ \\
$90-100$
\end{tabular}

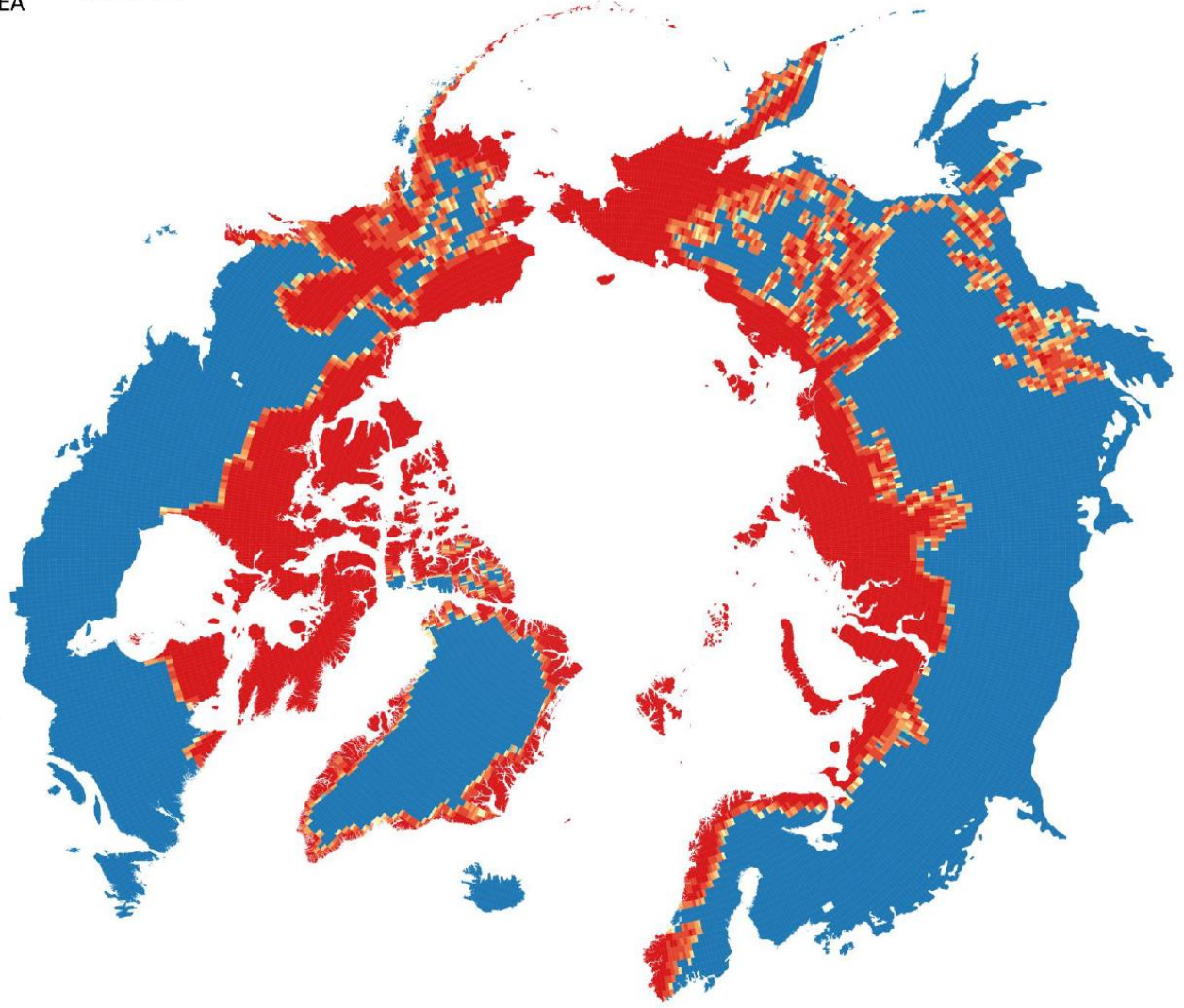




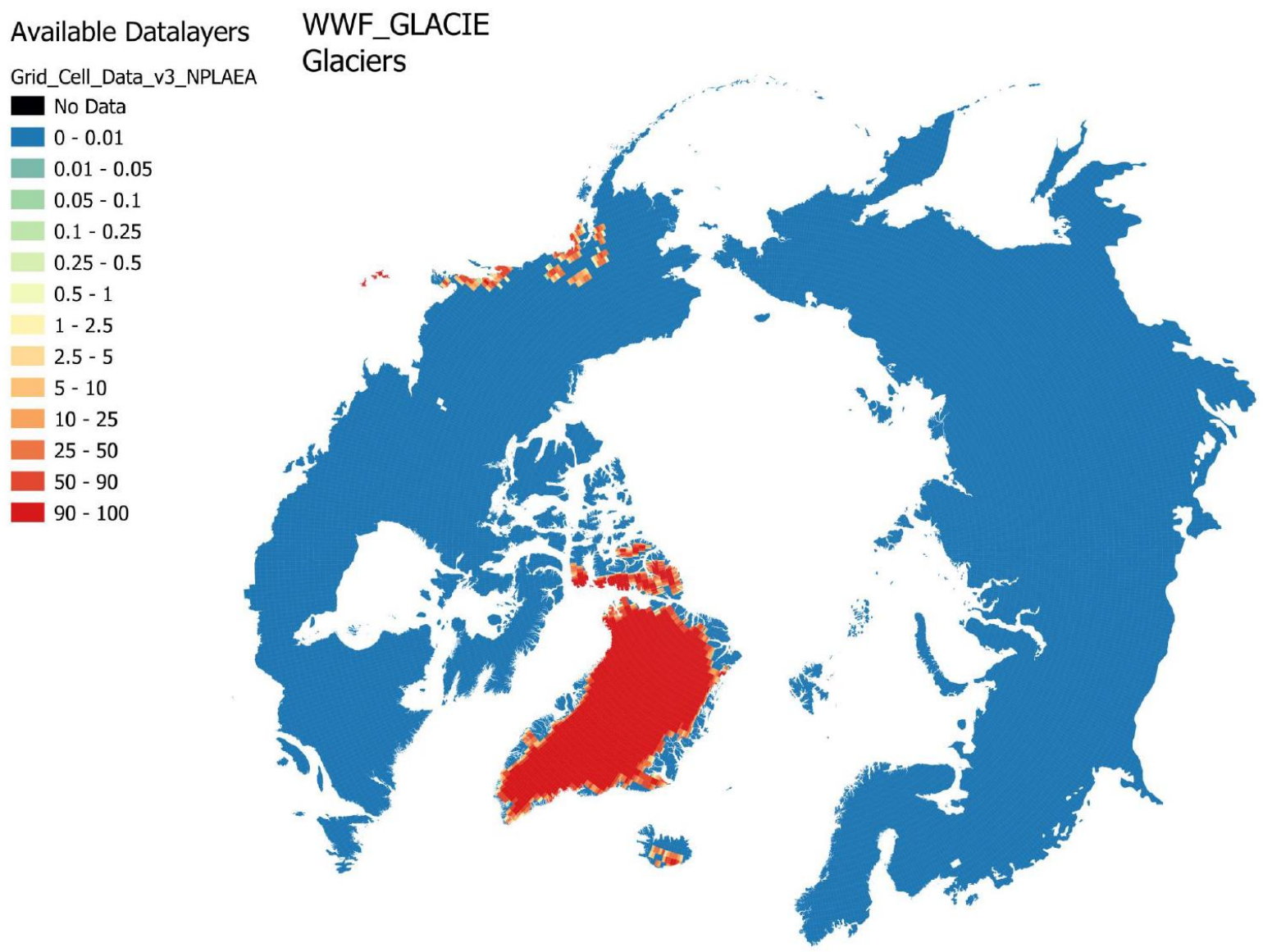


Available Datalayers

Grid_Cell_Data_v3_NPLAEA

No Data
$0-0.01$
$0.01-0.05$
$0.05-0.1$
$0.1-0.25$
$0.25-0.5$
$0.5-1$
$1-2.5$
$2.5-5$
$5-10$
$10-25$
$25-50$
$50-90$
$90-100$

\section{GIEMS_MAMI}

Giems D15 Mean annual Minimum Inundation

(i.e. permanent water)

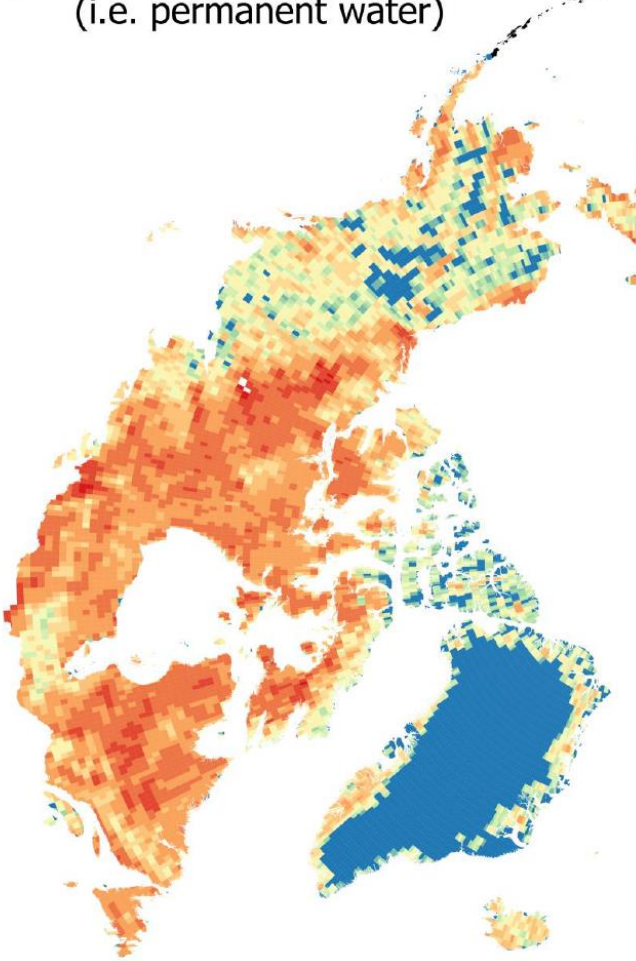

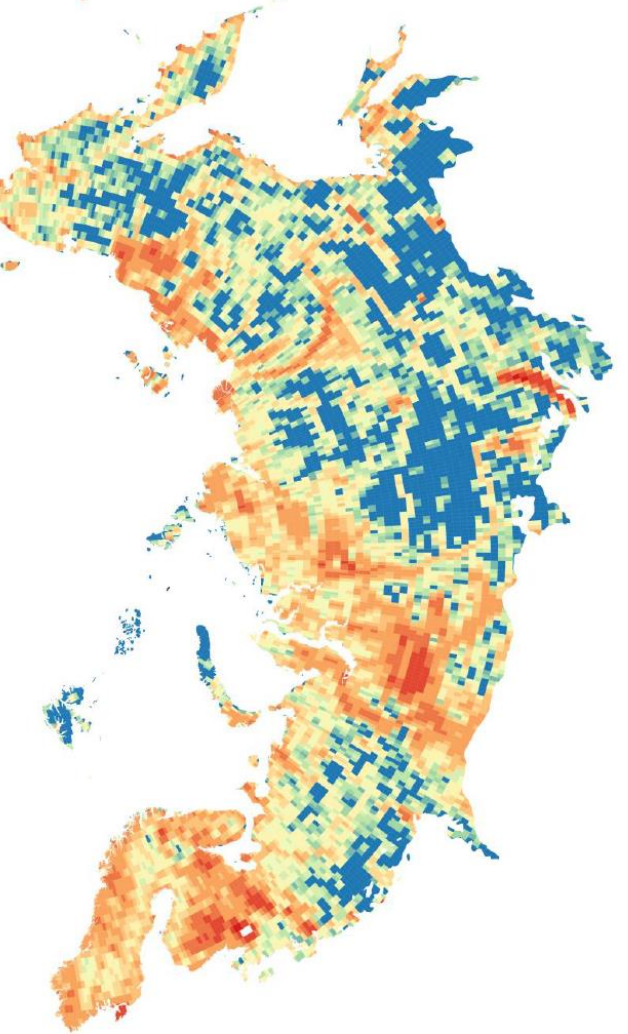


Available Datalayers

Grid_Cell_Data_v3_NPLAEA

No Data

$0-0.01$

$0.01-0.05$

$0.05-0.1$

$0.1-0.25$

$0.25-0.5$

$0.5-1$

$1-2.5$

$2.5-5$

- $5-10$

$10-25$

$25-50$

$50-90$

$90-100$

\section{YEDOMA_PCT \\ IRYP Yedoma coverage}

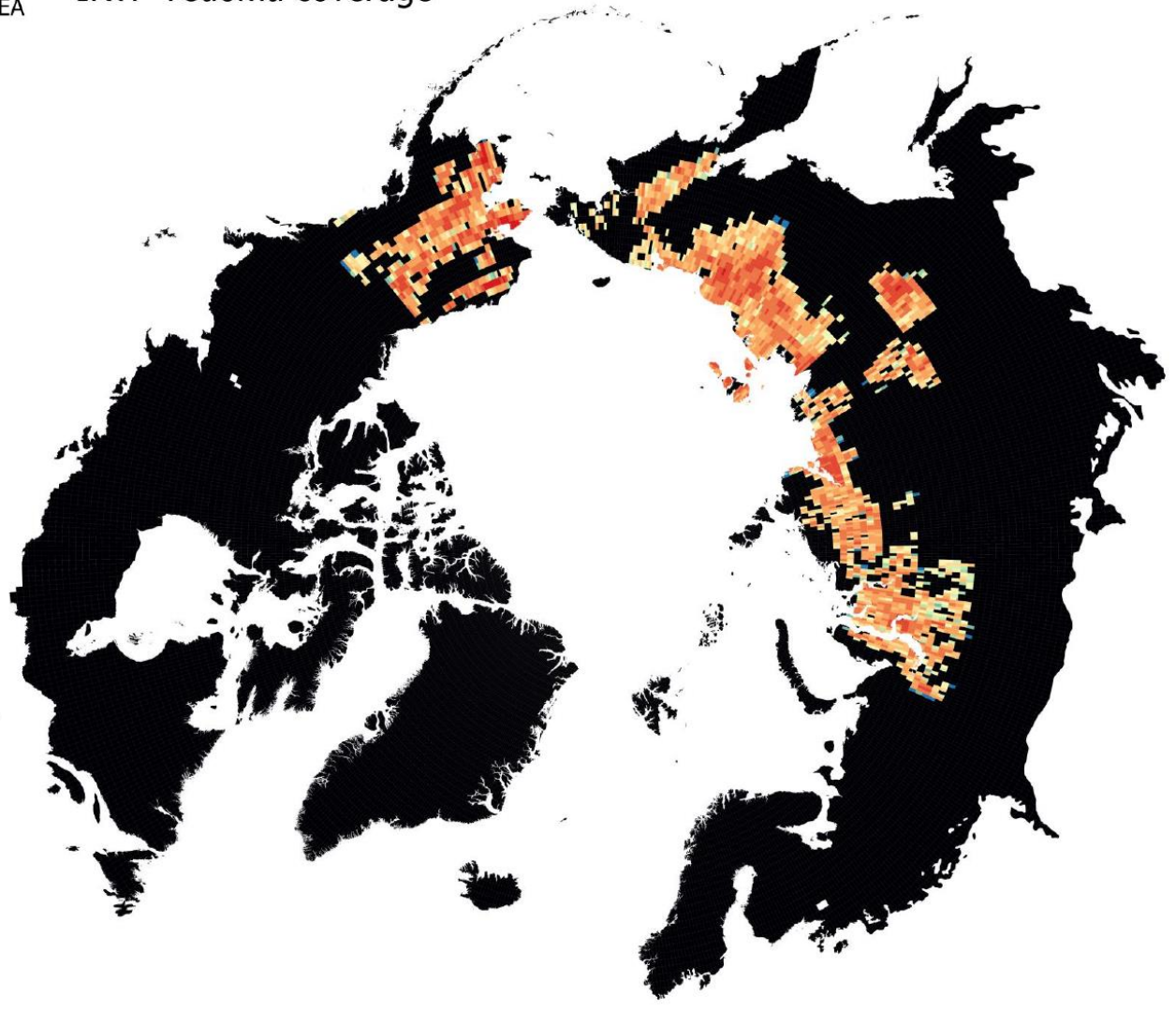


Available Datalayers

Grid_Cell_Data_v3_NPLAEA

\section{CAVM_BAR}

Circumpolar Arctic Vegetation Map - Barrens
$0-0.01$
$0.01-0.05$
$0.05-0.1$
$0.1-0.25$
$0.25-0.5$
$0.5-1$
$1-2.5$
$2.5-5$
$5-10$
$10-25$
- $25-50$
$50-90$
$90-100$

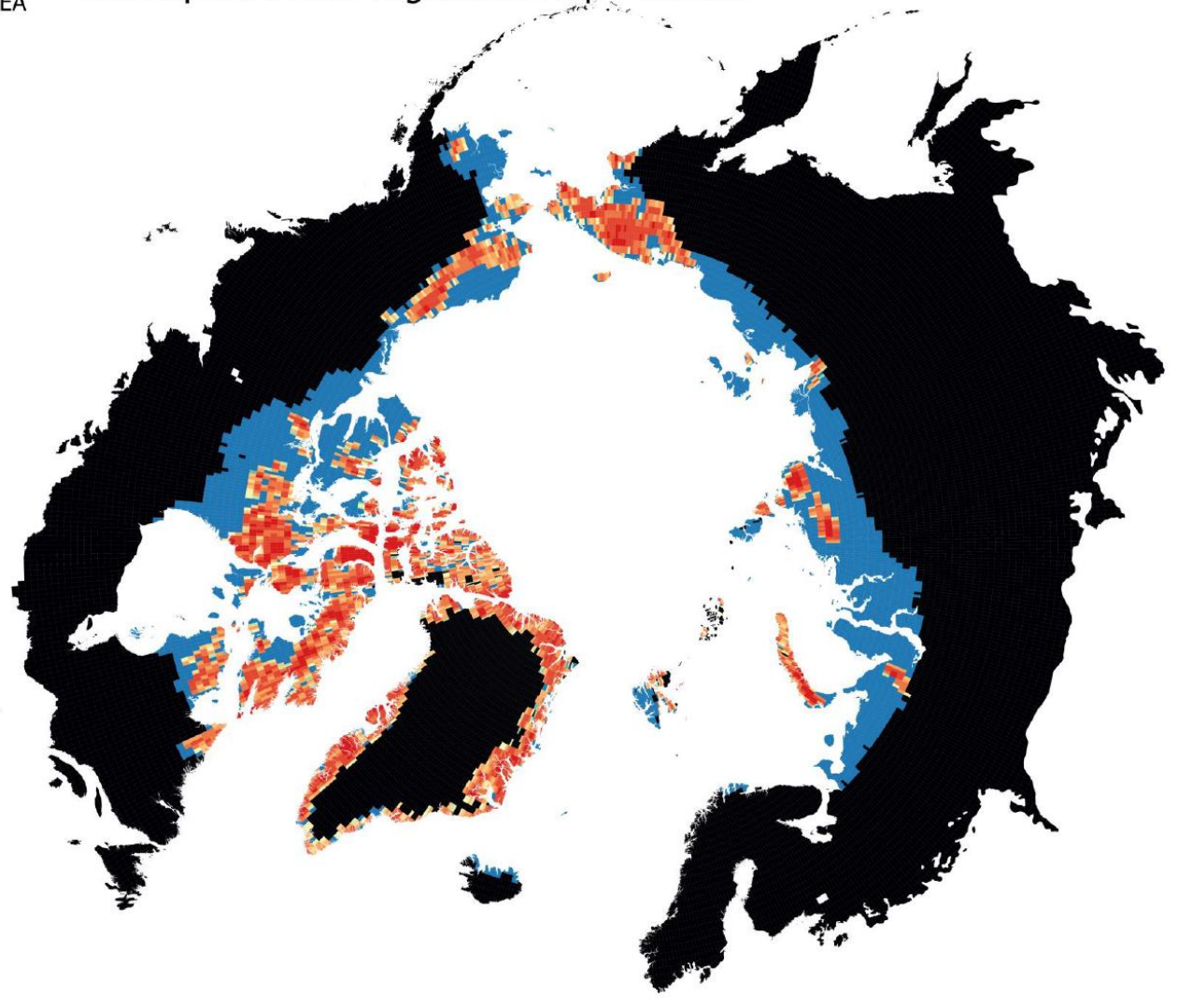


Available Datalayers

Grid_Cell_Data_v3_NPLAEA

\section{CAVM_GRA}

Circumpolar Arctic Vegetation Map - Graminoid tundra

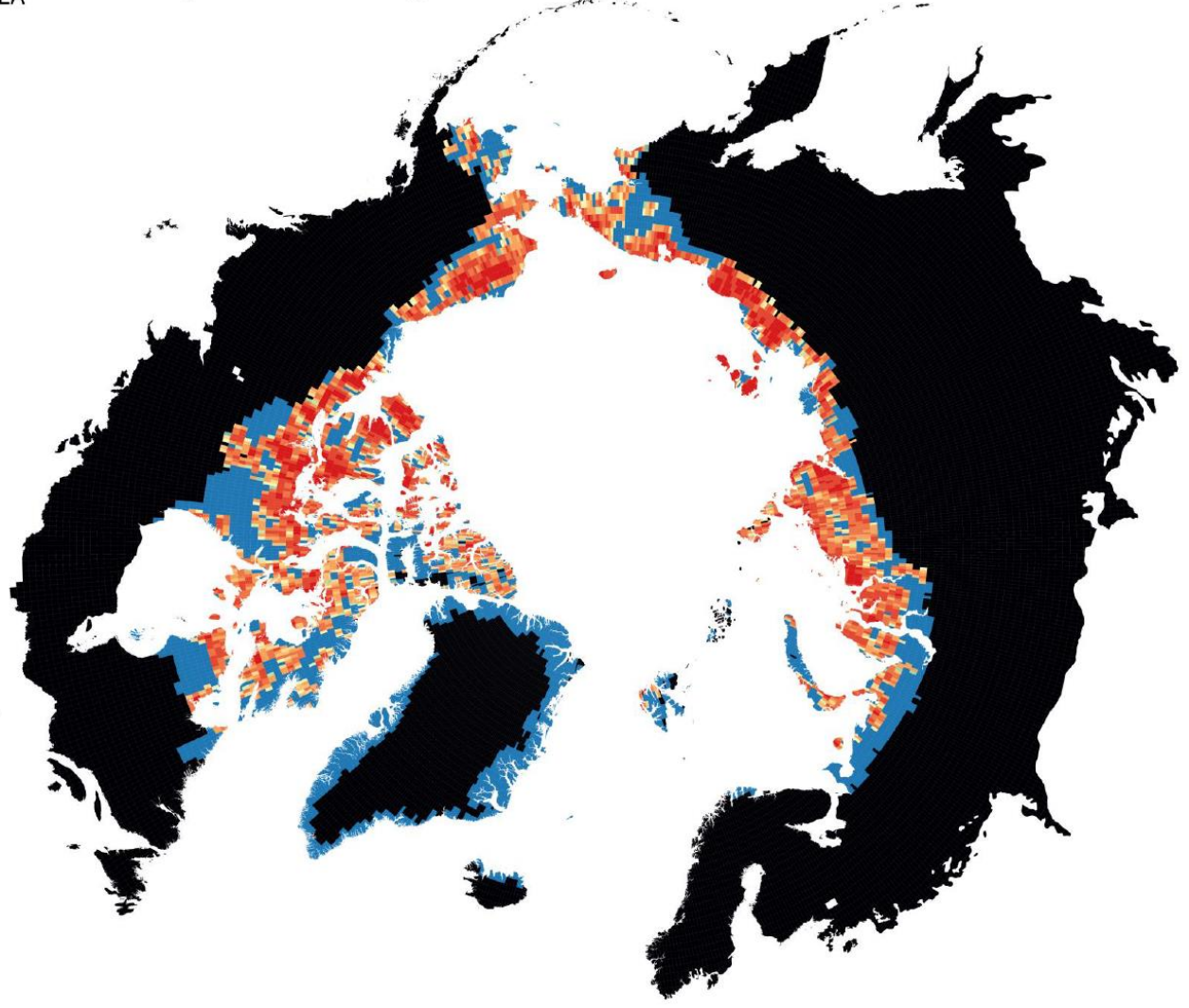


Available Datalayers

Grid_Cell_Data_v3_NPLAEA

\section{CAVM_SHR}

Circumpolar Arctic Vegetation Map - Shrubby tundra

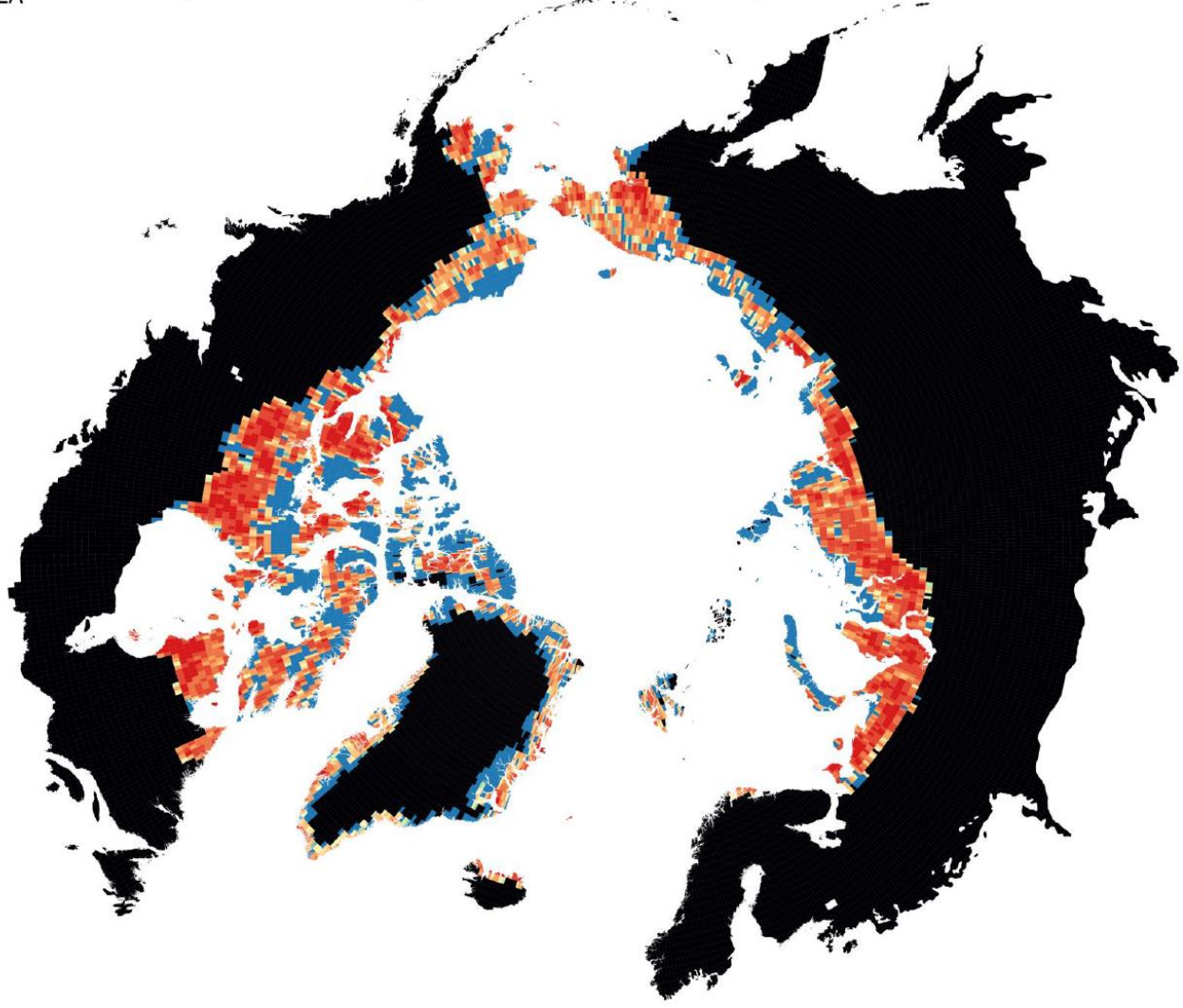


Available Datalayers

Grid_Cell_Data_v3_NPLAEA

\section{CAVM_WET}

Circumpolar Arctic Vegetation Map - Wet Sedge tundra

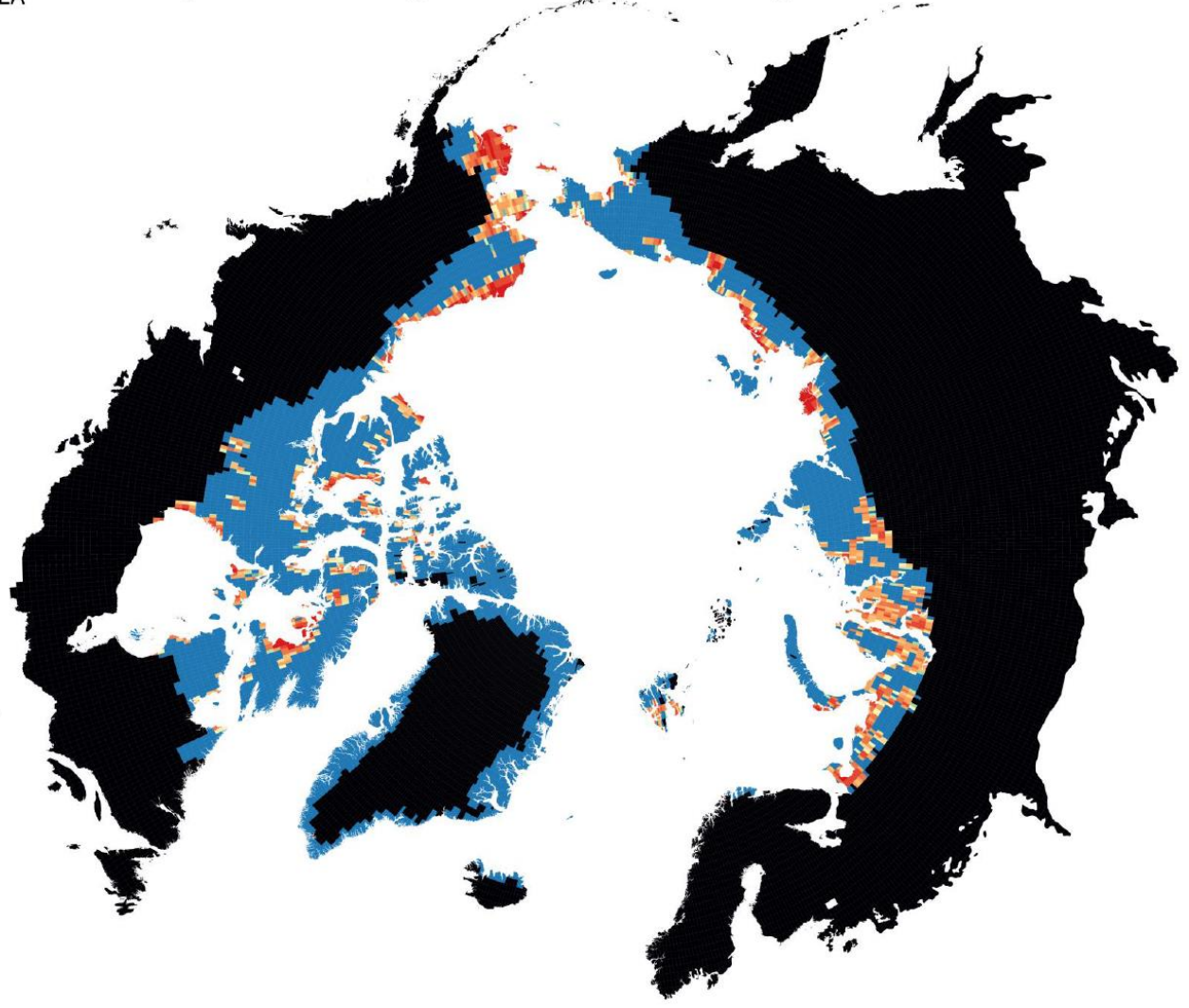


Available Datalayers

Grid_Cell_Data_v3_NPLAEA

$\square$ No Data

$\square-21.5--17.3$

$\square-17.3--14.9$

$\square-14.9--13.1$

$\square-13.1--11.6$

$\square-11.6--10$

$\square-10-8.3$

$\square-8.3--6.7$

$\square-6.7--5$

$\square-5--3.4$

$\square-3.4--1.6$

$\square-1.6-0.1$

$\square 0.1-1.9$

$\square$ 1.9-8
Temp_An

Mean annual temperature $(\operatorname{deg} C)$

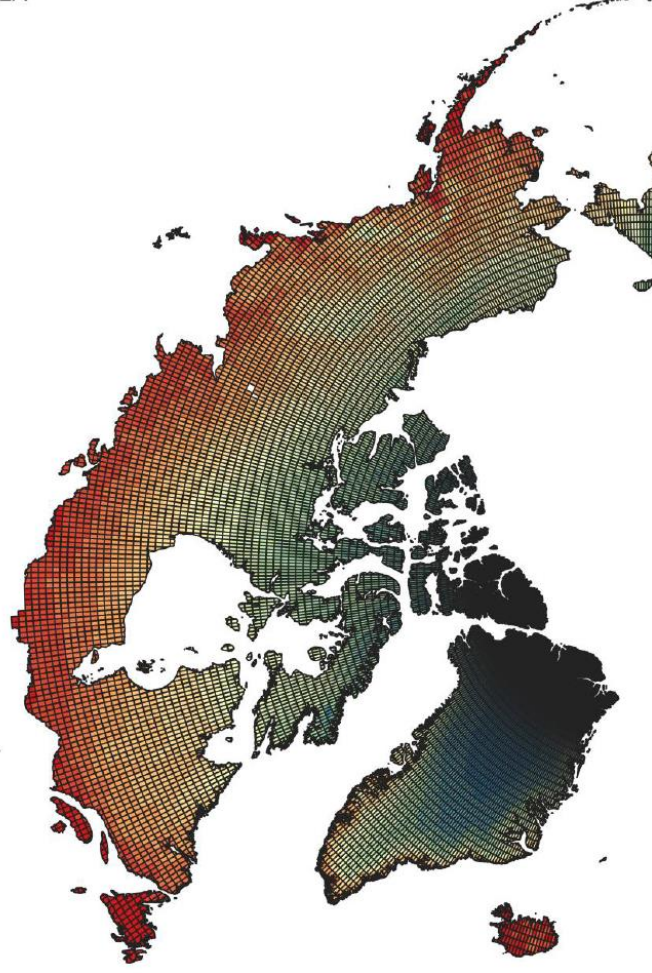<smiles>[C+]1CCC1</smiles>
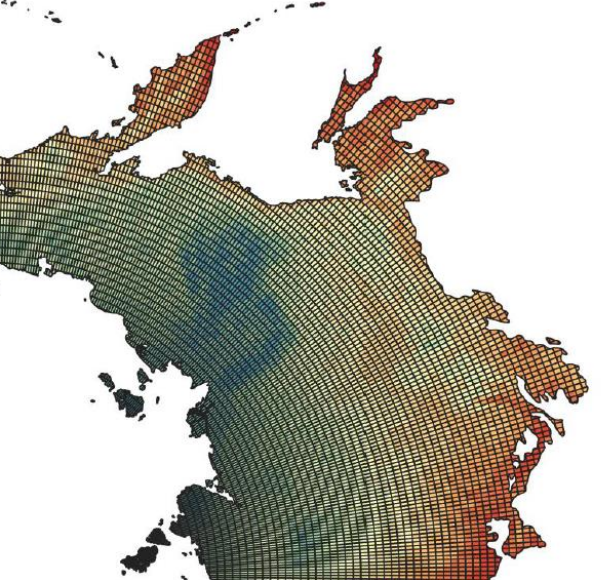

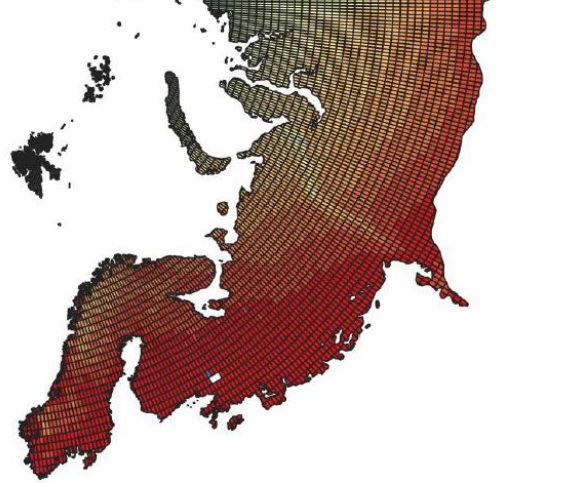


Available Datalayers

Grid_Cell_Data_v3_NPLAEA

\section{Precip_An}

Mean annual precipitation (mm)

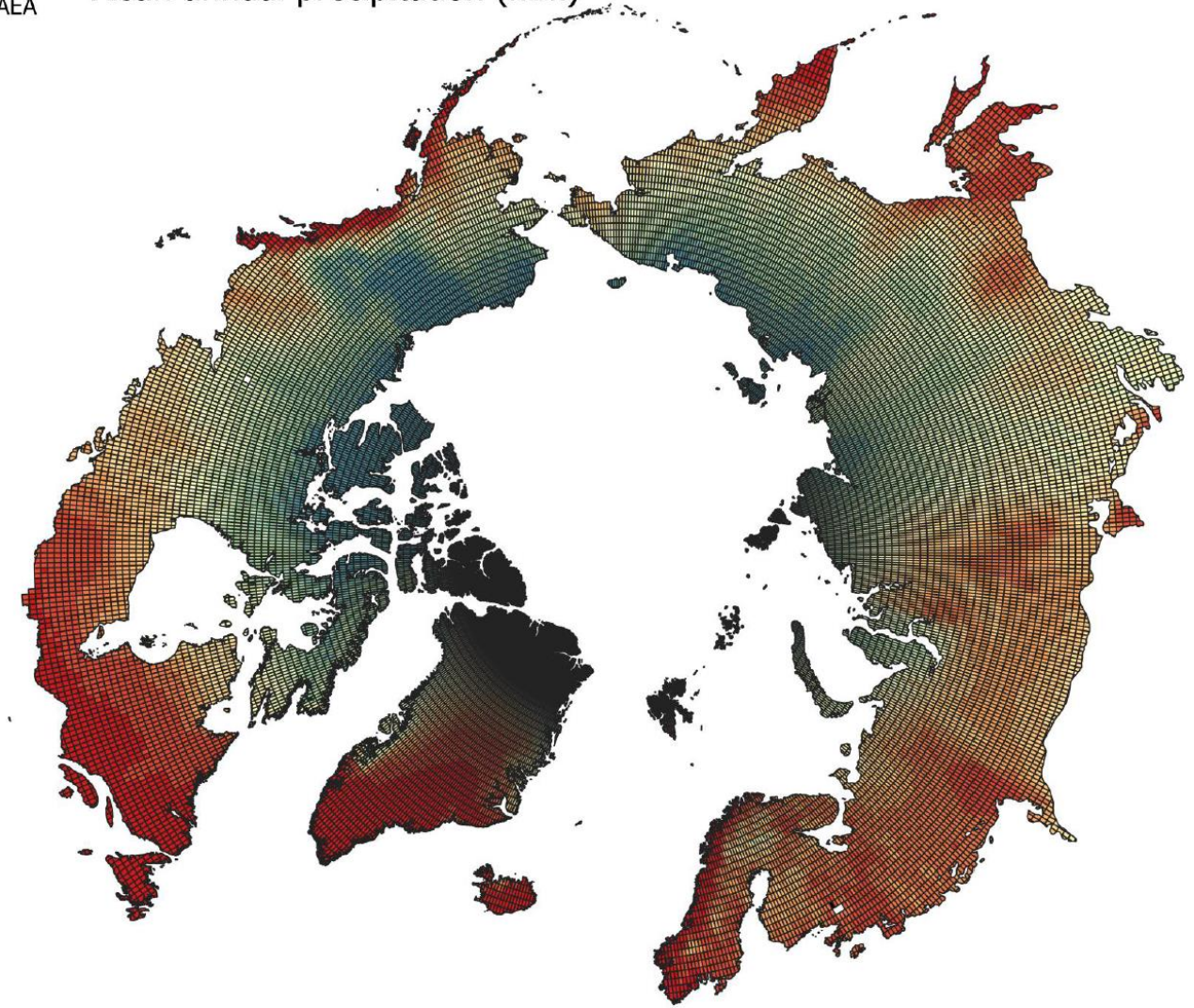

